\title{
THE ROLE OF DOPAMINE IN THE SENSITISED
}

\section{LOCOMOTOR ACTIVATING EFFECTS OF}

\section{METHYLENEDIOXYMETHAMPHETAMINE (MDMA) IN}

RATS.

Dave Gittings

\begin{abstract}
A thesis submitted to Victoria University of Wellington in fulfilment of the requirements for the degree of Doctor of Philosophy in Psychology
\end{abstract}

Victoria University of Wellington 


\section{Acknowledgements}

This whole thesis thing is a little torturous and you cannot, if you wish in any way to stay sane, do it alone.

I certainly did not.

To my long suffering, loving, supportive wife Lorraine, who supported me at the real start of this process, as a $1^{\text {st }}$ year undergraduate student. Allowing me to study, (and not work during my honours year), who read and corrected chapters, heard complaints and minor triumphs, suffered endless weekends alone, and who was always there for me. Thank you.

Thank you too to the lab crew. Vange, Katie, Guido, Karen, our adopted lab member Matt, our new lab member Sarah and especially to the rock and heart of our lab, Richard Moore. A special thanks to Dr. Joyce Colussi-Mas whose patience I exploited and probably pushed to the boundaries while learning HPLC procedures.

There were many, many more names of colleagues, friends and family all of whom I thank and keep in my thoughts.

It is traditional in terms of journal authorship to save the most important place for the first and/or last name on the page. That place is for Professor Susan Schenk (a.k.a. Suzy baby). Supervisor, mentor, manager and friend who dragged, cajoled, ordered and eventually persuaded a thesis out of me. It is nothing more than the absolute truth to say that it would not have happened without her and for whom I have an enormous amount of respect and gratitude. 


\begin{abstract}
Under certain regimens of repeated pre-exposure, psychostimulant drugs show an increase in locomotor activity across days of testing and, after abstinence from the drug, a greater responsiveness to a subsequent challenge dose of the drug. This phenomenon, termed behavioural sensitisation, is thought to underlie certain aspects of drug addiction such as drug seeking and relapse. Repeated administration of +/-3, 4-Methylenedioxymethamphetamine (MDMA, ecstasy) produced sensitised hyperactivity in rats suggesting a lasting neurological change. The present studies sought to evaluate some of the parameters around both the induction and expression of behavioural sensitisation to MDMA and to evaluate if the sensitivity of the dopamine (DA) $D_{1}$ and $D_{2}$ receptors had altered under the current pre-exposure regimen of MDMA. Further, following MDMA pre-exposure that results $n$ behavioural sensitisation, changes in potency to the reinforcing effects of MDMA were investigated through the self administration paradigm. Finally, high performance liquid chromatography (HPLC) was used to evaluate changes in brain amine levels following sensitisation to MDMA locomotor activating effects.
\end{abstract}

Rats received a pre-treatment regimen consisting of 5 daily injections of MDMA (0.0, 5.0 or $10 \mathrm{mg} / \mathrm{kg}$ i.p). MDMA-produced locomotor activity was measured after 2, 9 or 28 days of withdrawal. In other groups, hyperactivity following administration the DA $D_{1}$ agonist SKF81297 (0.0, 0.5, 1.0, 2.0, 4.0 or $8.0 \mathrm{mg} / \mathrm{kg})$, or the D2-like DA agonist apomorphine $(0.0,0.5,1.0,2.0$ or 4.0 $\mathrm{mg} / \mathrm{kg}$ ) was measured in groups that received pre-exposure to MDMA (10.0 
$\mathrm{mg} / \mathrm{kg}$ ) or vehicle. The effects of the $\mathrm{D}_{1}$ antagonist SCH23390 (0.0, 0.01, 0.02, or $0.04 \mathrm{mg} / \mathrm{kg})$, the $\mathrm{D}_{2}$ antagonist eticlopride $(0.03,0.01,0.003,0.05,0.1$, or $0.2 \mathrm{mg} / \mathrm{kg}$ ) or the $5-\mathrm{HT}_{2 \mathrm{C}}$ antagonist RS102221 $(0.0,0.25,0.5$, or $1.0 \mathrm{mg} / \mathrm{kg})$ on MDMA-produced hyperactivity in MDMA or vehicle pre-treated rats was also measured. In Experiment 3, effects of MDMA or vehicle pre-treatment on latency to acquisition of MDMA (0.5 or $1.0 \mathrm{mg} / \mathrm{kg} / \mathrm{infusion})$ selfadministration was measured. In Experiment 4 effects of pre-treatment on brain tissue levels of DA, its metabolite homovanillic acid (HVA), serotonin (5-HT) and its metabolite, 5-hydroxyindoleacetic acid (5-HIAA) were determined.

The regimen of 5 daily treatments of $10.0 \mathrm{mg} / \mathrm{kg}$ produced persistent behavioural sensitisation and cross-sensitisation to hyperactivity produced by DA receptor agonists. These effects were not, however, reflected in sensitised responses to the ability of the antagonists to attenuate MDMA-produced hyperactivity. Pre-treatment with MDMA did not decrease latency to acquisition of self-administration. Rather, there was an increased latency to acquisition of self-administration in the MDMA pre-treated rats. MDMA pretreatment decreased levels of the serotonin metabolite 5-HIAA in the frontal cortex and hippocampus. Following the current pre-treatment regimen, MDMA produced behavioural sensitisation is mediated by neuroadaptations in central dopaminergic substrates. The persistent locomotor sensitisation is similar to that produced by other amphetamine-like stimulants and might underlie use and abuse of this compound. 
MDMA

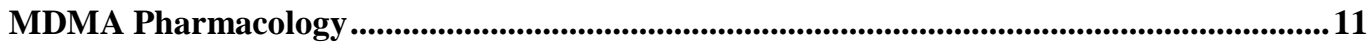

The deleterious effects of MDMA ...................................................................................................... 14

Brain reward mechanisms...................................................................................................17

Amphetamine induced Behavioural Sensitisation ............................................................................21

Sensitisation and Intravenous Self-Administration......................................................................24

Initiation and Expression of Sensitisation.........................................................................2

Role of Dopamine D1 and D2-like Receptors in Amphetamine Sensitisation..........................29

MDMA and Locomotor Activity .........................................................................................................32

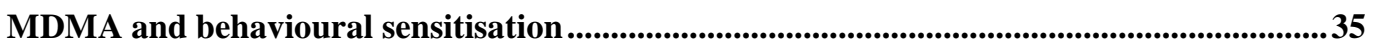

The current investigation..............................................................................................................................37

EXPERIMENT 1: INDUCTION AND EXPRESSION OF BEHAVIOURAL

SENSITISED RESPONDING TO MDMA LOCOMOTOR ACTIVATING

$\begin{array}{ll}\text { EFFECTS } & 39\end{array}$

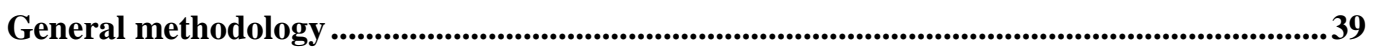

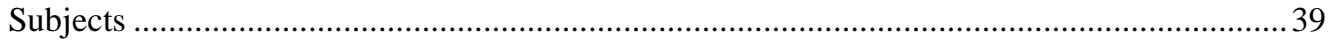

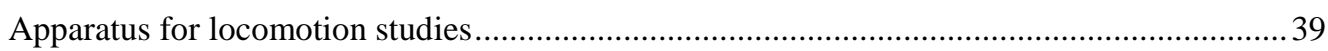

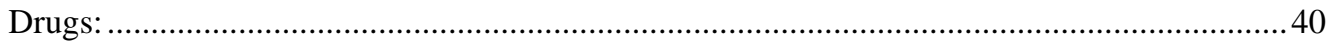


General Sensitisation Protocol .................................................................................. 41

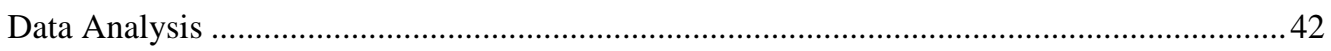

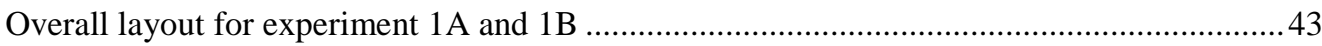

Experiment 1a Amphetamine-produced sensitisation ................................................. 43

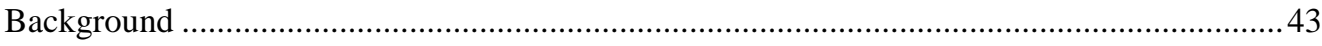

Experiment 1a Procedure ............................................................................................... 44

Experiment 1a Results. ..............................................................................................................45

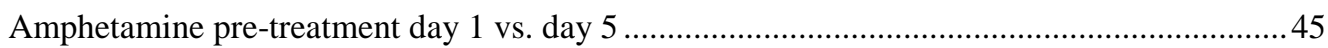

Amphetamine pre-treatment 2-day withdrawal ............................................................ 46

Amphetamine pre-treatment 28-day withdrawal .............................................................. 48

Experiment 1b, MDMA-Produced Sensitisation ....................................................................49

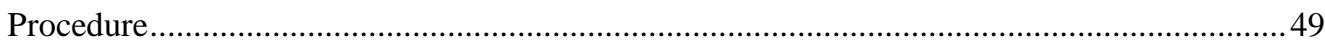

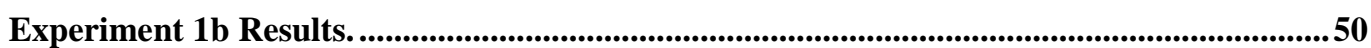

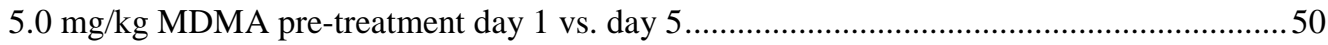

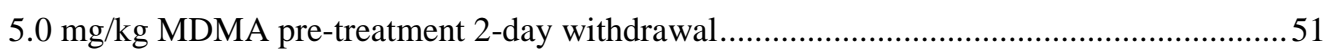

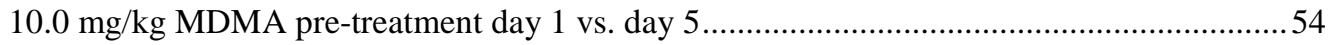

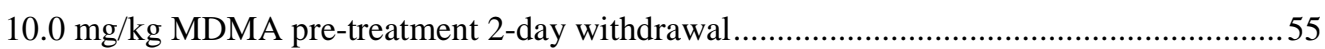

$10.0 \mathrm{mg} / \mathrm{kg}$ MDMA pre-treatment and 9 day withdrawal .............................................58

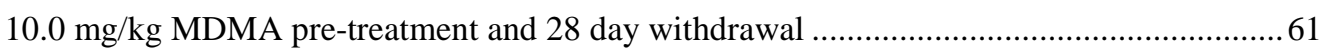

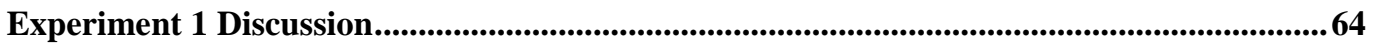

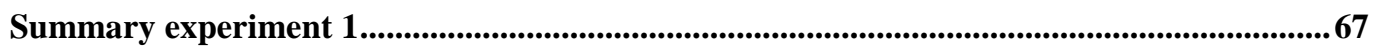

EXPERIMENT 2: CHANGES IN SENSITIVITY OF THE $\mathrm{D}_{1}$ AND $\mathrm{D}_{2}$ RECEPTOR TO REPEATED INTERMITTENT EXPOSURE OF MDMA 68

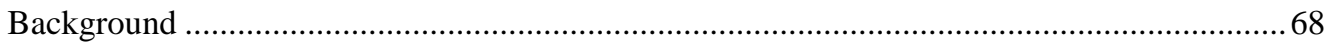

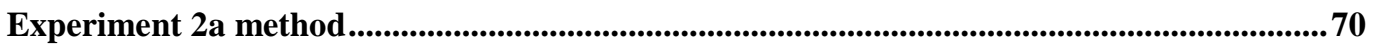

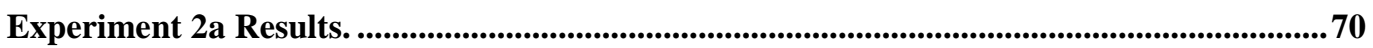


Effects of SCH23390 in MDMA sensitised rats..................................................................

Experiment 2b Results..........................................................................................................................

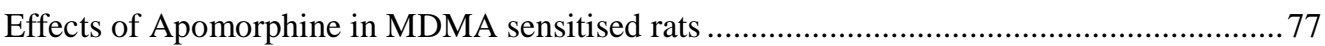

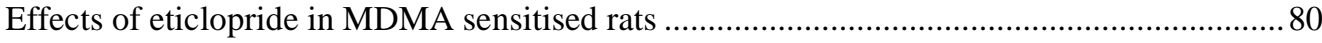

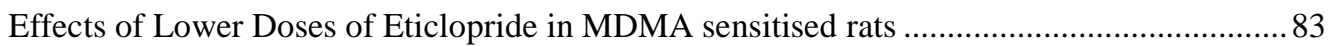

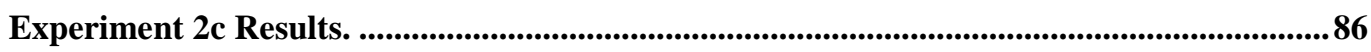

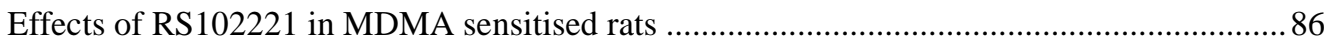

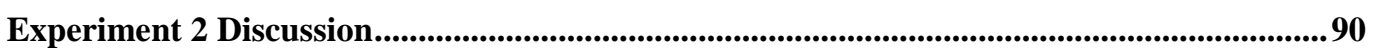

Experiment 2 summary …......................................................................................................................94

EXPERIMENT 3: CHANGES IN POTENCY OF REINFORCEMENT OF

MDMA AS MEASURED IN THE SELF-ADMINISTRATION PARADIGM

FOLLOWING REPEATED INTERMITTENT EXPOSURE TO MDMA 95

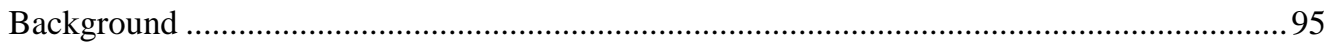

Materials and methods..........................................................................................................................99

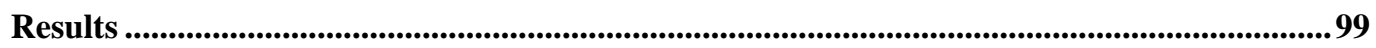

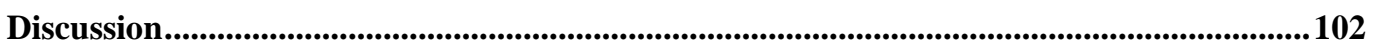

EXPERIMENT 4: ALTERATIONS OF BRAIN AMINE LEVELS

FOLLOWING REPEATED INTERMITTENT ADMINISTRATION OF

MDMA

Background

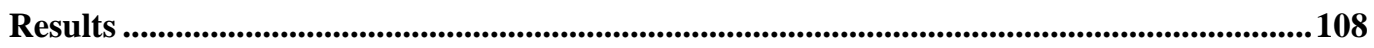

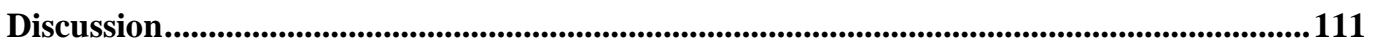




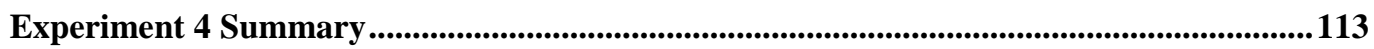

GENERAL DISCUSSION

$\begin{array}{ll}\text { REFERENCES } & 121\end{array}$ 


\section{MDMA}

The amphetamine derivative, 3, 4-methylenedioxymethamphetamine (MDMA or 'ecstasy') was synthesised around 1912 and a patent was granted in 1914 (Green, Mechan, Elliott, O'Shea, \& Colado, 2003; Kalivas, Duffy, \& White, 1998). It is chemically similar to amphetamine, methamphetamine, mescaline (see figure 1) and a number of ring-substituted phenethylamines and is both a stimulant and hallucinogenic compound (Battaglia, Brooks, Kulsakdinun, \& De Souza, 1988; Baumann, Wang, \& Rothman, 2006; Gold, Koob, \& Geyer, 1988).<smiles>CC(N)Cc1ccccc1</smiles><smiles>COc1cc(CCN)cc(OC)c1OC</smiles><smiles>CNC(C)Cc1ccc2c(c1)OCO2</smiles>

Figure 1.chemical structure of Amphetamine, mescaline and MDMA.

Research in the early part of the 20th century is scant but the LD 50 (the Lethal Dose in 50\% of animals tested) was investigated by the U.S. military in the 1950s. During the early 60s it was reportedly first used recreationally (Watson \& Beck, 1991). In the 1980's it was used as an adjunct to psychotherapy before the U.S. drug enforcement administration changed its classification to a schedule 1 drug and hence, illegal (Green, et al., 2003). 
MDMA was a popular recreational drug in the United Kingdom in the 1980's (Cole and Sumnall, 2003) with popularity of the drug increasing during the 1990's leading to more widespread use. A number of survey studies have suggested increased use throughout the 1990s depending upon the population sampled. For example, in a sample of 158 current drug users $82 \%$ said that they had used MDMA in the previous year (Williamson, et al., 1997) while only $4 \%$ of medical students surveyed at, or near, the same time reported MDMA use (Webb, Ashton, Kelly, \& Kamali, 1998). The same authors reported $13 \%$ use by UK university students while U.S. student's use increased from $2.8 \%$ in 1997 to $4.7 \%$ in 1999 and 10.6\% in the final 2000 survey (Strote, Lee, \& Wechsler, 2002).

The United Nations Office on Drugs and Crime (UNODC, 2004) presented long-term worldwide trends in production, trafficking and abuse of drugs. The reports revealed that the consumption of certain illicit drugs such as heroin and cocaine were decreasing while during the last previous decade, amphetamine-type stimulants (mainly MDMA) were the second most commonly used illicit drug.

In New Zealand, the Expert Advisory Committee on Drugs reported an increase in overall use. Those who positively responded to the question, "had they ever used MDMA?" increased from 3\% - 5.4\% between 1998 and 2001. The greatest reported use, as well as greatest increase 
in use, came from the 20-24 year age group of survey respondents. In this age group, use of MDMA during the previous 12 months rose from 3\%-10\% between 1998 and 2001 (The Expert Advisory Committee on Drugs [EACD], 2004). These figures put New Zealand on a roughly equal footing, in terms of use, with other overseas sample results.

Consistent with the reported increases of use have been increases in associated medical complications. MDMA induces a number of serious effects such as cardiac arrhythmias, hypertension, hyperthermia, hyponatremia (disturbance of the salts in the blood), liver complications, seizures and coma (Schifano, 2004). Deaths attributable to ecstasy use are rare but they are increasing. In the U.K., out of all the drug related deaths, ecstasy use in 1997 accounted for $1.2 \%$ rising to 4.1\% in 2002 (Schifano, Corkery, Deluca, Oyefeso, \& Ghodse, 2006).

\section{MDMA Pharmacology}

MDMA is a racemic molecule in that it has two enantiomers. The $(\mathrm{S})(+)$-enantiomer is a more potent dopamine releaser while the $(\mathrm{R})(-)-$ enantiomer shows a higher affinity for serotonin receptors (Johnson, Hoffman, \& Nichols, 1986). MDMA is usually formulated and consumed as a racemate, a 1:1 mixture of its enantiomers (Pizarro, et al., 2004) and acts on a number of different neurochemical systems releasing presynaptic serotonin (5-HT), dopamine (DA) and norepinephrine (NE). MDMA induces increases in extracellular 
monoamine concentrations through three direct actions (Cole \& Sumnall, 2003):

Firstly, MDMA is a substrate for the serotonin (SERT), dopamine (DAT) and norepinephrine (NET) transporters binding to, and blocking the transporter. As presynaptic plasma membrane transporters rapidly remove the released monoamine from the synapse, blockage of this process increases extracellular levels of all the monoamines (Colado, O'Shea, \& Green, 2004; Gough, Ali, Slikker, \& Holson, 1991; Green, et al., 2003; Lyles \& Cadet, 2003; S. R. White, Obradovic, Imel, \& Wheaton, 1996). Evidence of the transporter interactions of MDMA can be seen when serotonin selective reuptake inhibitors (SSRIs), such as fluoxetine, when co-administered with MDMA, attenuate increases in 5-HT (Berger, Gu, \& Azmitia, 1992; Hekmatpanah \& Peroutka, 1990; Rudnick \& Wall, 1992). Similarly, the DA reuptake inhibitor, GBR12909, prevented MDMA induced DA release in-vitro (Koch \& Galloway, 1997) as well as in-vivo (Nash \& Brodkin, 1991) . In addition, extracellular norepinephrine (NE) levels were reduced by coadministration of the NE-uptake blocker, desmethylimipramine (Fitzgerald \& Reid, 1990).

Secondly, when MDMA binds to the SERT it also induces a carrier mediated release of neurotransmitter. MDMA enters presynaptic nerve cells through passive diffusion across the membrane wall (Rudnick \& Wall, 1992) and through the actions of the SERT into the cell nerve 
endings (Crespi, Mennini, \& Gobbi, 1997). Once inside the cell, MDMA induces a mechanism of calcium independent release of serotonin into the synapse, by preventing the repackaging of cytosolic 5-HT into vesicles through the reversal of vesicular (Rudnick \& Wall, 1992, 1993) and plasma membrane(Iravani, Asari, Patel, Wieczorek, \& Kruk, 2000).

Thirdly, MDMA inhibits monoamine oxidase (MAO). MAO is an enzyme with two subtypes; MAO-A is found in the extracellular fluid, and MAO-B is located in the cytosolic fluid (Westlund, Denney, Kochersperger, Rose, \& Abell, 1985). Both MAO-A and MAO-B were inhibited by in-vitro application of MDMA although, there was a preferential effect on MAO-A (Gu \& Azmitia, 1993; Leonardi \& Azmitia, 1994). The consequence of this effect of MDMA resulted in high extracellular levels of 5-HT and a greater level of intracellular 5HT available for reverse vesicular transport. MAO-A also plays a central role in metabolising serotonin, norepinephrine and dopamine (Kato, Dong, Ishii, \& Kinemuchi, 1986). Extracellular increases in the monoamines are thereby also produced by MAO inhibition.

A linear proportional increase in MDMA-produced DA occurred with increasing levels of 5-HT (Jacocks \& Cox, 1992; S. R. White, Duffy, \& Kalivas, 1994) suggesting that increases in extracellular 5-HT may trigger DA release via interaction with receptors. There are at least 14 distinct 5-HT receptors belonging to seven families [5- $\mathrm{HT}_{1}$ through 5- 
$\mathrm{HT}_{7}$ ] (Hoyer, Hannon, \& Martin, 2002) with the 5-HT $1 \mathrm{~B}, 5-\mathrm{HT}_{2 \mathrm{~A}}, 5-$

$\mathrm{HT}_{2 \mathrm{C}}, 5-\mathrm{HT}_{3}$ and 5- $\mathrm{HT}_{4}$ receptors all involved in the modulation of DA

release. Of particular interest, activation of the $5-\mathrm{HT}_{2 \mathrm{~A}}$ and $5-\mathrm{HT}_{2 \mathrm{C}}$

receptors produce opposite effects on DA release. Systemic

administration of the 5- $\mathrm{HT}_{2 \mathrm{~A}}$ receptor antagonist ketanserin, and the selective 5-HT $2 \mathrm{~A}$ antagonist MDL100,907 attenuated MDMA-induced increases in striatal dopamine efflux (Nash, 1990; Schmidt, Abbate, Black, \& Taylor, 1990). In contrast, the selective 5-HT $2 \mathrm{C}$ receptor agonist, RO 60-0175, decreased DA release (Di Matteo, 2000) while the receptor antagonist, SB 243213, increased DA release (Berg, et al., 2006). These results suggest that in addition to MDMA induced DA release through DAT function, secondary actions of 5-HT also contribute to extracellular DA increases.

\section{The deleterious effects of MDMA}

There have been numerous investigations of the long term effects of MDMA in guinea pigs (Battaglia, Brooks, et al., 1988), dogs (Nishisawa, Mzengeza, \& Diksic, 1999), non-human primates (Frederick, et al., 1995), chickens (Bronson, Jiang, Clark, \& DeRuiter, 1994) and rats (e.g. Commins, et al., 1987; Malpass, White, Irvine, Somogyi, \& Bochner, 1999; Marston, Reid, Lawrence, Olverman, \& Butcher, 1999). 
It has long been noticed that the sensitivity to the neurotoxic effects of amphetamine derivatives such as MDMA differs across mammalian species. Primates are more vulnerable to substituted amphetamines than rats or guinea pigs whereas mice are remarkably tolerant (Stone et al., 1987). In rats, young animals were found to be much more resistant against the long-term neurotoxic effects of these drugs than adult ones (Broening et al., 1994) and different strains of rats have displayed different responses to MDMA. For example, MDMA is demethylenated by the CYP2D1 hepatic cytochrome P450 enzymes in the rat (Kumagai et al., 1994). This enzyme is expressed, differentially in rat strain with subsequent alterations in metabolism of MDMA (Malpass et al., 1999). The Dark Agouti rat for example, exhibits enzymic deficiencies whereas the Sprague Dawley strain has more effective CYP2D1 enzyme capacity.

Mice have also being used in investigations of the long term effects of MDMA, but the pharmacological effects of MDMA appear to differ from those of other species studied (Green, et al., 2003; Lyles \& Cadet, 2003). In mice, the acute effects of MDMA are similar to the rat (Logan, Laverty, Sanderson \& Yee, 1988) however, repeated large doses of MDMA (3 x 50mg) produced a small prolonged fall in 5-HT and 5-HIAA but marked falls in DA and DOPAC (Logan et al.,1988). 
A large number of studies have reported lasting decrements in 5-HT and its major metabolite, 5-hydroxyindoleacetic acid (5-HIAA); reductions in $[3 \mathrm{H}]$ paroxetine binding that reflect reduced density of SERT; and reduced serotonergic axonal density in brain tissue (Gouzoulis-Mayfrank \& Daumann, 2006 ; O'Shea, Granados, Esteban, Colado, \& Green, 1998; Ricaurte, McCann, Szabo, \& Scheffel, 2000).

Following MDMA exposure there is a biphasic modulation of 5-HT and 5-HIAA. There is an initial rapid increase in extracellular 5-HT (14 hours following injection) with levels returning to baseline within 24 hours. Over a period of 3-4 days there is evidence of deficits in 5-HT and 5-HIAA (Battaglia, et al., 1987; Colado, Murray, \& Green, 1993; Schmidt, 1987; Stone, Stahl, Hanson, \& Gibb, 1986). These deficits were reported following the administration of a single moderately high dose of MDMA (10mg/kg) (Schmidt, 1987) or repeated low $(4.0 \mathrm{mg} / \mathrm{kg}$ twice daily for 4 days) (O'Shea, et al., 1998) or high (10-40mgkg twice daily) (Commins, et al., 1987) doses.

Following a large dose of MDMA (20mg/kg twice daily for 4 days) a marked reduction in the density of uptake sites was observed (Battaglia, et al., 1987). A decrease in 5-HT and 5-HIAA does not, however, necessarily reflect axonal terminal damage. Immunocytochemical evidence supported the finding that neurodegeneration had occurred within terminal, dendritic and cell body regions (Commins, et al., 1987; O'Hearn, 1988). 
MDMA induced neurotoxicity in non-human primates has also been reported (Fischer, Hatzidimitriou, Wlos, Katz, \& Ricaurte, 1995; Insel, Battaglia, Johannessen, Marra, \& De Souza, 1989; Ricaurte, DeLanney, Irwin, \& Langston, 1988; Ricaurte, Martello, Katz, \& Martello, 1992; Scheffel, Lever, Stathis, \& Ricaurte, 1992). There is, however, an important difference between the non-human primate and rodent data. The dose required to induce deficits in non-human primates was less than that required for rodents (De Souza, Battaglia, \& Insel, 1990; Ricaurte, 1989) and the deficits were more persistent (Hatzidimitriou, McCann, \& Ricaurte, 1999).

It is tempting, given the non-human primate data, to infer that comparable MDMA induced deficits are produced in humans who abuse MDMA. Although there are indications of MDMA induced deficits (McCann, Mertl, Eligulashvili, \& Ricaurte, 1999; Ricaurte, DeLanney, Wiener, Irwin, \& Langston, 1988), a history of multiple drug use, variables such as questionable drug purity and dosage, make it difficult to draw robust, transferable conclusions from these studies.

\section{Brain reward mechanisms}

A number of converging pieces of evidence have implicated mesolimbic DA in brain reward mechanisms. Single cell recordings in monkeys showed increased extracellular DA levels in the ventral 
tegmental area (VTA) upon food presentation (Schultz, Apicella, \& Ljungberg, 1993). There were extracellular DA increases in the nucleus accumbens (NAc) during sex behaviour in the rat (Pfaus, et al., 1990). Similarly, access to water for water deprived rats, increased nucleus accumbens DA (Young, Joseph, \& Gray, 1992). In humans, neuroimaging techniques have provided evidence of increased dopamine activity in ventral striatal areas during reward related tasks (Schott, et al., 2008). Taken together, this strongly suggests that DA is a critical neurotransmitter for the mediation of reinforcement. Animal models are ideally suited for delineating aspects of not only natural rewards such as sex, and food, but also drug induced reinforcement.

The seminal work conducted by Olds and Milner (1954) showed that electrical brain stimulation could be powerfully reinforcing. These 'reward' substrates are within the medial forebrain bundle in what has come to be known as the 'reward pathway'. Subsequent studies have suggested that the reward pathway comprises the midbrain dopaminergic projections from the ventral tegmental area (VTA) into the nucleus accumbens (NAc) shell region and into the medial prefrontal cortex. Excitation and ensuing dopaminergic release from this system (the mesolimbic system) is critical to the acute reinforcing effects of drugs of abuse (Carelli, 2004; Dackis \& O'Brien, 2001; Di Chiara, et al., 2004; Kelley \& Berridge, 2002; Nestler, 2005; Robinson \& Berridge, 1993; Salamone \& Correa, 2002; Wise, 1998; Wolf, 2002). Indeed, nearly all drugs of abuse stimulate the release of dopamine at 
some point along the mesolimbic pathway and, regardless of the specific and primary mechanism of action, all drugs of abuse activate dopaminergic transmission (directly or indirectly) in the nucleus accumbens (Di Chiara, et al., 2004; Nestler, 2005).

One of the more powerful tools for measuring the reinforcing effect of drugs is the self-administration paradigm that allows drug-taking to be contingent on an operant response. In this procedure, laboratory animals are surgically prepared with an intravenous (IV) catheter and placed in an operant chamber with two response options (two levers, one the active lever, the other inactive). One response is associated with an IV infusion of a drug (active lever) the other response has no consequence (inactive lever). When presented with this choice, a significantly higher level of responding on the active lever suggests positive reinforcement is gained from infusion of the drug (Haney \& Spealman, 2008). Virtually all drugs that are abused by humans are reliably self-administered by animals (Fischman \& Schuster, 1978; Schuster \& Thompson, 1969) and the patterns of use seen in animal I.V. self administration comparable to the pattern of use seen in humans (Gardner, 2000; Spealman \& Goldberg, 1978). Thus, the selfadministration procedure provides a valid and reliable animal model of drug abuse liability and provides an animal model of human drugtaking and drug-seeking behaviours (Henningfield, Cohen, \& Heishman, 1991). 
Under baseline conditions, responding under fixed ratio schedules increase as the dose of drug is reduced. It has been suggested that this increase in responding is compensatory and maintains a constant blood level of drug regardless of available dose. Disruptions to the mesolimbic DA system alter this pattern of drug taking. For example, the DA receptor blocker pimozide (Risner \& Jones, 1976) or butaclamol (Yokel \& Wise, 1976) produced dose-dependent increases in intravenous self administration (IVSA) of amphetamine consistent with a reduction in dose (Pickens \& Thompson, 1968). Dialysate samples taken from the nucleus accumbens during IVSA of amphetamine showed elevated DA levels (Ranaldi, Pocock, Zereik, \& Wise, 1999).

However, dopamine release alone cannot account for the distinction between occasional drug use and the chronic drug dependent state known as 'addiction'. It has been suggested that drug addiction proceeds as a result of neuroadaptive processes in the brain reward system (Koob, 2006). When drugs of abuse repeatedly activate the reward system of the brain they induce a host of long lasting, complex neural adaptations that are maintained over time ranging from hours to years, and perhaps a lifetime (Kauer \& Malenka, 2007; Nestler, 2004). Adaptations of addiction have been modelled in the laboratory using animals (Deroche-Gamonet, Belin, \& Piazza, 2004), including a “prominent animal model of addiction", termed behavioural sensitisation (Wolf, 2002 (pg. 147)). 


\section{Amphetamine induced Behavioural Sensitisation}

Behavioural sensitisation has been studied to investigate

neuroadaptations that occur after repeated exposure to drugs of abuse

(Wise \& Bozarth, 1987). Behavioural sensitisation is a progressive, long lasting increase in the psychomotor stimulating property of drugs of abuse that manifests itself in a number of behaviourally measurable ways. Various behaviours such as, sniffing, rearing and head movements have all been reported although it is usually measured as the enhanced locomotor activity following repeated exposure (Pierce \& Kalivas, 1997; Post \& Rose, 1976; Robinson, 1984; Robinson \& Berridge, 1993; Stewart \& Badiani, 1993; Wolf, 1998).

Sensitisation was first reported early in the 1930's (e.g. Downs \& Eddy, 1932; Tatum \& Seevers, 1931) although it wasn't until the late 1960's and early 70's that investigations into amphetamine induced behavioural sensitisation were pursued in earnest (Robinson \& Becker, 1986). Initial studies established that repeated amphetamine administration lead to one of two states, either tolerance or sensitisation. The manifestation of either condition depended upon manipulation of a number of factors such as dose, drug exposure, and time after exposure. For example, continual exposure (for a two or three day period), or repeated multiple high doses of amphetamine, resulted in tolerance to drug produced hyperactivity (Kuczenski \& Leith, 1981). On the other hand, repeated intermittent administration 
(daily injections), of relatively low doses, induced sensitisation

(Robinson \& Kolb, 1999). A single exposure to amphetamine also produced sensitisation to a number of drug-produced behaviours, such as stereotypy (Browne \& Segal, 1977; Ellison \& Morris, 1981) or rotation (Robinson, 1984; Robinson, Becker, \& Presty, 1982). Repeated intermittent administration has been reported to produce a more robust and progressive increase in behaviour indicative of behavioural sensitisation (Kalivas \& Stewart, 1991).

Typically, single daily injections of $2-4 \mathrm{mg} / \mathrm{kg}$ amphetamine result in behavioural sensitisation (Robinson \& Kolb, 1999). More extreme exposures consisting of daily amphetamine administration in doses ranging from 5 to $32 \mathrm{mg} / \mathrm{kg}$ (i.p.) produced behavioural tolerance (e.g. Demellweek \& Goudie, 1983; Jackson, Bailey, Christie, Crisp, \& Skerritt, 1981; Lewander, 1971; Robinson \& Becker, 1982). It has been suggested that a critical factor is the interval between treatments rather than the dose (Robinson \& Becker, 1986). Thus, relatively infrequent injections spaced up to a week apart may be more efficacious in producing sensitisation than injections given close together (Robinson, 1984).

The observation of sensitisation is also dependant on time since last exposure. Sensitisation was observed 3 days after an amphetamine pretreatment regime with the magnitude of the response increasing 5 and 30 days post withdrawal (Kolta, Shreve, De Souza, \& Uretsky, 1985). 
Ideally, more than a day withdrawal following exposure is required as sensitisation has been observed 7, 14 and 28 days after the last dose but not after a single day withdrawal (Hitzemann, Tseng, Hitzemann, Sampath-Khanna, \& Loh, 1977).

Behavioural sensitisation is also dependent on the environmental context in which the drug is administered. Conditioned effects elicited by situational and environmental cues associated with the drug come to exert a powerful control over the manifestation of behavioural sensitisation. Typically, when examining environmental and contextual cues, the animals are taken from their home cages and moved to a novel test environment. Half of these, the paired group, are injected with a psychostimulant (drug paired with environment) and half with saline, the unpaired group. When removed from the test environment and placed back in their home cages the saline unpaired group receive the drug, thereby isolating the contextual environment from this group. On the test day, only the previously paired group showed a sensitised response (Pert, Post, \& Weiss, 1990).

A number of researchers have used similar methodology to examine the role of context in amphetamine produced sensitisation. Although context dependent sensitisation was blocked (Stewart \& Druhan, 1993), and extinguished once gained (Stewart \& Vezina, 1991), the majority of reports confirm that environmental contextual cues are extremely important for the manifestation of behavioural sensitisation (Ahmed, 
Stinus, Le Moal, \& Cador, 1993; Badiani, Anagnostaras, \& Robinson, 1995; Badiani, Browman, \& Robinson, 1995; Drew \& Glick, 1988; Mazurski \& Beninger, 1987; Stewart \& Druhan, 1993; Vezina, Giovino, Wise, \& Stewart, 1989).

\section{$\underline{\text { Sensitisation and Intravenous Self-Administration }}$}

Investigators typically, and successfully, have measured the latency to acquisition of self administration showing drug pre-exposed animals acquiring self administration faster than drug naive animals (Horger, Giles, \& Schenk, 1992; Horger, Shelton, \& Schenk, 1990; Piazza, Deminiere, Le Moal, \& Simon, 1989). Animals pre-exposed to a sensitising regimen of amphetamine were predisposed to-self administer amphetamine (Horger, Giles, \& Schenk, 1992; D. Piazza, Le Moal \& Simon, 1989) as indicated by decreased latency to acquire an operant response. However, pre-exposure to amphetamine decreased latency to acquisition of only low doses of drug ( Piazza, Deminiere, Le Moal, \& Simon, 1989) using a low fixed ratio (FR) reinforcement schedule. When high doses of the drug were made available, under the same FR schedule, there was no difference between amphetamine and vehicle pre-exposed animals (Lorrain, Arnold, \& Vezina, 2000) suggesting prior exposure may reduce the threshold reinforcing dose.

When high doses of amphetamine were available in the selfadministration paradigm, amphetamine break point on a progressive 
ratio (PR) schedule of reinforcement were higher for amphetamine preexposed rats (Mendrek, et al., 1998; Vezina, Pierre \& Lorrain, 1999). In the PR schedule, the number of lever responses required to obtain a reinforcer is increased for each successive reinforcer until a 'break point' that fails to support continued operant responding is reached. It has been suggested that increases in break point from drug pre-exposed animals reflects higher motivation to further seek the drug (Arnold \& Roberts, 1997).

Decreases in latency to acquisition and higher break points indicate pre-exposure to amphetamine enhances drug seeking as well as the acquisition rate of self-administration. One suggestion for this alteration has been linked to the sensitisation of mesolimbic dopamine neurons. Higher break points have been associated with increases in NAc DA (Vezina et al., 1999) as well as sensitisation to the locomotor activating effects of amphetamine (Mendrek, et al., 1998; Vezina et al., 1999).

Non-human primates, mice and rats will all self-administer MDMA (Banks, et al., 2007; Braida \& Sala, 2002; Cornish, et al., 2003; Daniela, Brennan, Gittings, Hely, \& Schenk, 2004; Daniela, Gittings, \& Schenk, 2006; Fantegrossi, Ullrich, Rice, Woods, Winger, 2002; Fantegrossi, et al., 2004; Ratzenboeck, Saria, Kriechbaum, \& Zernig, 2001; Schenk, Gittings, Johnstone, \& Daniela, 2003; Schenk, Hely, Gittings, Lake, \& Daniela, 2008; Schenk, et al., 2007). There have 
however, been noted differences in latency to acquisition of MDMA self-administration when compared to other self-administered drugs. Acquisition of MDMA self-administration is relatively slow (Schenk et al., 2003) with more variability in the latency to acquisition compared with other self-administered drugs (e.g. Horger, et al., 1990; Horger, et al., 1992).

These differences might be due to the different pharmacology of MDMA. It has been suggested that drugs with a greater effect on DA compared to 5-HT have a higher subjective reinforcement value (Wee, Anderson, Baumann, Rothman, Blough, \& Woolverton, 2005) with reinforcing efficacy positively correlated with inhibition of dopamine reuptake (Ritz, Lamb, Goldberg, \& Kuhar, 1988; Wilcox, Rowlett, Paul, Ordway, \& Woolverton, 2000) and increases in extracellular DA (Self \& Nestler, 1995). Moreover, it has been suggested that the ratio of DA to 5-HT is a better indicator of drug abuse potential than solely a positive correlation with DA reuptake inhibition or increased DA release. For example, when different equipotent DA releasers that differed in 5-HT release were self administered by rhesus monkeys, responding was lower when 5-HT potency was higher (Wee, et al., 2005). Further, Ritz and Kuhar (1989) reported a negative correlation between potency as a reinforcer and 5-HT transporter binding affinity. These data suggest that the ratio of 5-HT to DA is an important determinant of self administration. 
Because of the predominant effect of MDMA on the serotonin system it has been suggested that the lower DA:5-HT ratio may explain the increased latency to acquisition of self-administration of MDMA (Schenk, et al., 2007). For example, acquisition to MDMA self administration for drug naive rats was produced in about 12 days (Schenk et al., 2003), whereas acquisition to cocaine selfadministration has been reported in as few as 5 days (Schenk \& Partridge, 1997). With repeated administration of MDMA, there are long-term reductions in brain tissue concentrations of 5-HT and in 5HT reuptake sites (Ricaurte et al., 2000; Green et al., 2003; Gudelsky andYamamoto, 2003) thereby increasing the DA:5-HT ratio. With continued self-administration studies, further decreases in 5-HT would be produced and this might explain the development of MDMA as an efficacious reinforcer (Schenk, et al., 2007) .

\section{Initiation and Expression of Sensitisation}

Behavioural sensitisation is comprised of two distinct components, 1) initiation (also called 'development', 'acquisition' or 'induction) and 2) expression. The initiation of sensitisation is the development of the augmented locomotor behaviour while the expression refers to the manifestation of that behaviour (Kalivas \& Stewart, 1991; Pierce \& Kalivas, 1997; Robinson \& Becker, 1986; Stewart \& Badiani, 1993). Effects on different components of the mesolimbic DA system have been attributed to these two processes. 
DA in the ventral tegmental area VTA appears to be responsible for the induction of behavioural sensitisation following repeated amphetamine exposure (Nelson, Wetter, Milovanovic, \& Wolf, 2007; Pierce \& Kalivas, 1997; Vanderschuren \& Kalivas, 2000; Vezina, 1996; Wolf \& Xue, 1998). Direct infusion of DA antagonists into the VTA completely blocked the acute locomotor activating effects of amphetamine (Vezina \& Stewart, 1989). Repeated amphetamine injections into the VTA induced behavioural sensitisation to either systemically, or intra NAc amphetamine (Bjijou, Stinus, Le Moal, \& Cador, 1996; Cador, Bjijou, \& Stinus, 1995; Hooks, Jones, Liem, \& Justice Jr, 1992; Kalivas \& Weber, 1988; Vezina \& Stewart, 1989). In contrast, injections of amphetamine into other mesolimbic substrates did not result in sensitisation (Hitzemann, Wu, Hom, \& Loh, 1980; Kalivas \& Weber, 1988; Perugini \& Vezina, 1994). It would appear that drug effects within the VTA underlie the induction of behavioural sensitisation.

Acute administration of amphetamine increased DA overflow in the NAc (Carboni, Imperato, Perezzani, \& Di Chiara, 1989; Kalivas \& Stewart, 1991; Robinson \& Berridge, 1993; Sharp, Zetterstrom, Ljungberg, \& Ungerstedt, 1987), but repeated intra-NAc administration did not result in further increases in synaptic DA (Dougherty \& Ellinwood, 1981). Intra-NAc amphetamine produced locomotor activity (Pierce \& Kalivas, 1995), and repeated administration resulted 
in sensitisation. However, there was no sensitised response to a further amphetamine challenge (Kalivas \& Weber, 1988). Thus the pattern of responding to a sensitising regime of amphetamine differs when the drug is infused into the VTA or the NAc.

A comparison of the effect of amphetamine administered into the VTA and NAc helps to clarify their role in induction and expression of amphetamine sensitisation. (Cador, et al., 1995). Amphetamine injected into the NAc dose-dependently increased locomotor activity but repeated exposure failed to produce behavioural sensitisation. Repeated injections into the VTA did not produce locomotor activity but resulted in locomotor activity following an intra-NAc amphetamine challenge. It was concluded that repeated amphetamine expose to the NAc was not responsible for the dopaminergic adaptations underlying behavioural sensitisation (Cador, et al., 1995)

\section{Role of Dopamine D1 and D2-like Receptors in Amphetamine Sensitisation}

In the 1970's it was proposed that there were two classes of dopamine receptor, the D1 and D2 (Cools \& Van Rossum, 1976; Kebabian \& Calne, 1979). Around the 1990's further heterogeneity revealed at least five subtypes of dopamine receptors (D1-D5) (Civelli, Bunzow, \& Grandy, 1993; Sibley \& Monsma, 1992). The five subtypes are now divided into two families and these are referred to as the D1-like (D1, D5) and the D2-like (D2, D3, D4) dopamine receptors. The most 
notable distinguishing function of the two receptor subtypes is the effect on adenylyl cyclase with the D1-like increasing and the D2-like decreasing adenylyl cyclase activity or having no effect. A further difference is the presence (or otherwise) of an autoreceptor; with pharmacological studies indicating that the DA autoreceptor is of the D2 type (Nisoli, et al., 2009). DA D2 receptors function both as presynaptic autoreceptors and as postsynaptic receptors. Presynaptic autoreceptors modulate dopamine synthesis and release, and inhibit neuronal firing.

Pre-treatment with the D1-like receptor antagonist, SCH23390, blocked the development of sensitisation produced by intra-VTA infusions of amphetamine (Vezina \& Stewart, 1989). SCH23390 also blocked the development of sensitisation produced by repeated systemic injections of amphetamine (Stewart \& Vezina, 1989). These finding implicated a critical role of D1-like receptors in the VTA in amphetamine sensitisation. However, an alternative explanation for the attenuation of sensitisation was raised. It was suggested that intra-VTA administration of the D1 like antagonist may have diffused into the entire brain (Di Chiara, 1993) explaining why subsequent administration of amphetamine had not produced a sensitised response. As a test of this hypothesis, intra-VTA amphetamine was co-administered with $\mathrm{SCH} 23390$, sulpiride (a selective D2 antagonist) or kitanserin (5- $\mathrm{HT}_{2}$ antagonist). SCH23390, but not ketanserin or sulpiride, dose dependently blocked the induction of behavioural sensitisation. (Bjijou, 
et al., 1996). Systemic administration of the D2 receptor antagonist, Ro22-2586, also failed to effect the development of sensitisation (Vezina \& Stewart, 1989). As was found with sulpiride, intra-VTA administration of other D2 antagonists, spiperone or eticlopride, also failed to alter the induction of sensitisation to the locomotor activating effect of amphetamine (Bjijou, et al., 1996; Vezina, 1996). Thus DA D1-like, but not D2-like, receptors within the VTA appear critical to the initiation of sensitisation to amphetamine.

Repeated amphetamine administration induced a subsensitivity of $\mathrm{D}_{2}$ autoreceptors (Wolf, White, Nassar, Brooderson, \& Khansa, 1993) which may, in part, explain the failure of the $\mathrm{D}_{2}$ antagonists to block the induction of sensitisation. These autoreceptors are impulse regulating on the pre-synaptic neuron and prolonged exposure to amphetamine reduced the responsiveness of the receptors thereby increasing DA synthesis and release. White and Wang (1984) showed that a relatively high daily dose of amphetamine $(1$ or $2 \times 5 \mathrm{mg} / \mathrm{kg}$ i.p. for 5 days) significantly reduced the ability of intravenous apomorphine (a non-selective DA agonist, having a slightly higher affinity for $\mathrm{D}_{2^{-}}$ like dopamine receptors) to suppress dopamine firing in the VTA suggesting a subsensitivity of the $\mathrm{D}_{2}$ autoreceptor. With increases in dopamine release being induced through $\mathrm{D}_{2}$ autoreceptor subsensitivity, blocking the $\mathrm{D}_{2}$ receptor, as Vezina and Stewart (1989) and Bjijou and colleagues (1996) had done, would not be expected to block the process 
of induction to amphetamine but rather augment the process

(Vanderschuren, Schoffelmeer, Mulder, \& De Vries, 1999).

DA VTA autoreceptor subsensitivity is a transient alteration which does not persist during withdrawal from repeated amphetamine.

Following repeated exposure to a low dose of amphetamine, and 3 days withdrawal, intra-VTA application of the $\mathrm{D}_{2}$ agonist, quinpirole, failed to reduce firing rates suggesting a subsensitivity of the autoreceptor. This decreased response, however, was no longer evident 14 days following treatment, even though behavioural sensitisation persisted (Wolf et al., 1993).

\section{MDMA and Locomotor Activity}

MDMA increases the release and prevents reuptake of DA. Following MDMA administration, increases in extracellular DA have been reported in striatum (Gudelsky \& Yamamoto, 2008; Schmidt, Levin, \& Lovenberg, 1987; Steele, Nichols, \& Yim, 1987), nucleus accumbens (Bankson \& Yamamoto, 2004; Cadoni, et al., 2005), prefrontal cortex (Nair \& Gudelsky, 2004) and hippocampus (Shankaran \& Gudelsky, 1998).

The mechanism of DA release is both transporter and impulse dependent with DAT inhibitors (Nash \& Brodkin, 1991; Shankaran, Yamamoto, \& Gudelsky, 1999) since the sodium channel blocker, 
tertrodotoxin, (Yamamoto, Nash, \& Gudelsky, 1995) attenuated release. MDMA induced locomotor activity was also attenuated by systemic administration of the $\mathrm{D}_{1}$ like antagonist, $\mathrm{SCH} 23390$, (Daniela et al., 2004) and the $\mathrm{D}_{2}$ antagonist, eticlopride (Ball, Budreau \& Rebec, 2003).

Although MDMA primarily promotes DA release via the transporter, the serotonin selective reuptake inhibitor (SSRI), fluoxetine, suppressed MDMA stimulated DA release suggesting a role of serotonergic mechanisms (Callaway, Wing, \& Geyer, 1990). Further, 5-HT2 agonists potentiated (Gudelsky et al., 1994) and 5-HT 2 antagonists suppressed (Nash, 1990; Schmidt et al., 1994; Yamamoto et al., 1995) the MDMA-induced DA increase. More specifically, the 5- $\mathrm{HT}_{2 \mathrm{~A}}$ receptors may modulate DA through increasing regulation of either DA synthesis or DA neuron firing rate (Schmidt et al. 1992; Gudelsky et al. 1994). Indeed, basal firing rate of DA neurons were increased by 5$\mathrm{HT}_{2 \mathrm{C}}$ receptor antagonists and inhibited by $5-\mathrm{HT}_{2 \mathrm{C}}$ receptor agonists (Di Matteo et al. 2000; Gobert et al. 2000) through a tonic inhibitory influence on release (Ball \& Rebec, 2005).

Because of the well documented role of DA in locomotor activity it is not surprising that both peripheral and central administration of MDMA increased locomotor activity. Gold and Koob (1988) were one of the first to demonstrate MDMA produced locomotor activity in rats and since then there have been a number of other reports (e.g. Bubar, 
Pack, Frankel, \& Cunningham, 2004; Yamamoto \& Spanos, 1988). MDMA induced locomotor activity was decreased by systemic administration of the $\mathrm{D}_{1}$ like antagonist, SCH23390 (Daniela, et al., 2004) and the $\mathrm{D}_{2}$ like antagonist, eticlopride (Ball, Budreau, \& Rebec, 2003). Moreover, pharmacological blockade of the DAT inhibited MDMA induced locomotor activity (Callaway et al., 1990). The selective 5-HT $2 \mathrm{~A}$ antagonist MDL 100,907, also suppressed MDMA produced hyperactivity. Other less selective $5-\mathrm{HT}_{2 \mathrm{~A}}$ antagonists (ritanserin, methiothepin, MDL 28,133A, SR46349 and clozapan) also reduced MDMA stimulated activity (Ball \& Rebec, 2005; Kehne, et al., 1996) but the 5- $\mathrm{HT}_{2 \mathrm{C}}$ antagonist, SB242084, potentiated the locomotor stimulant effects of MDMA (Fletcher, Sinyard, \& Higgins, 2006). It has been suggested that the 5-HT antagonists altered MDMA produced hyperactivity by modulating DA release (Ball \& Rebec, 2005).

Of interest, chronic treatment with DOI, although a $5-\mathrm{HT}_{2 \mathrm{~A}}$ agonist, produced an inhibitory regulation of the $5-\mathrm{HT}_{2 \mathrm{C}}$ receptor, which increased MDMA produced locomotor activity. This was attributed to 5- $\mathrm{HT}_{2 \mathrm{~A}}$ mechanisms because the response to the $5-\mathrm{HT}_{2 \mathrm{C}}$ receptor agonist, MK212, remained unaffected by repeated DOI pre-treatment. (Ross, Herin, Frankel, Thomas, \& Cunningham, 2006). Indeed, repeated DOI treatment decreased $5-\mathrm{HT}_{2 \mathrm{~A}}$ receptor protein expression in the PFC and shell of the NAc. Because 5- $\mathrm{HT}_{2 \mathrm{~A}}$ receptor activation increased DA release (Ball \& Rebec, 2005), these findings suggest that 
5- $\mathrm{HT}_{2 \mathrm{~A}}$ receptors in the DA terminal areas of the PFC and NAc might be critical to MDMA produced hyperactivity.

\section{MDMA and behavioural sensitisation}

Few studies have examined behavioural sensitisation to MDMA and fewer still have examined the mechanisms underlying the development or expression of sensitisation. Repeated intermittent administration of MDMA produced a progressive and enduring increase in the behavioural response to the drug. One of the early investigations into MDMA behavioural sensitisation was conducted by Spanos and Yamamoto (1989) who studied both the acute and chronic behavioural effects of MDMA. Acute effects showed a dose related increase in MDMA produced locomotor activity. Chronic exposure, consisting of alternate-day injections with locomotor challenge doses after the sixth and twelfth injections, produced a dose dependent increase in all behavioural measures. Furthermore, authors reported correlated extracellular in-vivo voltammetery measures of DA release paralleling the time course of MDMA induced hyperlocomotion. When examining the chronic behavioural effects of MDMA exposure Kalivas, Duffy and White (1998) concurred with Spanos and Yamamoto (1989), finding an augmented behavioural response to the drug. In addition, and paralleling amphetamine induced DA release, they found a dose dependent increase in extracellular DA in the nucleus accumbens suggesting there may be patterns of MDMA produced neuroadaptations that overlap with other commonly abused amphetamines. In corroboration 
with this finding, MDMA induced increases in cell firing in the dorsal striatum were increased in sensitised rats (Ball et al., 2006). Serotonergic mechanisms might also be involved since the $5-\mathrm{HT}_{1 \mathrm{~B} / 1 \mathrm{D}}$ antagonist, GR127935, attenuated the development of sensitisation (McCreary et al., 1999). However, Modi, Yang, Swann, \& Dafn (2006) failed to find cross sensitisation to amphetamine and methylphenidate after repeated MDMA administration. Chronic administration produced sensitisation of only a transient nature evident on challenge day 13 but not on day 38. Chronic dosage of $5 \mathrm{mg} / \mathrm{kg}$ persisted for a longer period of time with motor indices of sensitisation still evident on day 38 . The administration of $10.0 \mathrm{mg} / \mathrm{kg}$ MDMA however, produced increases in locomotor activity. This does not rule out the possibility of overlapping neural adaptations but may suggest those adaptations to be more akin to cocaine rather than amphetamine or methylphenidate.

Intra-NAc core administration of the $\mathrm{D}_{1}$-like receptor antagonist, SCH23390, prevented the expression, but not the development, of behavioural sensitisation (Ramos, Goni-Allo, \& Aguirre, 2004). Although Ramos et al. (2004) did not observe sensitised responding

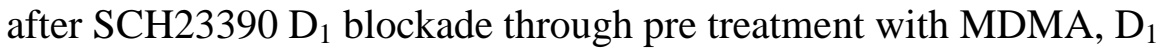
receptor activation must still have occurred. The longer half life of MDMA versus $\mathrm{SCH} 23390$ would ensure $\mathrm{D}_{1}$ receptor activation past any evident time analysis of the 60 minute test for locomotion or post activity test chamber when the rats were placed back in their home cage. Indeed, the obvious interpretation is that made by the authors in 
that the $\mathrm{D}_{1}$ receptor is not involved in the induction of sensitised responding. It was argued that projections from the prefrontal cortex (PFC) might mediate behavioural sensitisation to MDMA because ibotenic acid lesions of the dorsal medial PFC, that destroyed cell bodies, blocked both the induction and expression of sensitisation (Ramos, Goni-Allo, \& Aguirre, 2005b). Dopaminergic mechanisms were implicated since administration of the $\mathrm{D}_{1}$ like receptor agonist, SCH23390, into the medial PFC blocked the expression of sensitisation. Because $\mathrm{SCH} 23390$ is also a $5-\mathrm{HT}_{2 \mathrm{C}}$ receptor agonist, this mechanism in the medial PFC might play a key role in behavioural sensitisation to MDMA. This idea was supported by the finding that attenuation of sensitisation produced by SCH23390 was reversed by administration of the 5- $\mathrm{HT}_{2 \mathrm{C}}$ receptor antagonist, RS 102221 and sensitisation was produced by the 5- $\mathrm{HT}_{2 \mathrm{C}}$ agonist MK212 (Ramos, Goni-Allo, \& Aguirre, 2005a). These data support the idea that MDMA induced sensitisation was mediated by $5-\mathrm{HT}_{2 \mathrm{C}}$ receptor stimulation in the medial PFC and not by the blockade of medial PFC $\mathrm{D}_{1}$ receptors.

\section{The current investigation}

MDMA induces locomotor, as well as sensitised locomotor responding that can be attenuated through dopaminergic antagonists. Despite a plethora of evidence suggesting a crucial role of dopamine in behavioural sensitisation to psychostimulants, its role in MDMA sensitisation is yet to be fully investigated. It has been postulated that 
activation of $\mathrm{DA} \mathrm{D}_{1}$ receptors initiate the neural adaptations underlying amphetamine sensitisation (e.g. Stewart and Vezina 1989; Kalivas and Stewart 1991; Bjijou et al. 1996; Vezina 1996). DA D 2 pre-synaptic receptors show evidence of transient sub-sensitivity (White and Wang (1984) while DA $\mathrm{D}_{2}$ post-synaptic receptors may become sensitised (Wolf et al., 1993). However, the role in MDMA induced sensitisation is less clear. One way to address this is through behavioural pharmacology.

The following set of experiments aims to firstly determine parameters for the development of sensitisation to the locomotor activating effects of MDMA and it is hypothesised that repeated intermittent administration will produce an augmented locomotor activity in response to a further challenge dose of the drug. Secondly, the thesis will determine whether cross-sensitisation is produced to the locomotor activating effects of $\mathrm{D}_{1}$-like and/or $\mathrm{D}_{2}$-like receptor agonists and antagonists. Thirdly, the relevance of sensitisation to drug self administration will be evaluated. Finally, because deficits in 5-HT have been reported following exposure to MDMA, HPLC analysis will be used. Tissue levels of 5-HT, DA and their primary metabolites will be measured to ascertain what changes in neurochemical levels result from repeated administration of MDMA. 


\section{Experiment 1: Induction and expression of behavioural sensitised responding to MDMA locomotor activating effects}

\section{General $\underline{\text { methodology }}$}

Subjects

The subjects were male Sprague-Dawley rats, weighing between 250-350g (approximately 60 days old). The animals were bred at Victoria University in Wellington, New Zealand and were initially housed in pairs and then housed singly in a temperature- $\left(21^{\circ} \mathrm{C}\right)$ and humidity- $(55 \%)$ controlled room. The colony was maintained on a 12-hr light/dark cycle with lights on at 0700. Food and water were available ad libitum except during testing periods. Laboratory animal care principles of the Victoria University of Wellington Animal Breeding Facility were followed, and the Victoria University of Wellington Animal Ethics Committee approved all protocols.

Apparatus for locomotion studies

Eight open field chambers (450mm x 450mm; Med Associates (ENV515) Vermont, USA) equipped with four banks of 16 photocells on each of the internal walls of the chamber were used to measure horizontal locomotion. Photocells were set at $25 \mathrm{~mm}$ above the floor of the chamber and spaced evenly at $25 \mathrm{~mm}$ centres around the periphery. 
The open field boxes were interfaced with a computer and data were obtained using Med Associates software. Each activity chamber was enclosed in sound attenuating boxes (Med associates; Vermont USA). A beam 'box' was pre-set encompassing a 3 x 3 beam square $(50 \mathrm{~mm} \mathrm{x}$ 50mm). Movement outside of this 'box' broke the beams and constituted one locomotor count.

All testing was conducted during the light cycle. A red house light was illuminated during testing and white noise was also continually present to mask extraneous disturbances. Prior to and after each locomotor activity test, the chamber interiors were cleaned and wiped with Virkon ' $S$ ' disinfectant (Southern Veterinary Supplies, NZ).

Drugs:

- Racemic MDMA hydrochloride, (ESR Ltd, Porirua, New Zealand).

- $d$-Amphetamine, (SIGMA; Australia).

- SCH23390 Hydrochloride, [R(+)-7-Chloro-8-hydroxy-3-methyl-1phenyl-2,3,4,5-tetrahydro-1H-3-benzazepine hydrochloride], (Tocris Bioscience, Natick, Massachusetts).

- SKF81297 hydrobromide, [R-(+)-6-chloro-7,8-dihydroxy-1-phenyl2,3,4,5-tetrahydro-1-H-3-benzazepine hydrochloride], (Tocris Bioscience, Natick, Massachusetts).

- Apomorphine hydrochloride, [R-5,6,6a,7-tetrahydro-6-methyl-4Hdibenzo[de,g]quinoline-10,11-diol hydrochloride], (Tocris Bioscience, Natick, Massachusetts). 
- Eticlopride, [S(-)-3-Chloro-5-ethyl-N-[(1-ethyl-2-pyrrolidinyl)methyl]-6hydroxy-2-methoxybenzamide hydrochloride], (SIGMA; Australia). All the above drugs were dissolved in sterile saline (0.9\%NACL).

- RS102221, [8-[5-(2,4-Dimethoxy-5-(4-

trifluromethylphenylsulfonamido)phenyl-5-oxopentyl]-1,3,8triazaspiro[4,5]decane-2,4-dione hydrochloride], (Tocris Bioscience, Natick, Massachusetts).

All the above drugs were dissolved in sterile saline (0.9\% NACL) apart from RS102221 which was suspended in a solution of $1 \%$ polysorbate 80 (Tween $\left.{ }^{\circledR} 80\right)$.

Subcutaneous (SC) or Intraperitoneal (IP) injections were in a volume of 1 $\mathrm{ml} / \mathrm{kg}$. All drug doses refer to the salt.

General Sensitisation Protocol

Rats were housed individually and were weighed and handled daily, one week prior to the commencement of all experiments.

Days 1-5:

Rats were transported daily from their home cages to the locomotor activity room and placed into the middle of the open field chambers. Locomotor activity was recorded for 15 or 30 minutes, recording was then paused while rats were administered drug or saline and activity was recorded for an additional 60 minutes. Activity data were collected at 5 
min intervals during the $30 \mathrm{~min}$ pretreatment and $60 \mathrm{~min}$ post-treatment periods.

Days 6 \& 7:

For the majority of experiments, there was a two day withdrawal period during which the rats remained in the home cages. A number of experiments had extended withdrawal periods (see table 1) in which the rats remained in their home cages.

Day 8:

Rats were transported from their home cages to the locomotor activity room and placed into individual activity chambers. Activity was recorded during a 15 or 30 minute pretreatment and 60 minute post-treatment period.

Data Analysis

Data analyses (unless otherwise specified) were conducted on the activity counts during the post injection interval. Locomotor responses were analysed using a 1,2 or 3-way (as specified in each results section) repeated measures Analysis of Variance (ANOVA) with the repeated measure of time. 
Overall layout for experiment 1A and 1B

Table 1.

\begin{tabular}{|c|c|c|c|c|c|c|}
\hline & \multicolumn{6}{|c|}{ Pre-treatment } \\
\hline & \multicolumn{2}{|c|}{ Exp. 1A } & \multicolumn{3}{|c|}{ Exp. 1B } & \multirow[b]{2}{*}{ Vehicle } \\
\hline & $\begin{array}{l}\text { Amphetamine } \\
(2.0 \mathrm{mg} / \mathrm{kg})\end{array}$ & Vehicle & $\begin{array}{l}\text { MDMA } \\
(5.0 \mathrm{mg} / \mathrm{kg})\end{array}$ & Vehicle & $\begin{array}{l}\text { MDMA } \\
(10.0 \mathrm{mg} / \mathrm{kg})\end{array}$ & \\
\hline $\begin{array}{l}\text { Day } 1 \text { vs. } \\
\text { day } 5\end{array}$ & Yes & Yes & Yes & Yes & Yes & Yes \\
\hline $\begin{array}{c}\text { 2-day } \\
\text { Withdrawal }\end{array}$ & Yes & Yes & Yes & Yes & Yes & Yes \\
\hline $\begin{array}{c}\text { 9-day } \\
\text { withdrawal }\end{array}$ & No & No & No & No & Yes & Yes \\
\hline $\begin{array}{c}\text { 28-day } \\
\text { withdrawal }\end{array}$ & Yes & Yes & No & No & Yes & Yes \\
\hline
\end{tabular}

Table 1. Within experiment 1, drug pre-treatment and withdrawal periods vary. The table identifies the drug pre-treatment administered and withdrawal period used.

Experiment 1a Amphetamine-produced sensitisation

Background

Repeated intermittent exposure to a number of stimulant drugs produces a sensitised locomotor response. The sensitised behavioural responses reflect a host of neuroadaptations. These complex changes are greatly impacted upon by a number of parameters in the drug administration regimen including withdrawal time from the last drug administration (Kolta, et al., 1985) dose ( Kalivas \& Duffy, 1993; Paulson, Camp, \& Robinson, 1991; Paulson \& Robinson, 1995), drug exposure duration (Robinson \& Becker,1986), and the context in which the drug is delivered (Badiani, Browman, et al., 1995; Badiani, Camp, \& Robinson, 1997; 
Robinson, Browman, Crombag, \& Badiani, 1998; Stewart \& Badiani, 1993).

To this end Experiment 1 as a whole was designed to determine the protocols required to induce reliable sensitisation to the locomotor activating effects of MDMA. To start, experiment 1 reproduced amphetamine sensitisation and then used the delivery and withdrawal protocols to attempt to induce MDMA sensitisation. Different doses of MDMA were used in the pre-treatment regimen, and following drug abstinence, varying challenge doses were administered in order to determine whether there were changes in the dose response function. Because MDMA is an amphetamine derivative, it was hypothesised that the induction and expression protocols for sensitisation to the behavioural effects of amphetamine and MDMA would be similar.

\section{Experiment 1a Procedure}

On days $1-5$, rats (numbers vary and are reported in each experiment) were given a single daily administration of amphetamine $(0.0$ or 2.0 $\mathrm{mg} / \mathrm{kg}$, IP). This dose and injection regimen has been shown to produce persistent sensitisation to the locomotor stimulant effects of amphetamine (Vanderschuren, Schmidt, et al., 1999) and has been used in a number of previous investigations (Laudrup \& Wallace, 1999; McNamara, Davidson, \& Schenk, 1993; Nordquist, et al., 2008). 
After either 2 or 28 days of withdrawal, during which all rats were left in home cages, the locomotor activating effects of amphetamine $(0.0$ or 0.5 $\mathrm{mg} / \mathrm{kg}$, IP) were measured as described above.

Experiment $\underline{\text { la Results. }}$

Amphetamine pre-treatment day 1 vs. day 5

Figure 1.1 shows locomotor activity as a function of time on Days 1 and 5 of the pre-treatment regimen. A mixed 3-way ANOVA [Day $(1 \& 5) x$ Drug (amph or vehicle) X Time (12 five min bins)] on the counts post injection ('time 0') revealed a significant main effect of Day $(F(1,22)=$ 21.65, $\mathrm{p}<0.05)$, Drug $(\mathrm{F}(1,22)=219.74, \mathrm{p}<0.05)$ and a significant interaction between Day and Drug $(\mathrm{F}(1,22)=14.98$, $\mathrm{p}<0.05)$. There was also a 3 way interaction for Day x Drug x Time $(F(11,242)=2.46, \mathrm{p}<$ 0.05). A post hoc analysis of the amphetamine data (Day $x$ Time) showed that locomotor activity counts were higher on day 5 compared to day 1 of testing $(\mathrm{F}(1,22)=18.95, \mathrm{p}<0.05)$. 


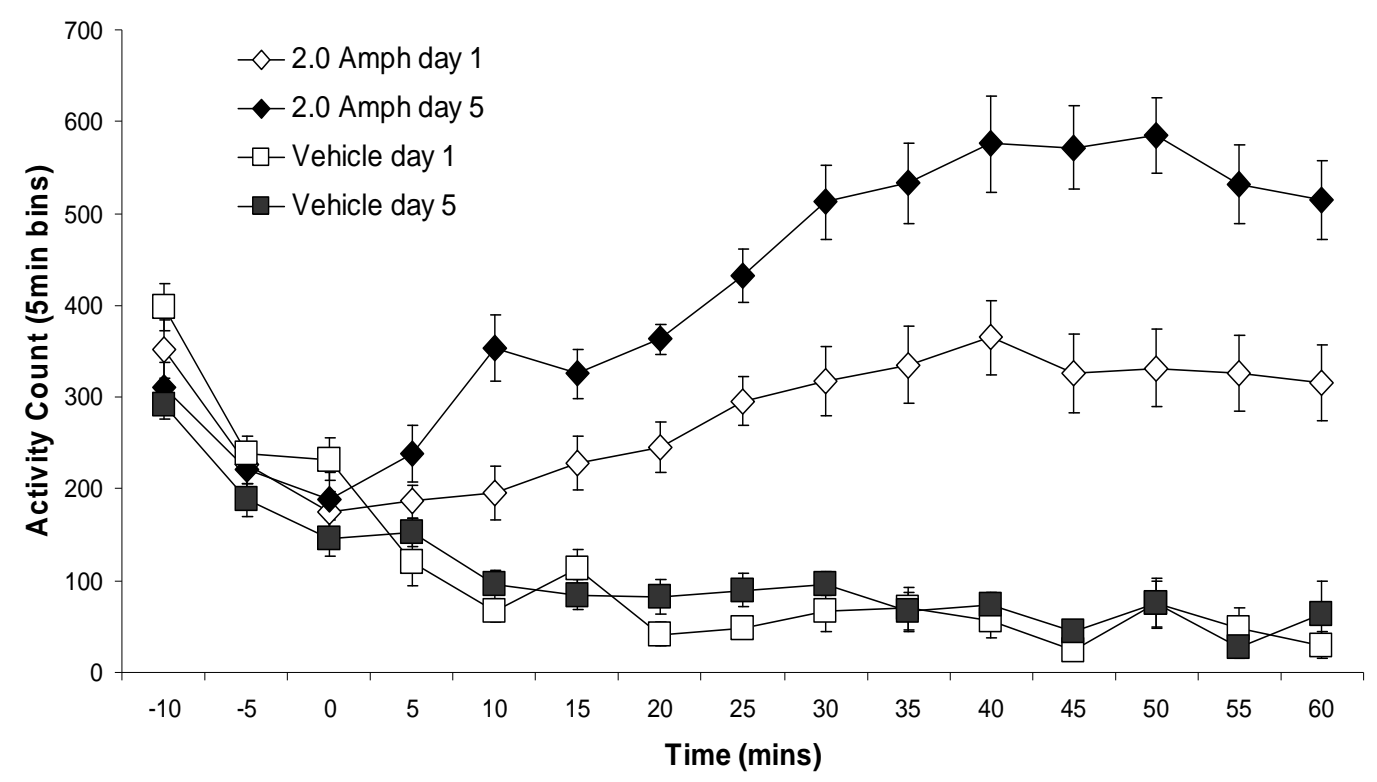

Figure 1.1. Locomotor counts for the 75 minutes of testing across days. Rats were administered either amphetamine $(2.0 \mathrm{mg} / \mathrm{kg}$ i.p.) $(n=12)$ or vehicle $(n=12)$ each day in the testing chamber. Locomotor counts are summed into bins of 5 minute intervals with time ' 0 ' being the time of drug injection.

Amphetamine pre-treatment 2-day withdrawal

Figure 1.2 shows locomotor activity as a function of time on challenge day (day 8). A mixed 3-way ANOVA [pre-treatment (amph or vehicle) $x$ Dose $(0.0$ or $0.5 \mathrm{mg} / \mathrm{kg}) \times$ time (12 five min bins)] revealed a significant effect of pre-treatment $(\mathrm{F}(1,82)=3.99, \mathrm{p}<0.05)$, and Dose $(\mathrm{F}(1,82)=$ 11.56, $\mathrm{p}<0.05)$, but no interaction between pre-treatment and Dose $(\mathrm{F}(1,82)=1.04, \mathrm{~ns})$ 


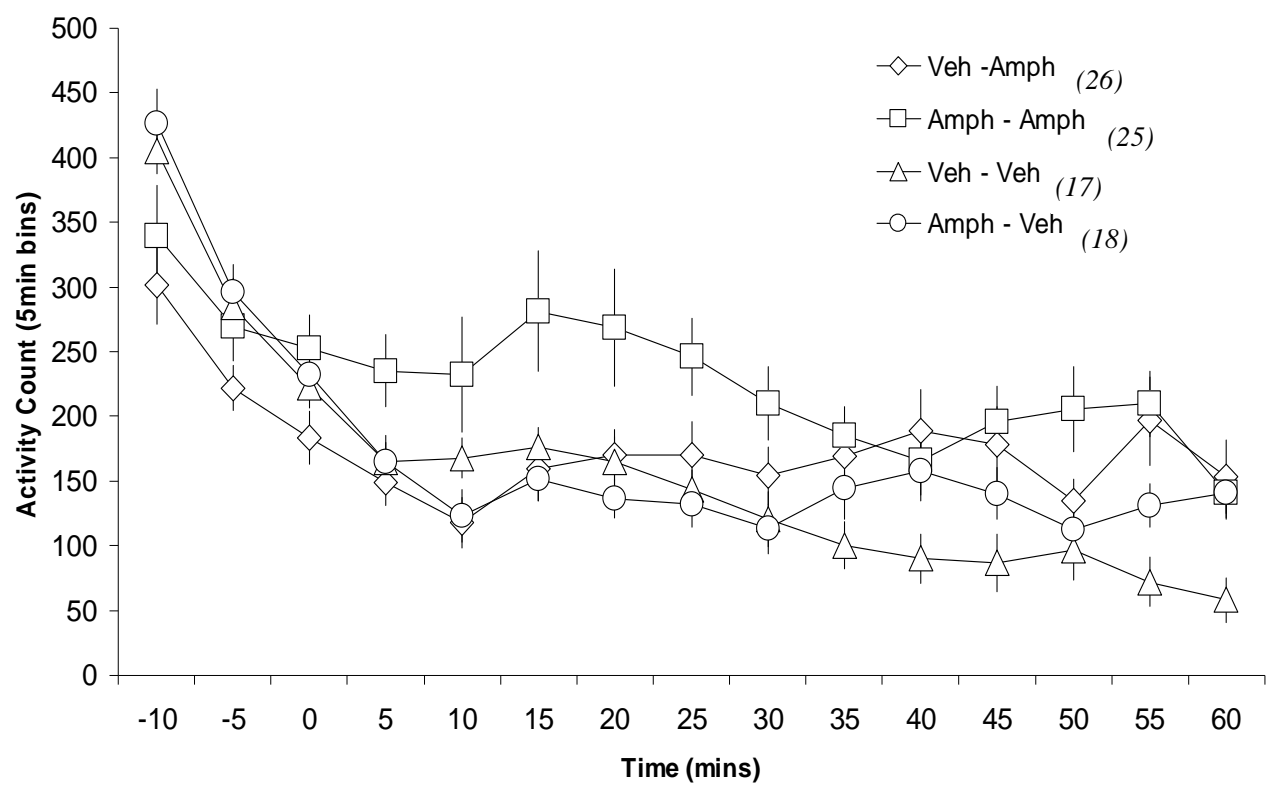

Figure 1.2. Locomotor counts for the 75 minutes of testing following injection of either amphetamine $(0.5 \mathrm{mg} / \mathrm{kg}$ i.p. $)$ or vehicle. Data were collected following 2 days withdrawal. The first listing in the legend identifies the group's pre-treatment drug while the second indicates the challenge drug. Sample sizes are in brackets beside the listings.

Locomotor counts are summed into bins of 5 minute intervals with time ' 0 ' being the time of drug injection.

Group differences were examined with a 1-way ANOVA (Veh-Amph, Amph-Amph, ) on post injection totals. An overall difference between the groups was found $(\mathrm{F}(1,49)=4.18, \mathrm{p}<0.05)$. Whereas the low dose of amphetamine failed to produce significant locomotor activation in the vehicle pre-treated rats, increased activity was produced in the amphetamine pre-treated rats during the initial 30 minute post injection period. When total locomotion for just the initial post injection 30 minute period was compared activity in the Amph-Amph group was significantly higher than activity of all other groups $(\mathrm{p}<0.05)$. 


\section{Amphetamine pre-treatment 28-day withdrawal}

A further group of vehicle $(n=7)$ and amphetamine $(n=7)$ pre-treated rats were administered $0.5 \mathrm{mg} / \mathrm{kg}$ i.p. amphetamine 28 days following the sensitisation regimen. Figure 1.3 shows the time course for the total 75 minutes following amphetamine (0.5mg/kg i.p.) administration.

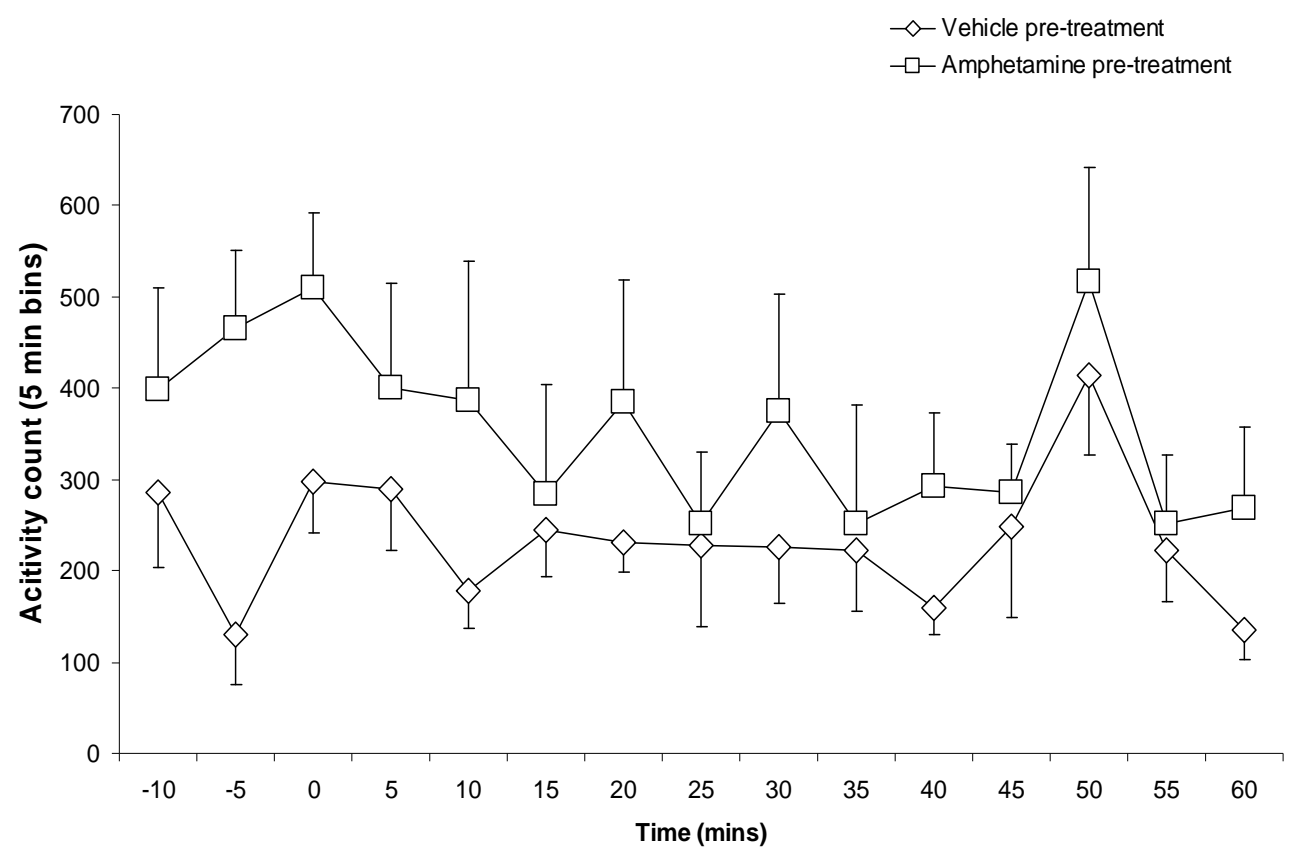

Figure 1.3. Locomotor counts for the 75 minutes of testing following 28 days withdrawal. All animals were challenged with amphetamine $(0.5 \mathrm{mg} / \mathrm{kg}$ i.p. $)$ with the legend indicating vehicle and amphetamine pretreated rats. Locomotor counts are summed into bins of 5 minute intervals with time ' 0 ' being the time of drug injection

The amphetamine pre-treated rats tended to be more responsive to the effect of amphetamine but the effects were of much smaller magnitude than when testing was conducted following 2 days withdrawal (Figure 1.2). Additionally, amphetamine pre-treated rats tended to have higher activity scores during the pre-treatment phase of testing although 
variability throughout testing was high. A repeated measures ANOVA (pre-treatment $x$ time) failed to reveal any significant differences between the two groups over the 30 minutes post injection $(F(1,6)=1.085, \mathrm{p}>$ $0.05)$ or the 60 min post injection period $(\mathrm{F}(1,12)=1.247, \mathrm{p}>0.05)$.

\section{Experiment $1 b, \underline{\text { MDMA-Produced Sensitisation }}$}

Procedure

On days $1-5$, rats were given a single daily administration of MDMA $(0.0,5.0$ or $10.0 \mathrm{mg} / \mathrm{kg}$ i.p. $)$ and activity was measured. These doses were chosen based on previous literature that has demonstrated sensitisation (Ramos, et al., 2005a; Spanos \& Yamamoto, 1989). After 2, 9 or 28 days of withdrawal, during which all animals remained in their home cages, locomotor activating effects of MDMA $(0.0,2.5,5.0 \& 10.0 \mathrm{mg} / \mathrm{kg}$ i.p. $)$ were measured as above. (28 day withdrawal animals were housed in pairs during the 28 day drug abstinence period). 
Experiment $1 b$ Results.

$\underline{5.0 \mathrm{mg} / \mathrm{kg} \text { MDMA pre-treatment day } 1 \text { vs. day } 5}$

During initial tests, a large sample of rats were administered repeated intermittent administration of the lower $(5.0 \mathrm{mg} / \mathrm{kg}$, IP) dose of MDMA. The locomotor activating effects of MDMA as a function of time on Days 1 and 5 of treatment are presented in Figure 1.4. MDMA produced hyperactivity $(\mathrm{F}(1,84)=83.24, \mathrm{p}<0.05)$ was not substantially altered by repeated exposure and the ANOVA failed to reveal significant effects of Day $(\mathrm{F}(1,84)=2.2$, ns) or an interaction between Day and Drug $(\mathrm{F}(1,84)$ $=3.21, \mathrm{~ns})$. 


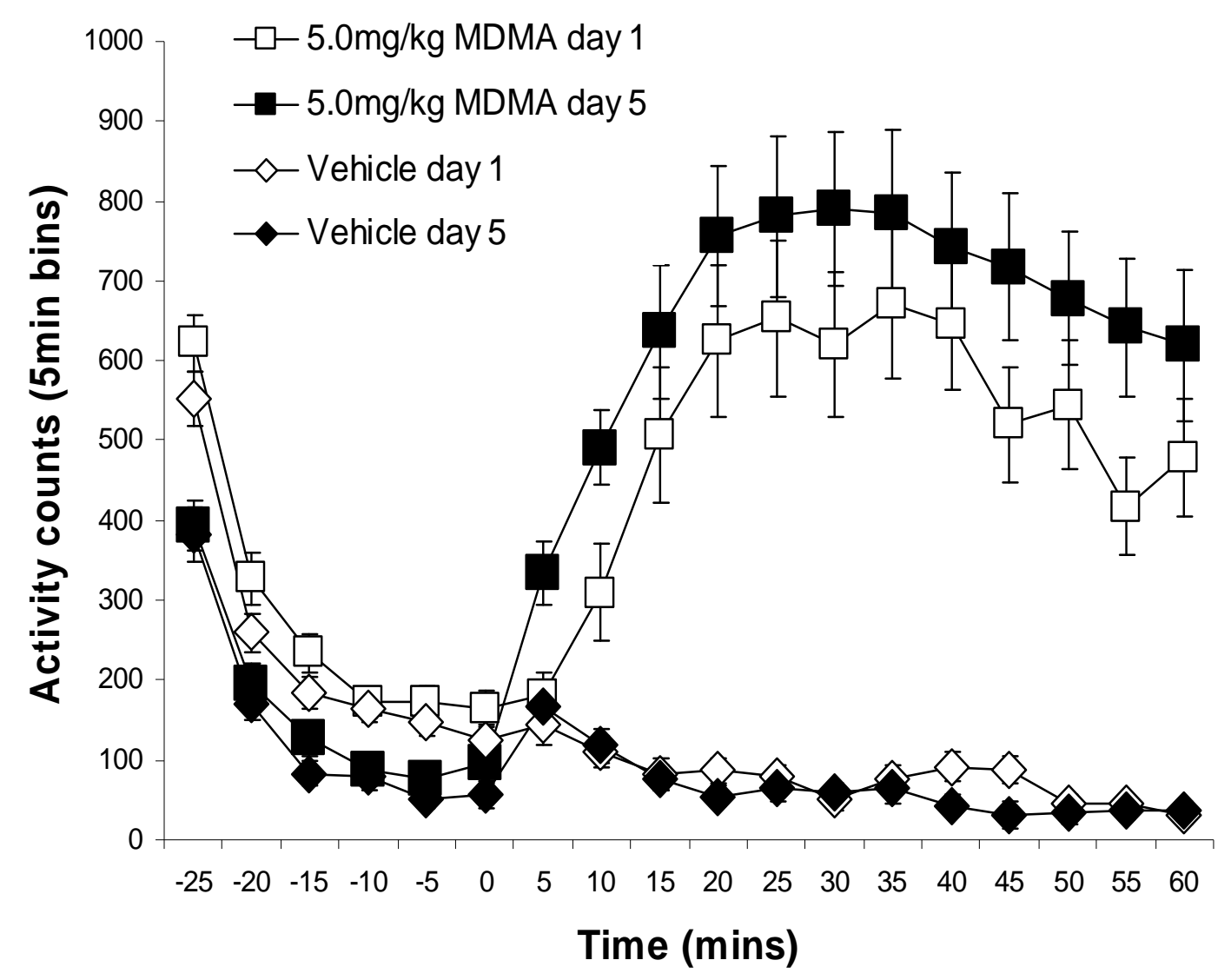

Figure 1.4. Average locomotor counts for the 90 minutes of testing on day 1 and 5 following administration of MDMA (5.0mg/kg i.p.) $(n=43)$ or vehicle $(n=43)$ in the test boxes. Locomotor counts are summed into bins of 5 minute intervals with time ' 0 ' being the time of drug injection.

$\underline{5.0 \mathrm{mg} / \mathrm{kg} \text { MDMA pre-treatment 2-day withdrawal }}$

Following a two day withdrawal the motor activating effects of various doses of MDMA $(0.0,2.5,5.010 .0 \mathrm{mg} / \mathrm{kg})$ were measured. Figure 1.5 shows the time course data. 


\section{Vehicle pre-treated}

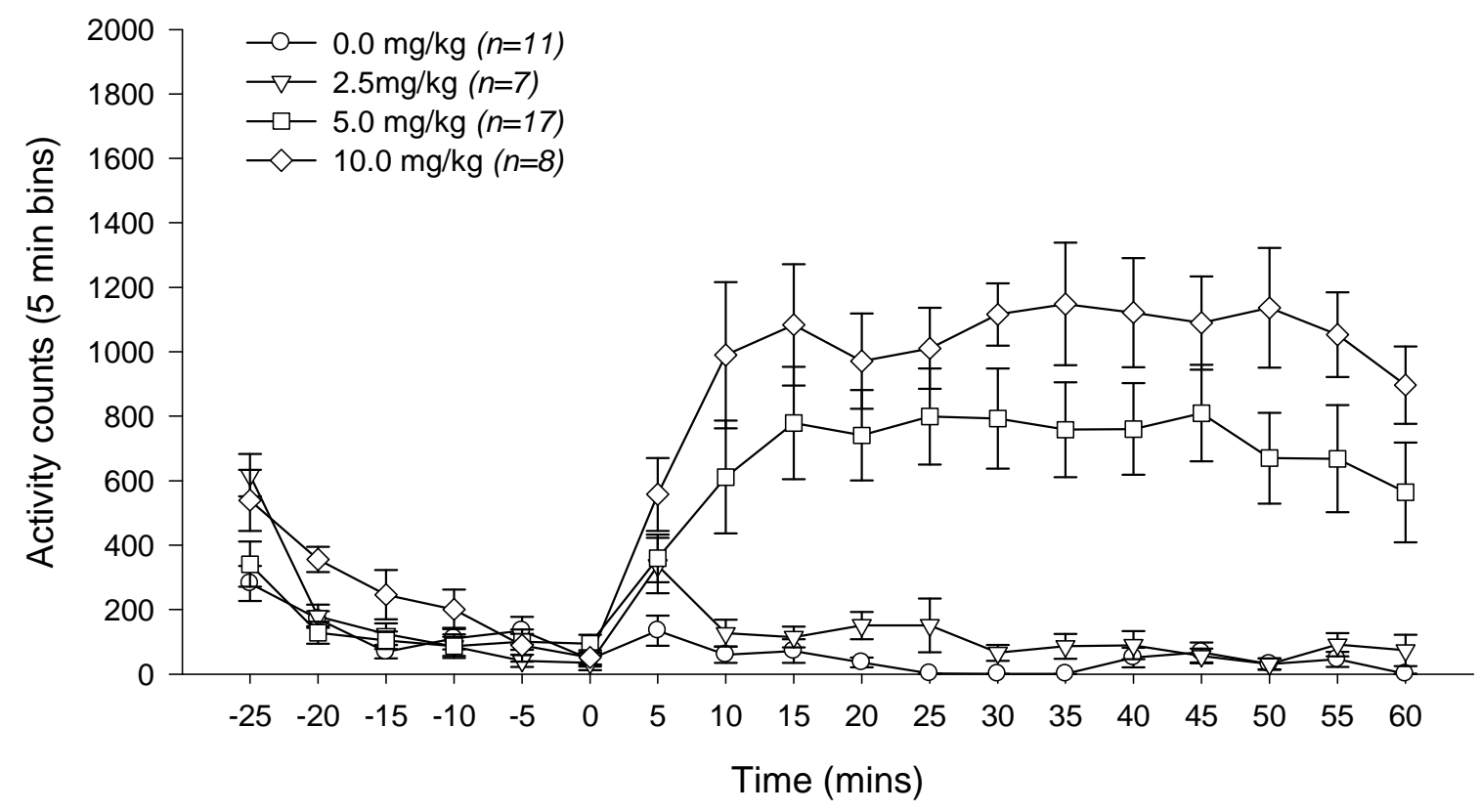

\section{MDMA pre-treated}

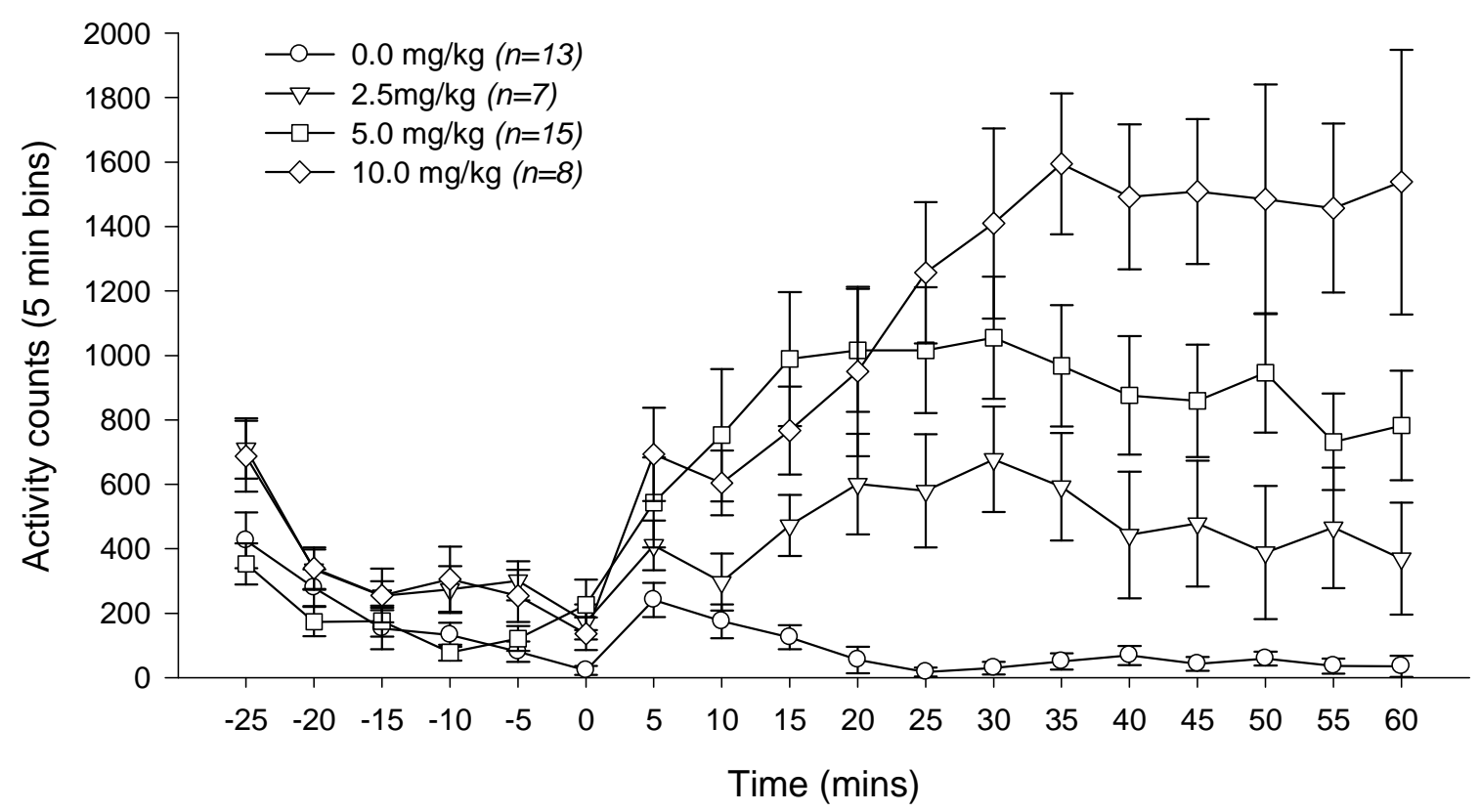

Figure 1.5. Locomotor activating effects of various doses of MDMA following a 2-day withdrawal from daily administration of MDMA $(5.0 \mathrm{mg} / \mathrm{kg}$ i.p.) or vehicle. Top panel is the time course of locomotor activity for vehicle pre-treated rats. Bottom panel is the time course of locomotor activity for MDMA pre-treated rats. Locomotor counts are summed into bins of 5 minute intervals with time ' 0 ' being the time of drug injection 
A mixed 3-way ANOVA [Pre-treatment (MDMA or vehicle) x Dose (0.0,

$2.5,5.0,10.0) x$ time (12 five min bins)] revealed a main effect of Pre-

treatment $(\mathrm{F}(1,79)=4.08, \mathrm{p}<0.05)$ and Dose $(\mathrm{F}(3,79)=23.73, \mathrm{p}<0.05)$

but no significant interaction between Pre-treatment and Dose $(\mathrm{F}(3,79)=$ $0.44, \mathrm{~ns})$.

Figure 1.6 presents the total activity data collapsed across time following each dose of MDMA for the MDMA and vehicle pre-treatment groups.

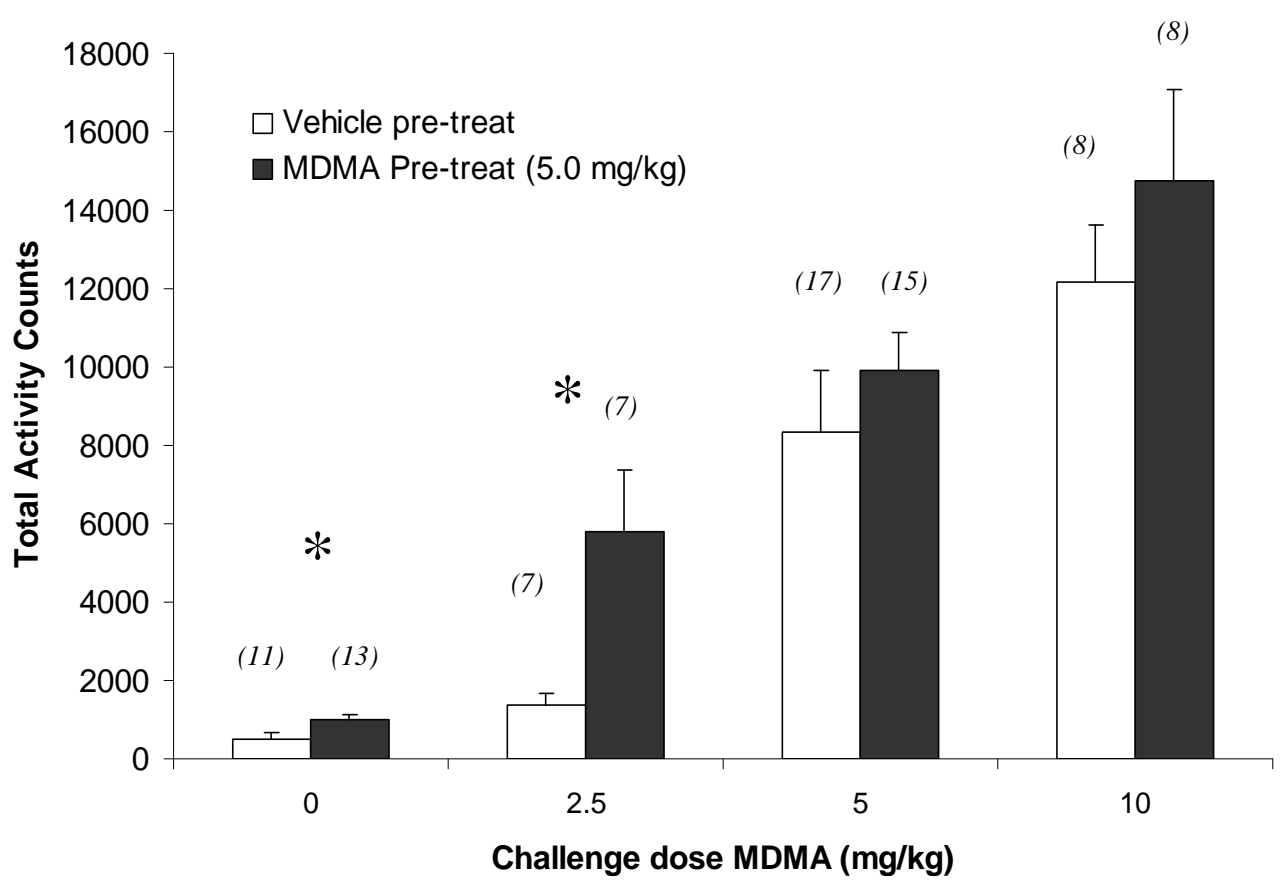

Figure 1.6. Total locomotor counts on challenge day for the 60 minutes post injection with vehicle and MDMA (5.0 mg/kg i.p.) pre-treated rats. After two days of withdrawal rats were challenged with MDMA $(0.0,2.5$, 5.0 or $10.0 \mathrm{mg} / \mathrm{kg}$ i.p.). * difference from vehicle pre-treated group.

Analysis on total locomotor activity counts during the 60 minutes postinjection period was conducted using a 2-way ANOVA (Pre-treatment $x$ Dose). Main effects were echoed from the repeated measures analysis 
above [a main effect for Pre-treatment $(F(1,79)=4.08, \mathrm{p}<0.05)$ and Dose $(F(3,79)=23.73, p<0.05)]$. Independent samples t-tests revealed MDMA pre-treated rats were more responsive to the $0.0 \mathrm{mg} / \mathrm{kg}(\mathrm{t}(22)=-2.04, \mathrm{p}<$ $0.05)$ and the $2.5 \mathrm{mg} / \mathrm{kg}(\mathrm{t}(6.396)=-2.57, \mathrm{p}<0.05)$ doses (Levene's test for equal variances violated, adjusted df reported).

\section{$10.0 \mathrm{mg} / \mathrm{kg}$ MDMA pre-treatment day 1 vs. day 5}

Figure 1.7 shows MDMA-produced hyperactivity on Days 1 and 5 of the higher dose pre-treatment regimen $(0.0(n=19)$ or $10.0(n=21) \mathrm{mg} / \mathrm{kg}$ i.p. $)$ A mixed 3-way ANOVA [Day $(1 \& 5) x$ Drug (MDMA or vehicle) $X$ Time (12 five min bins)] on the post injection ('time 0') data revealed a main effect of Drug $(F(1,38)=284.57, \mathrm{p}<0.05)$, Day $(F(1,38)=4.87$, $\mathrm{p}<0.05)$ and an interaction $(\mathrm{F}(1,38)=7.86, \mathrm{p}<0.05)$. There was also a 3 way interaction for Day x Drug x Time $(F(11,418)=4.43, \mathrm{p}<0.05)$. Post hoc analysis on the MDMA data (Day $x$ Time) showed that MDMAproduced hyperactivity was greater on Day 5 compared to Day 1 of treatment $(\mathrm{F}(1,36)=5.16, \mathrm{p}<0.05)$. 


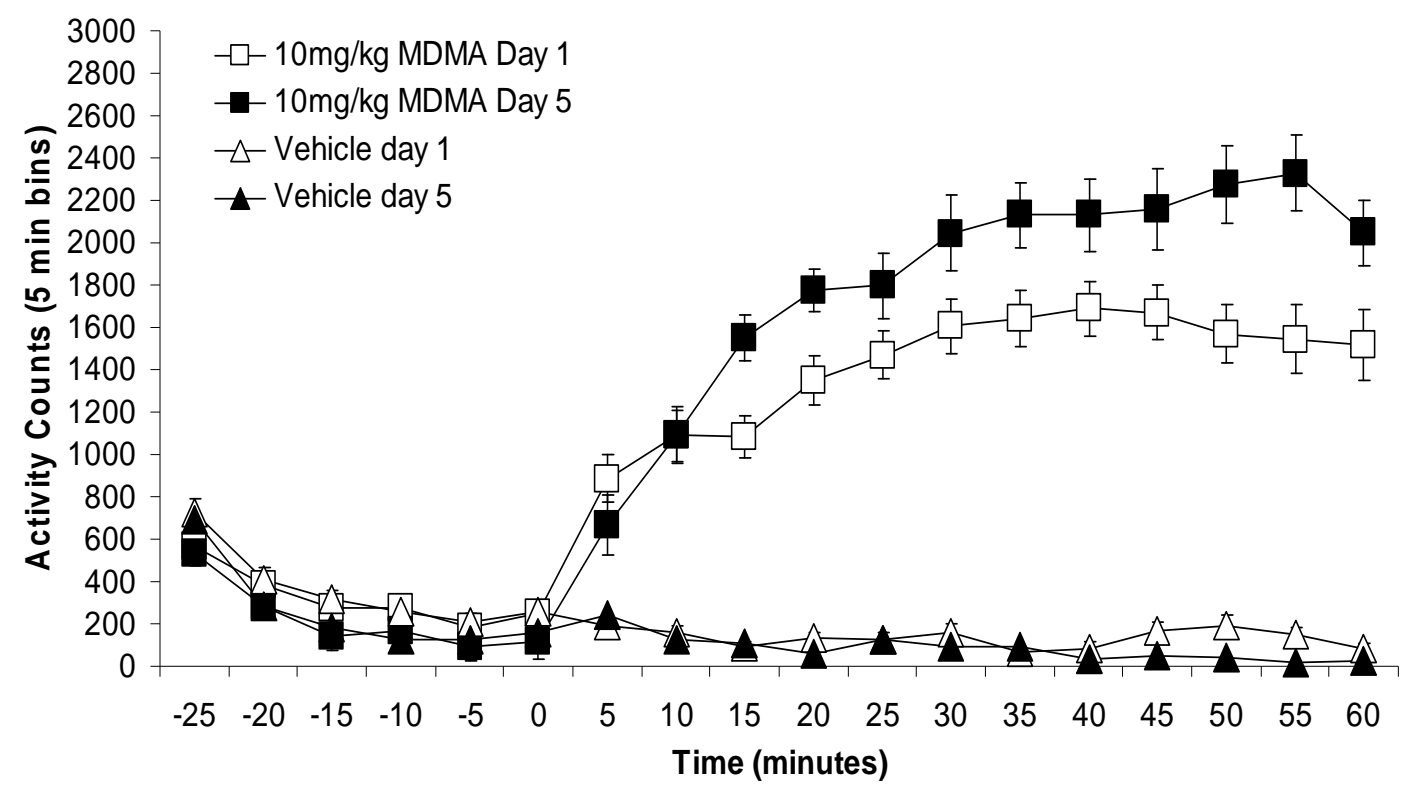

Figure 1.7 Average locomotor counts for the 90 minutes of testing across days. Rats were administered either MDMA (10.0mg/kg i.p.) $(n=21)$ or vehicle $(n=19)$ each day in the test chambers. Locomotor counts are summed into bins of 5 minute intervals with time ' 0 ' being the time of drug injection.

$10.0 \mathrm{mg} / \mathrm{kg}$ MDMA pre-treatment 2-day withdrawal

Following a two day withdrawal locomotor activating effects of various doses of MDMA (0.0, 2.5, $5.010 .0 \mathrm{mg} / \mathrm{kg})$ were measured. Figure 1.8 below presents the time course data. 

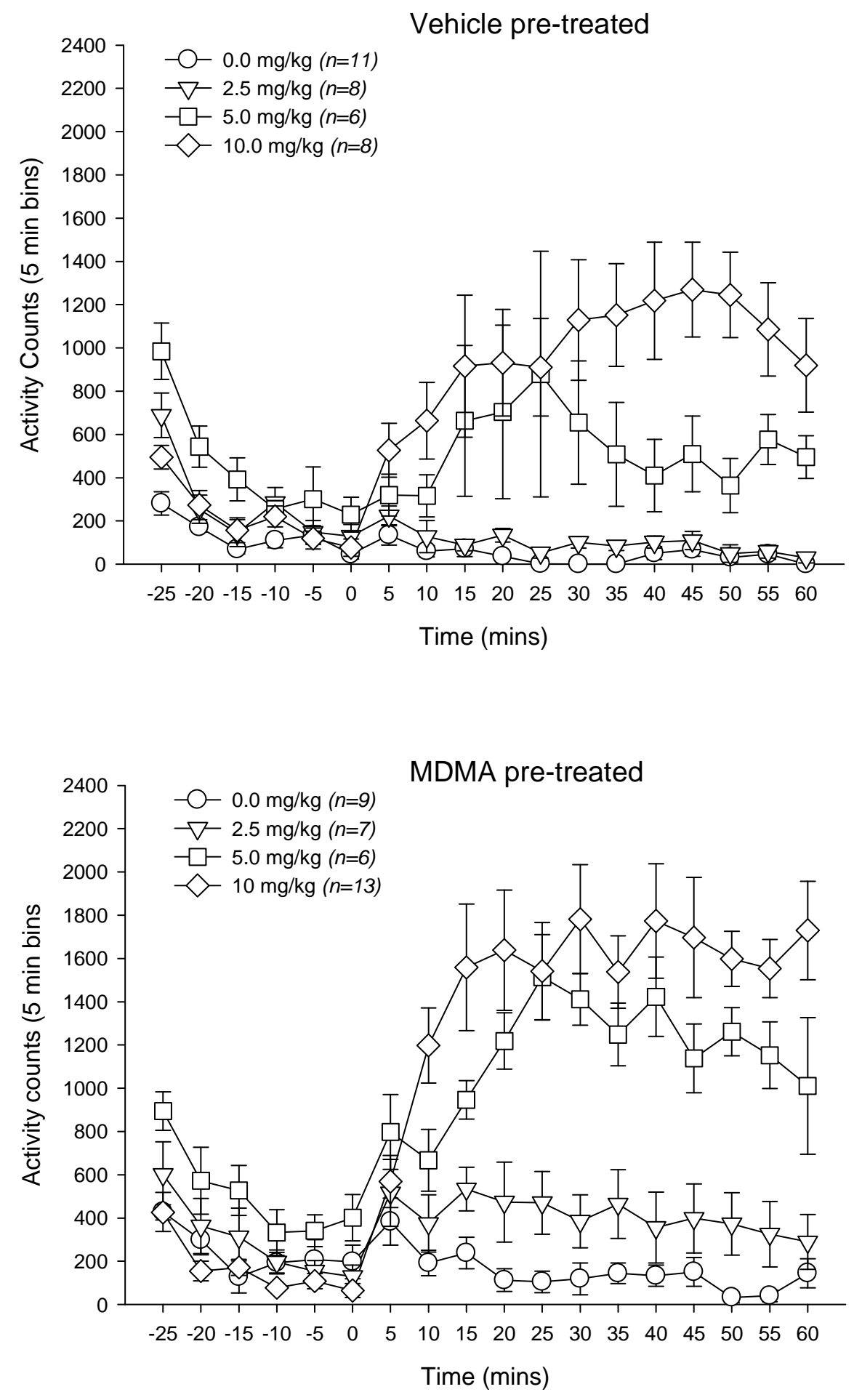

Figure 1.8. Locomotor activating effects of various doses of MDMA following a 2-day withdrawal from daily administration of MDMA $(10.0 \mathrm{mg} / \mathrm{kg}$ i.p.) or vehicle. Top panel is the time course of locomotor activity for vehicle pre-treated rats. Bottom panel is the time course of locomotor activity for MDMA pre-treated rats. Locomotor counts are summed into bins of 5 minute intervals with time ' 0 ' being the time of drug injection 
A repeated measures ANOVA [pre-treatment (MDMA or vehicle) x Dose

$(0.0,2.5,5.0,10.0) x$ time (12 five min bins)] revealed a main effect of

Pre-treatment $(\mathrm{F}(1,60)=15.841, \mathrm{p}<0.05)$ and Dose $(\mathrm{F}(3,60)=35.71$,

$\mathrm{p}<0.05)$ but no significant interaction between Pre-treatment and Dose

$(\mathrm{F}(3,60)=1.46, \mathrm{~ns})$.

Figure 1.9 presents the total activity data collapsed across time following each dose of MDMA for the MDMA and vehicle pre-treatment groups.

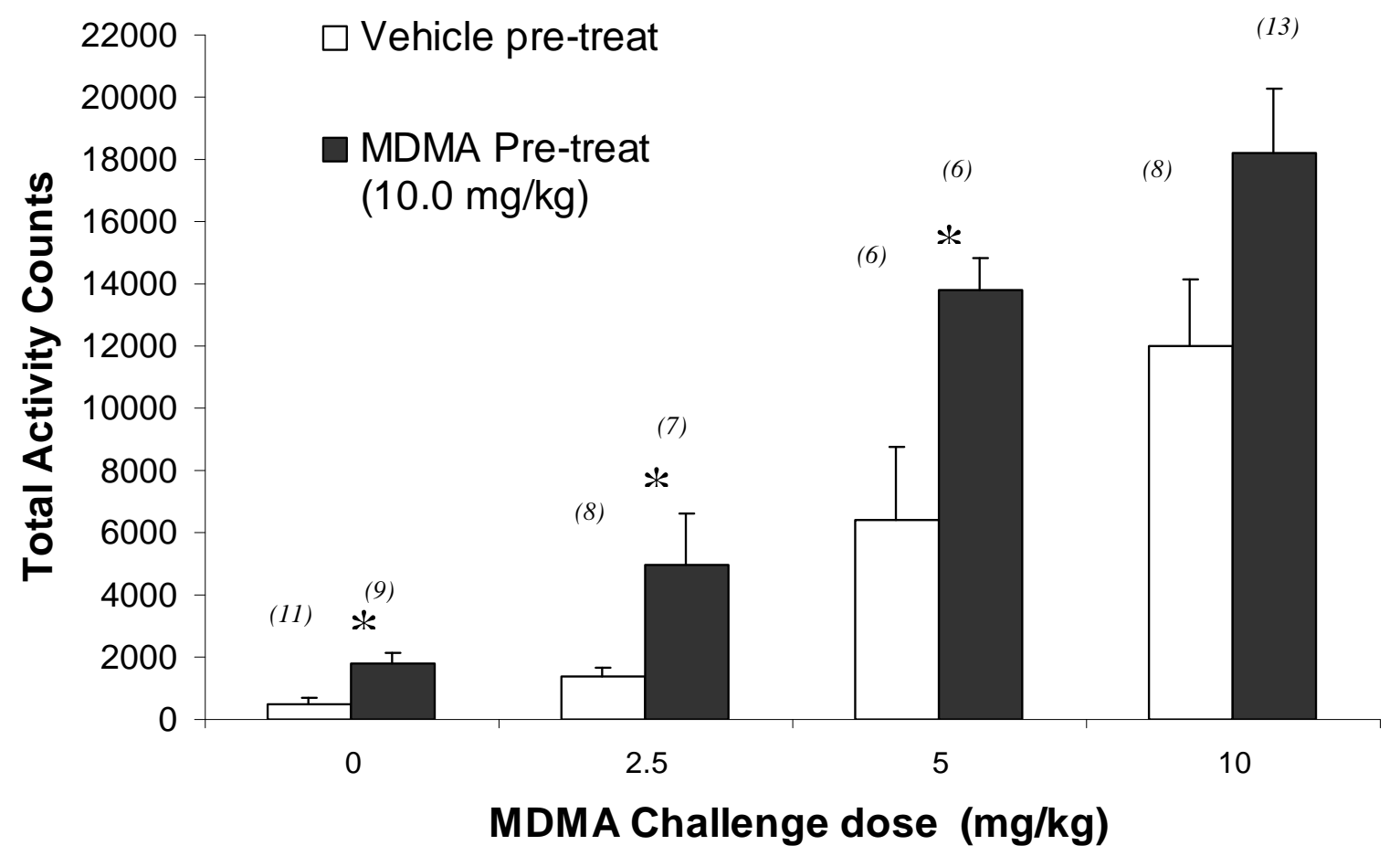

Figure 1.9. Total locomotor counts on challenge day for the 60 minutes post injection with vehicle and MDMA (10.0 mg/kg i.p.) pre-treated rats. After two days of withdrawal rats were challenged with MDMA $(0.0,2.5,5.0$ or $10.0 \mathrm{mg} / \mathrm{kg}$ i.p.). Numbers in brackets above each column is the sample size. * difference from vehicle pre-treated group 
Analysis on total locomotor activity counts was conducted by using a 2-

way ANOVA (Pre-treatment $x$ Dose). Post hoc t-tests revealed an

increase in the activating effect of all doses of MDMA $(\mathrm{p}<0.05)$ accepting

the $10.0 \mathrm{mg} / \mathrm{kg}$ challenge dose.

$10.0 \mathrm{mg} / \mathrm{kg}$ MDMA pre-treatment and 9 day withdrawal

Figure 1.20 shows the time course of MDMA-produced hyperactivity $(0.0$ or $5.0 \mathrm{mg} / \mathrm{kg}$, IP) for rats that had been pre-treated with the higher dose of MDMA (0.0 or $10.0 \mathrm{mg} / \mathrm{kg}$, IP) 9 days earlier.

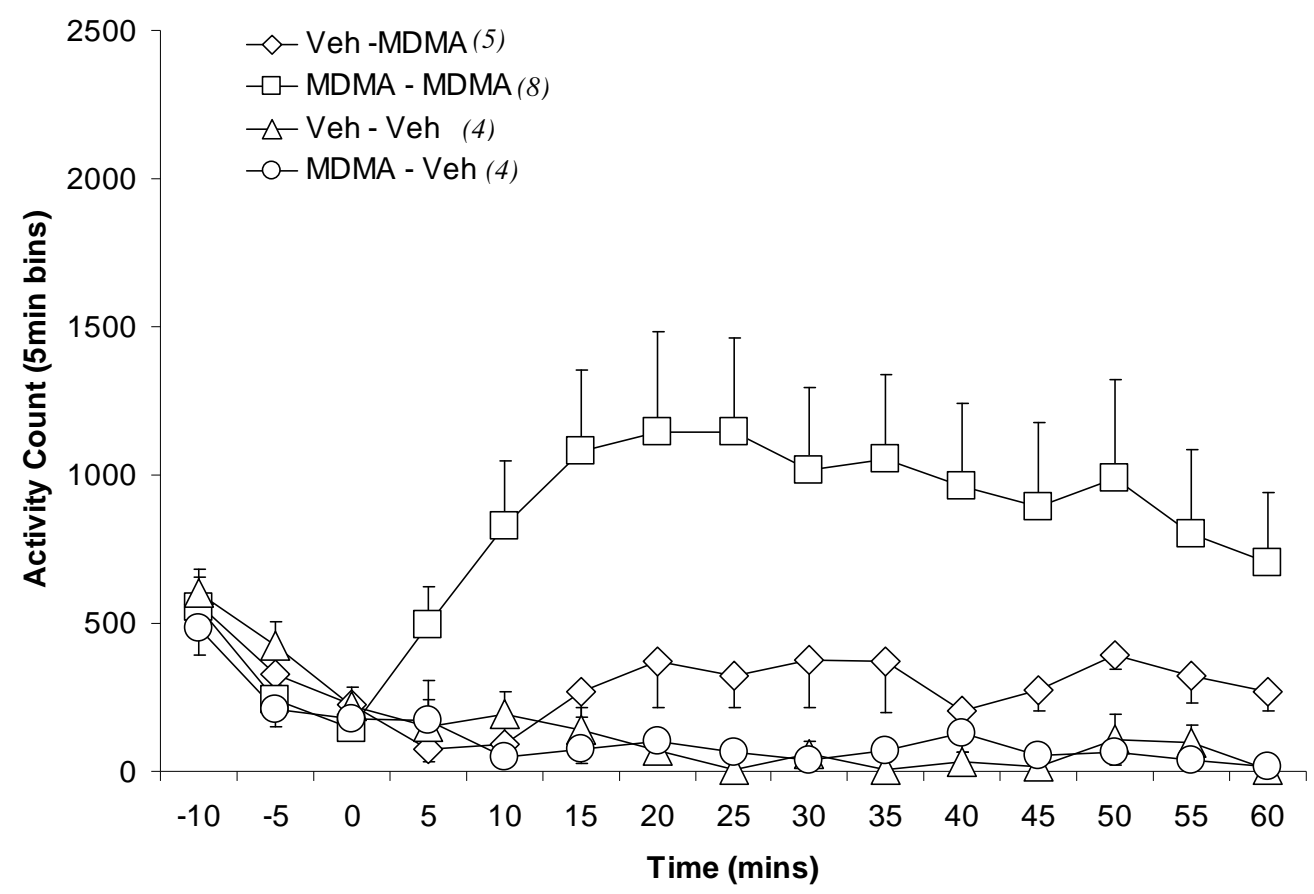

Figure 1.20. Locomotor activating effects of MDMA $(0.0$ or $5.0 \mathrm{mg} / \mathrm{kg}$ i.p.) following a 9-day withdrawal from daily administration of MDMA $(10.0 \mathrm{mg} / \mathrm{kg}$ i.p.) or vehicle. The first listing in the legend identifies the group's pre-treatment drug while the second indicates the challenge drug. Sample sizes are in brackets beside the listings. Locomotor counts are summed into bins of 5 minute intervals with time ' 0 ' being the time of drug injection. 
A repeated measures 3-way ANOVA [pre-treatment (MDMA or vehicle) $x$ challenge (MDMA or vehicle) $x$ time (12 five min bins)] failed to reveal a significant effect of pre-treatment $(F(1,17)=2.59$, ns), or, perhaps due to the small sample sizes, an interaction between pre-treatment and challenge $(F(1,17)=2.60, n s)$. However, there was a main effect of Challenge $(\mathrm{F}(1,17)=5.66, \mathrm{p}<0.05)$.

Figure 1.21 shows the time course of MDMA-produced hyperactivity $(0.0$ or $10.0 \mathrm{mg} / \mathrm{kg}, \mathrm{IP})$ for rats that had been pre-treated with MDMA ( 0.0 or $10.0 \mathrm{mg} / \mathrm{kg}$, IP) 9 days earlier.

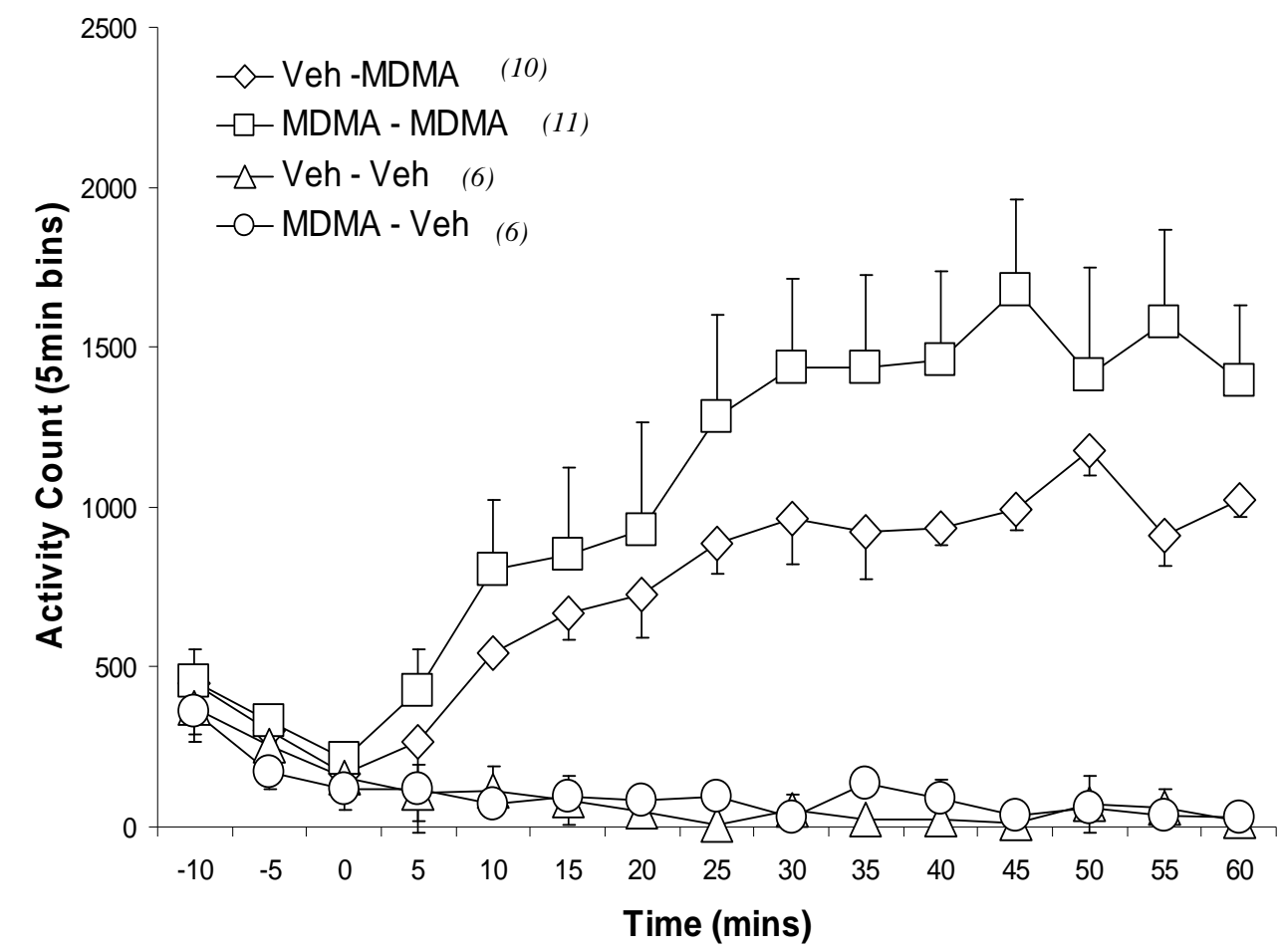

Figure 1.21 . Locomotor activating effects of MDMA $(0.0$ or $10.0 \mathrm{mg} / \mathrm{kg}$ i.p.) following a 9-day withdrawal from daily administration of MDMA $(10.0 \mathrm{mg} / \mathrm{kg}$ i.p.) or vehicle. The first listing in the legend identifies the group's pre-treatment drug while the second indicates the challenge drug. Sample sizes are in brackets beside the listings. Locomotor counts are summed into bins of 5 minute intervals with time ' 0 ' being the time of drug injection. 
A repeated measures 3-way ANOVA [pre-treatment (MDMA or vehicle) $x$ challenge (MDMA or vehicle) $x$ time (12 five min bins)] failed to reveal a significant effect of pre-treatment $(F(1,29)=2.097, \mathrm{~ns})$, or an interaction between pre-treatment and challenge $(\mathrm{F}(1,29)=1.26$, ns $)$, but a main effect for challenge $(\mathrm{F}(1,29)=93.39, \mathrm{p}<0.05)$.

Figure 1.22 presents the total post-injection activity data collapsed across time following 9 days withdrawal for the MDMA and vehicle pretreatment groups.

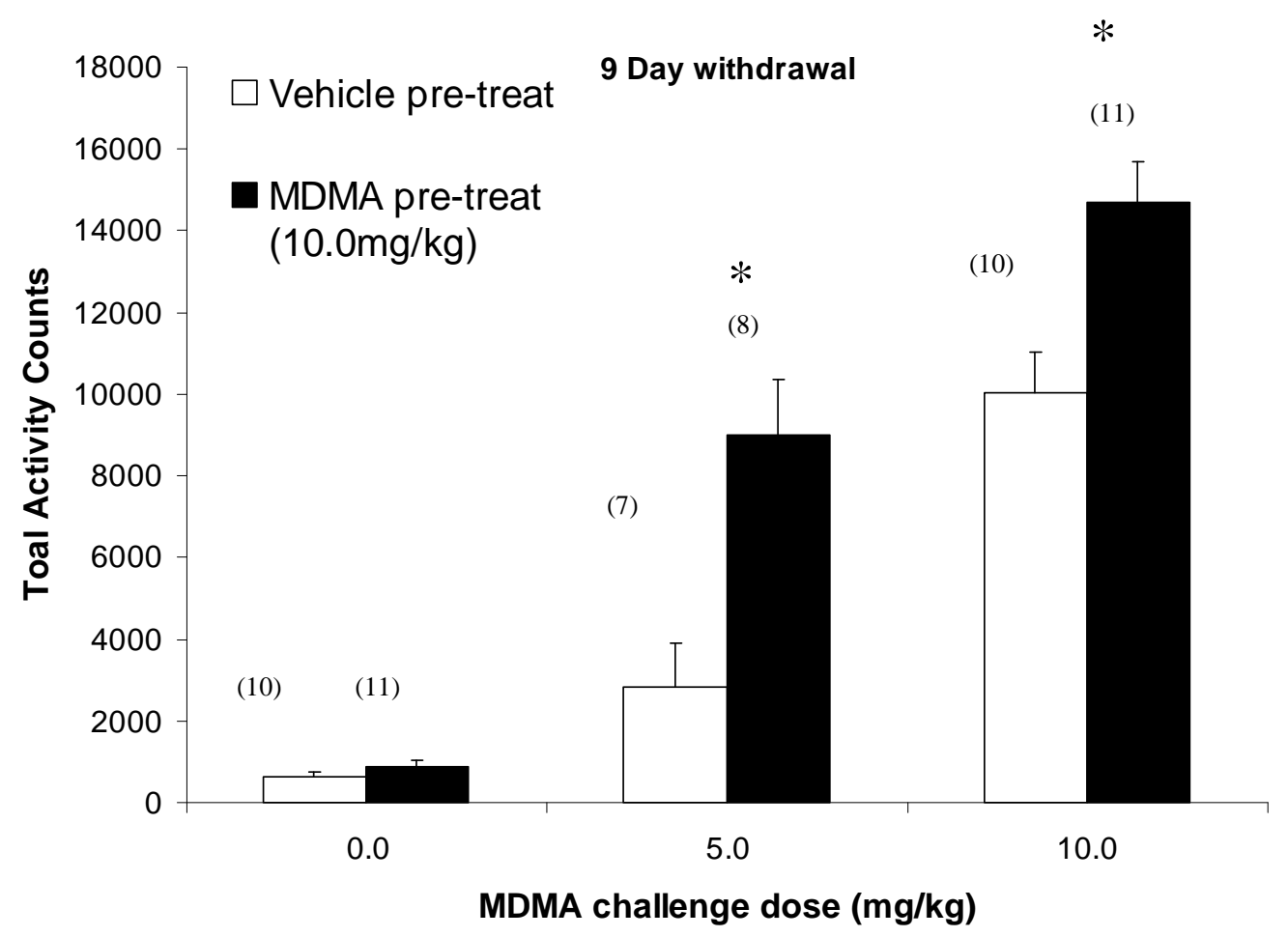

Figure 1.22. Total post injection locomotor counts on challenge day for the 60 minutes post injection with vehicle and MDMA $(10.0 \mathrm{mg} / \mathrm{kg}$ i.p.) pre-treated rats. After nine days of withdrawal rats were challenged with MDMA (0.0, 5.0 or $10.0 \mathrm{mg} / \mathrm{kg}$ i.p.). Numbers in brackets above each column is the sample size. $*$ difference from vehicle pre-treated group 
Analysis on total locomotor activity counts was conducted by using a 2way ANOVA (Pre-treatment $x$ Dose). There were main effects for both pre-treatment $(\mathrm{F}(1,49)=5.39, \mathrm{p}<0.05)$ and dose $(\mathrm{F}(2,49)=32.48, \mathrm{p}<$ 0.05). Post hoc contrasts revealed an increase in the activating effect of both the $5.0 \mathrm{mg} / \mathrm{kg}$ MDMA and $10.0 \mathrm{mg} / \mathrm{kg}$ MDMA challenge dose $(\mathrm{p}<0.05)$.

\section{$10.0 \mathrm{mg} / \mathrm{kg}$ MDMA pre-treatment and 28 day withdrawal}

Figure 1.23 shows the time course of rats challenged with MDMA (5.0 \& $10.0 \mathrm{mg} / \mathrm{kg}$ i.p.) following the 28 day withdrawal period from the MDMA $(10.0 \mathrm{mg} / \mathrm{kg})$ pre-treatment 


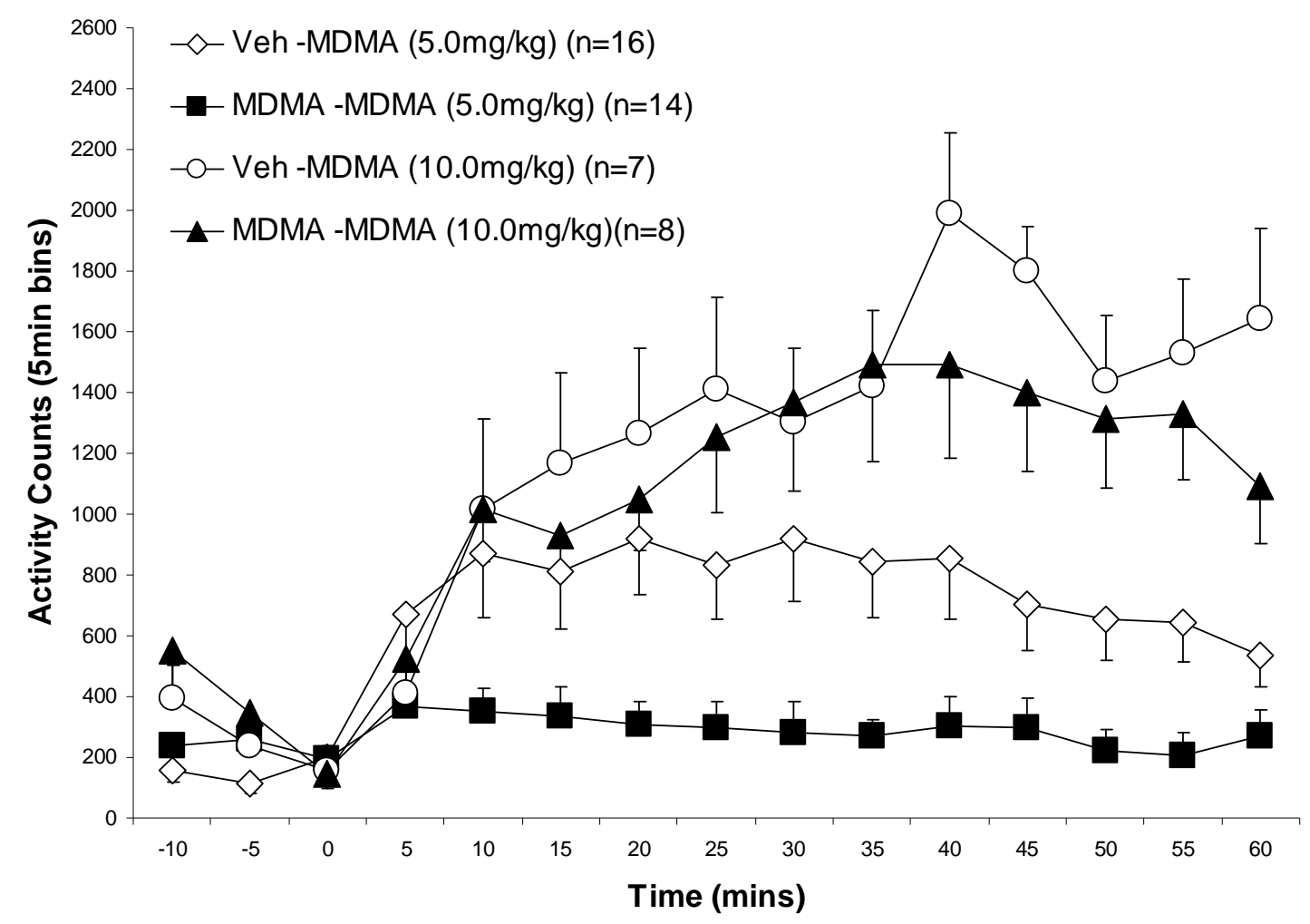

Figure 1.23. Locomotor activating effects of MDMA $(5.0$ or $10.0 \mathrm{mg} / \mathrm{kg}$ i.p.) following a 28-day withdrawal from daily administration of MDMA $(10.0 \mathrm{mg} / \mathrm{kg}$ i.p.) or vehicle. The first listing in the legend identifies the group's pre-treatment drug while the second indicates the challenge drug. Sample sizes are in brackets beside the listings. Locomotor counts are summed into bins of 5 minute intervals with time ' 0 ' being the time of drug injection.

A repeated measures 3-way ANOVA [pre-treatment (MDMA or vehicle) $x$ Dose $(5.0 \& 10.0$ MDMA) $x$ time (12 five min bins)] revealed a significant effect of pre-treatment $(\mathrm{F}(1,41)=4.97, \mathrm{p}<0.05)$, in addition to a main effect of Dose $(F(1,41)=25.53, \mathrm{p}<0.05)$, but no interaction between pre-treatment and Dose $(\mathrm{F}(1,41)=1.04$, ns $)$. 
Figure 1.24 presents the total post-injection activity data collapsed across time following 28 days withdrawal for the MDMA and vehicle pretreatment groups.

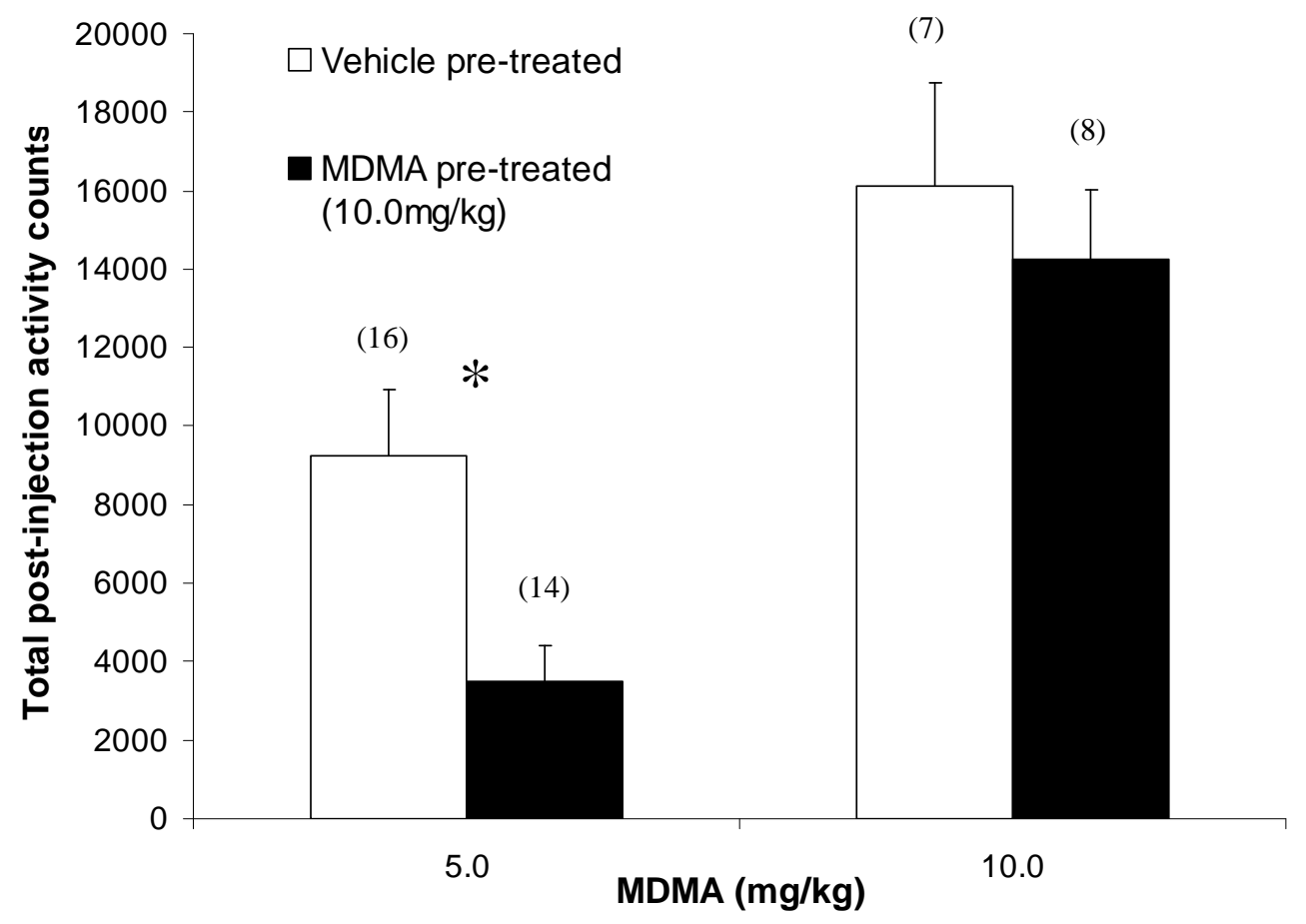

Figure 1.24. Total post injection locomotor counts on challenge day for the 60 minutes post injection with vehicle and MDMA (10.0 mg/kg i.p.) pre-treated rats. After 28 days of withdrawal rats were challenged with MDMA (5.0 or $10.0 \mathrm{mg} / \mathrm{kg}$ i.p.). Numbers in brackets above each column are the sample sizes. * difference from vehicle pre-treated group

Analysis on total locomotor activity counts was conducted by using a 2way ANOVA (Pre-treatment $x$ Dose $)$ revealing both a Dose $(\mathrm{F}(1,41)=$ 4.97, $\mathrm{p}<0.05)$ and Pre-treatment $(\mathrm{F}(1,41)=4.97, \mathrm{p}<0.05)$ main effect. Post hoc contrasts revealed an increase in the activating effect of the 5.0 $\mathrm{mg} / \mathrm{kg}$ MDMA challenge dose $(\mathrm{p}<0.05)$ but no difference in the $10.0 \mathrm{mg} / \mathrm{kg}$ MDMA challenge dose. 


\section{Experiment 1 Discussion}

This experiment was designed to develop protocols for sensitisation to the locomotor activating effects of MDMA. Repeated intermittent administration of both amphetamine and MDMA produced sensitised hyperactivity. This sensitised response was apparent during the pretreatment regimen and also following a 2 and 9-day withdrawal period for the MDMA pre-treated rats.

Amphetamine-induced locomotor activity increased markedly from day 1 to day 5. Following a 2-day withdrawal period, the response to a low dose of amphetamine was also enhanced. Additional tests were conducted to examine the persistence of the sensitised response however an amphetamine-produced sensitised response was no longer apparent following a 28 day withdrawal period. Although, 4 of the 7 amphetamine pre-treated animals had total post-injection locomotor counts approaching twice that of the average vehicle pre-treated group but variability was large and, as a group, it was not statistically reliable

This finding is in contrast to other studies that have demonstrated an increase in the sensitised response following an extended withdrawal period of 28 days (Hitzemann, Tseng, Hitzemann, Sampath-Khanna \& Loh, 1977; Paulson \& Robinson,1995, 1996). It is possible that a different pre-treatment regimen may have resulted in a more persistent sensitised response in the above studies. However, under the current 
conditions, sensitisation to the locomotor activating effects of amphetamine was observed 3, but not 28 days, following exposure.

In contrast to the effects of repeated exposure to amphetamine, MDMAproduced hyperactivity following the low dose $(5 \mathrm{mg} / \mathrm{kg})$ failed to increase between days 1 and 5 of exposure. This result concurs with other findings (Ball, Budreau, \& Rebec, 2006). Higher dose exposures however, showed an increase in MDMA produced activity from days 1-5 of exposure.

Following exposure to repeated doses of $5.0 \mathrm{mg} / \mathrm{kg}$ MDMA, a sensitised response to the effects of the lower dose of $2.5 \mathrm{mg} / \mathrm{kg}$ was observed. Repeated exposure to the higher dose of $10.0 \mathrm{mg} / \mathrm{kg}$ MDMA increased locomotor activity between days 1 and 5 and following two days of withdrawal a sensitised response was observed to two lower doses (2.5 and $5.0 \mathrm{mg} / \mathrm{kg}$ ) of MDMA. Thus, the dose-effect curve for MDMAproduced hyperactivity was shifted leftwards following both pretreatment regimens. Two other investigations have shown sensitisation following a similar MDMA pre-treatment regimen. In one, rats were treated for six consecutive days with $10.0 \mathrm{mg} / \mathrm{kg}$ MDMA, and tested with the same dose of MDMA following a 5-day withdrawal period (Modi, Yang, Swann, \& Dafny, 2006). In the other, rats were treated for 5 days with a single dose of $10.0 \mathrm{mg} / \mathrm{kg}$ per day followed by a 2 day withdrawal period (Colussi-Mas \& Schenk, 2008). In both investigations $10.0 \mathrm{mg} / \mathrm{kg}$ pre-treatment produced a robust increase in MDMA-produced 
hyperactivity across days during the pre-treatment period. The current investigation, in conjunction with the above data, suggests that a single, daily administration of the $10.0 \mathrm{mg} / \mathrm{kg}$ pre-treatment dose compared to that of the $5 \mathrm{mg} / \mathrm{kg}$ is the more effective pre-treatment dose during a 5 -day exposure period to observe sensitisation.

The present results suggest that a short withdrawal period enhances the manifestation of MDMA- induced behavioural sensitisation. The majority of investigations into MDMA sensitisation have also imposed a relatively short withdrawal period ranging from 48 hours to 12 days (Kalivas, et al., 1998; McCreary, Bankson, \& Cunningham, 1999; Ramos, et al., 2004; Spanos \& Yamamoto, 1989). Consistent with these findings is the current data that show after 9 days withdrawal form repeated exposure to 10.0mg/kg MDMA there was a sensitised response.

Following longer withdrawal period of 28 days, however, sensitisation was no longer apparent. Instead, when compared to controls, the hyperactive response to $5.0 \mathrm{mg} / \mathrm{kg}$ MDMA - was decreased. This finding contrasts with a study that demonstrated sensitisation when testing was conducted following a 38 day withdrawal period (Modi, et al., 2006). The current results however, should be interpreted cautiously as the total locomotor activity counts in the saline control rats were extremely high. However, the locomotor counts for the MDMA pre-treated animals are comparable to the locomotor counts observed after 2 days (Figure 1.9) and 9 days (figure 1.22) withdrawal. One possible reason for the 
increased response in vehicle rats is that during the 28 day withdrawal period rats were housed in pairs rather than singly as in the other groups. Housing environment is known to alter subsequent drug responses and animals housed in groups were more sensitive to amphetamine induced locomotor activity (Schaefer \& Michael, 1991). If this is also true for MDMA produced hyperactivity the data suggest a differential influence of prior drug exposure.

Of interest, there was a greater response in locomotor activity following administration of vehicle to the MDMA pre-treated rats. This conditioned effect has also been demonstrated following repeated administration of amphetamine (Anagnostaras \& Robinson, 1996; Drew \& Glick, 1988; Mazurski \& Beninger, 1987; Vezina, et al., 1989). Although not specifically tested for, the current results suggest a role of context in the expression of MDMA-induced locomotor sensitisation.

\section{$\underline{\text { Summary }} \underline{\text { experiment }} \underline{1}$}

A sensitisation protocol was developed to induce sensitised responding to MDMA. An augmented locomotor response was evident across days of pre-treatment (day 1 vs. 5) and also evident with withdrawal periods of up to 9 days after the last exposure. Repeated administrations of either 10.0 or $5.0 \mathrm{mg} / \mathrm{kg}$ for 5 days showed sensitised locomotor responding to a lower dose of the drug, however, the regimen of 5 daily treatments of $10.0 \mathrm{mg} / \mathrm{kg}$ produces persistent sensitisation. 


\section{Experiment 2: Changes in sensitivity of the $D_{1}$ and $D_{2}$ receptor to repeated intermittent exposure of MDMA}

Background

An important mechanism underlying amphetamine produced hyperactivity is an increase in extracellular levels of DA in cell bodies and terminal regions of the mesolimbic system. Repeated intermittent administration of amphetamine increases the dopamine response and this sensitised neurochemical response is believed to result in behavioural sensitisation. The expression of sensitisation is typically measured as an increase in drug produced hyperactivity that can be explored with pharmacological manipulation of dopamine release, through for example, receptor activation or suppression.

The role of the $D_{1}$ and $D_{2}$ receptors in amphetamine sensitisation has previously been investigated. Sensitisation was blocked by the $\mathrm{D}_{1}$-like antagonist, SCH23390 (Drew \& Glick, 1990; Vezina \& Stewart, 1989; Vezina, 1996) and sensitised locomotor activation was observed in response to the selective $\mathrm{D}_{1}$ dopamine receptor agonist, $\mathrm{SKF} 81297$, in amphetamine pre-treated rats (Chen et al., 2003). Intra VTA pre-exposure to the $\mathrm{D}_{2}$ antagonist, eticlopride, blocked amphetamine produced locomotor activity (Tanabe, Suto, Creekmore, Steinmiller, Vezina, 2004) but effects of the mixed $\mathrm{D}_{1} / \mathrm{D}_{2}$ agonist, apomorphine, has been equivocal. Following amphetamine-produced sensitisation, sensitisation to apomorphine-produced 
stereotypy was observed (Kuczenski \& Segal, 1999) but this pre-treatment regimen failed to increase apomorphine-produced horizontal activity (Vanderschuren et al., 1999).

Blockade of dopamine $\mathrm{D}_{1}$ like and $\mathrm{D}_{2}$-like receptors significantly attenuated MDMA-induced locomotor activity in rats (Ball et al., 2003; Daniela et al., 2004). A role of dopamine receptors in both the initiation and expression of sensitisation has been suggested (Ramos et al., 2004; 2005a; 2005b). Cross sensitisation to amphetamine has also been demonstrated suggesting common neural adaptations mediating behavioural sensitisation (Modi et al., 2006).

To date, the role of the $\mathrm{D}_{1}$ and $\mathrm{D}_{2}$ receptors in the expression of sensitisation to the behavioural effects of MDMA has not been comprehensively examined. The current investigation aims to identify potential changes in $D_{1}$ and $\mathrm{D}_{2}$ receptor sensitivity as a result of repeated intermittent exposure to MDMA. It is hypothesised that the DA $\mathrm{D}_{1}$ and $\mathrm{D}_{2}$ receptors will be sensitised following a regimen of repeated intermittent MDMA administration. The response to the selective $\mathrm{D}_{1}$-like agonist, $\mathrm{SKF} 81297$, and the $\mathrm{D}_{1} / \mathrm{D}_{2}$ agonist, apomorphine will be determined in MDMA sensitised rats. Additionally, the potency of selective antagonists to attenuate MDMA produced hyperactivity will also be measured. 


\section{Experiment $\underline{2 a} \underline{\text { method }}$}

Experiment 2 follows the previously described general sensitisation methodology of five, single daily injections of MDMA $(10.0 \mathrm{mg} / \mathrm{kg})$ followed by 2 days withdrawal.

The ranges of doses chosen for $\mathrm{SCH} 23390$ have been shown to attenuate MDMA produced hyperlocomotion (Daniela et al., 2004). The dose range of eticlopride was based on Ball et al. (2003) demonstration of the attenuation of MDMA produced hyperactivity. Doses of the $\mathrm{D}_{1}$ selective agonist, SKF81297, were based on Reavill, Bond, Overend, \& Hunter, (1993) and doses of apomorphine were chosen based on previous amphetamine sensitisation studies (Kuczenski \& Segal, 1999; Vanderschuren, Beemster, \& Schoffelmeer, 2003; Võikar, et al., 1999). The doses for the selective 5-HT $2 \mathrm{C}$ antagonist, RS102221, were based on Bonhaus, et al., (1997).

\section{Experiment $\underline{2 a} \underline{\text { Results. }}$}

Effects of SKF81297 in MDMA sensitised rats

Figure 2.1 shows the time course of the effects of SKF81297 in vehicle and MDMA pre-treated rats. A three-way ANOVA [Pre-treatment (10.0 MDMA or vehicle) X Dose (0.0, 0.5, 1.0, 2.0, 4.0 and 8.0) X Time (12 five minute bins)] was conducted. There was a main effect of Pre-treatment $(\mathrm{F}(1,72)=$ $20.48, \mathrm{p}<0.05)$, and of Dose $(\mathrm{F}(5,72)=16.36, \mathrm{p}<0.05)$, but no interaction between Pre-treatment and Dose $(\mathrm{F}(5,72)=1.04$, ns $)$. 

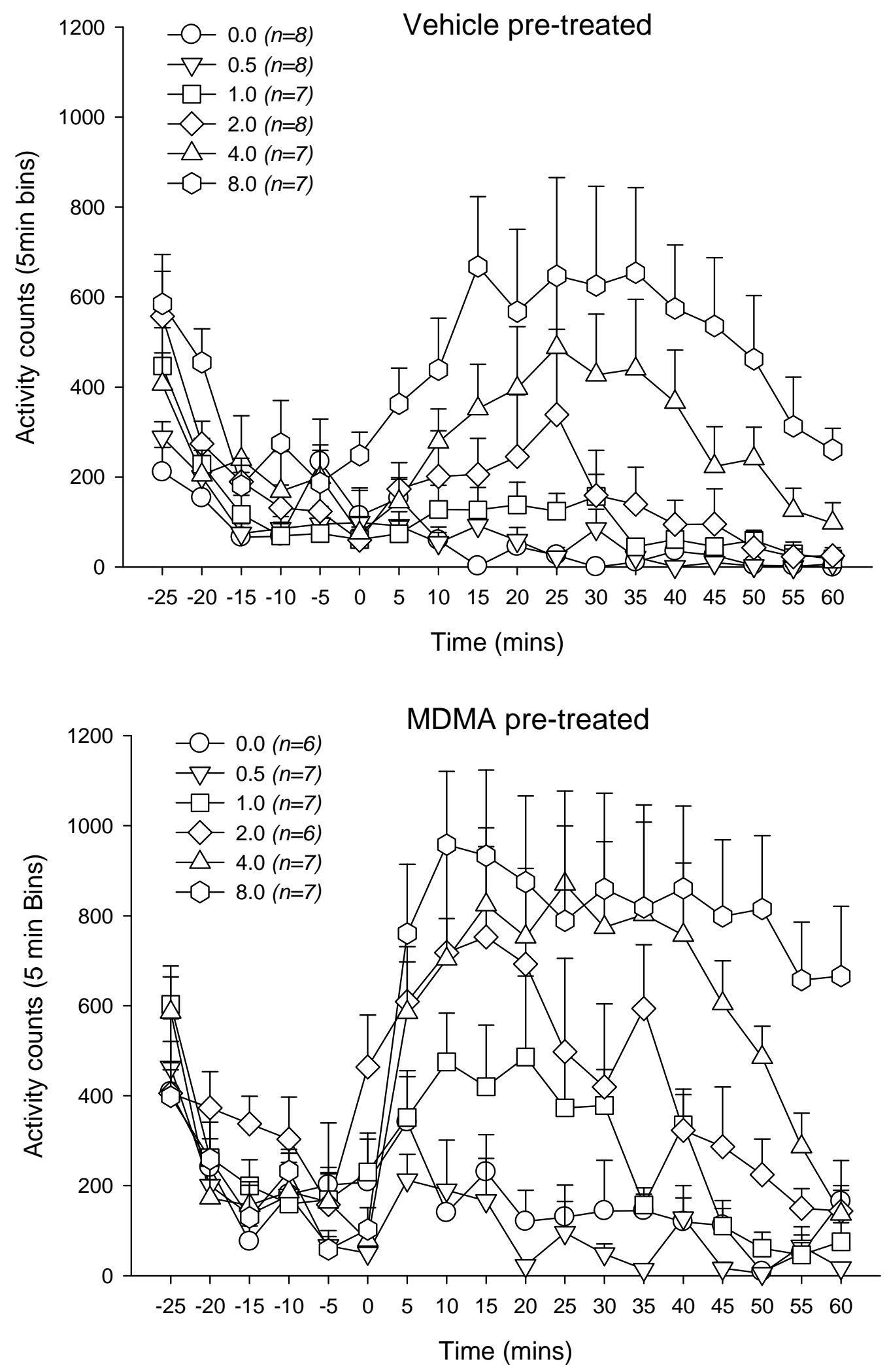

Figure 2.1. Locomotor activating effects of SKF81297 in MDMA and vehicle pre-treated rats. Symbols represent the mean (+SEM) number of activity counts. Locomotor counts are summed into bins of 5 minute intervals with time ' 0 ' being the time of drug injection. 
Figure 2.2 below presents the above data as total locomotor counts following the injection of various doses of SKF81297. Analysis on total locomotor activity counts was conducted by using a 2-way ANOVA (Pre-treatment $x$ Dose) with post hoc contrasts. Post hoc contrasts revealed an effect of pre-treatment for the $0.0 \mathrm{mg} / \mathrm{kg}$ groups $(\mathrm{F}(1,12)=$ $14.64, \mathrm{p}<0.05)$, the $1.0 \mathrm{mg} / \mathrm{kg}$ groups $(\mathrm{F}(1,12)=14.0, \mathrm{p}<0.05)$, the 2.0 $\mathrm{mg} / \mathrm{kg}$ groups $(\mathrm{F}(1,12)=5.68, \mathrm{p}<0.05)$ and the $4.0 \mathrm{mg} / \mathrm{kg}$ groups $(\mathrm{F}(1,12)=5.66, \mathrm{p}<0.05)$.

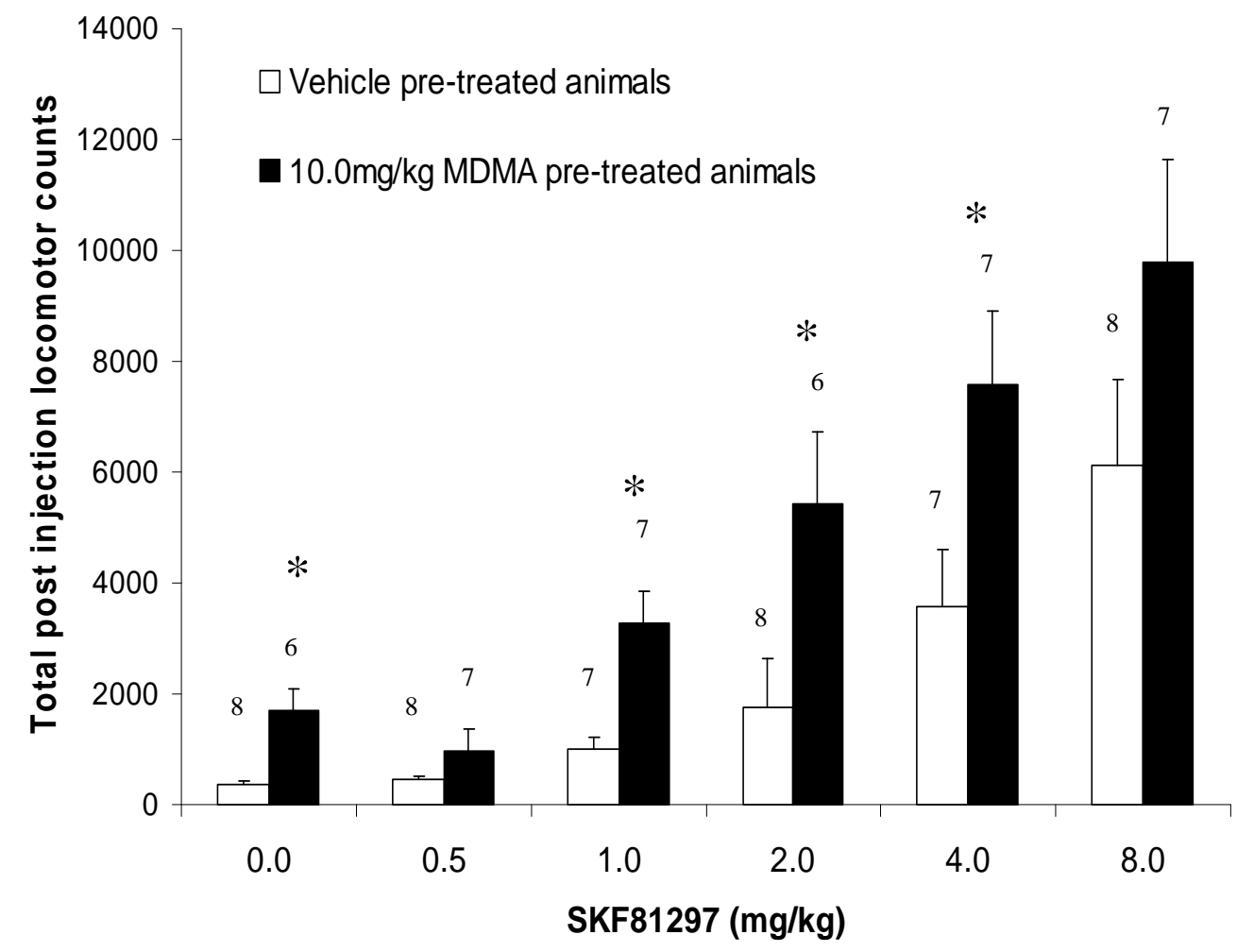

Figure 2.2. Mean total locomotor counts (+SEM) on challenge day during the 60 minute post injection period with for vehicle and MDMA $(10.0 \mathrm{mg} / \mathrm{kg}$ i.p. $)$ pre-treated rats. Numbers above each column represent the sample size used. $*$ difference from vehicle pre-treated group 
Effects of SCH23390 in MDMA sensitised rats

Following the sensitisation regimen of 5 daily injections of MDMA (0.0 or $10.0 \mathrm{mg} / \mathrm{kg}$ ) and 2-day withdrawal effects of the $\mathrm{D}_{1}$-like antagonist, $\mathrm{SCH} 23390$, on the locomotor activating effect of $5.0 \mathrm{mg} / \mathrm{kg}$ MDMA was measured. Figure 2.3 shows locomotor activity as a function of time on test day (day 8). A three-way ANOVA [Pre-treatment (10.0 MDMA or vehicle) X Dose (0.0, 0.01, 0.02, and 0.04) X Time (12 five minute bins)] revealed a main effect of Pre-treatment $(\mathrm{F}(1,54)=13.40, \mathrm{p}<0.05)$, and Dose $(\mathrm{F}(3,54)=$ 4.74, $\mathrm{p}<0.05)$, but no interaction between Pre-treatment and Dose $(\mathrm{F}(3,54)=$ 1.29, ns). 

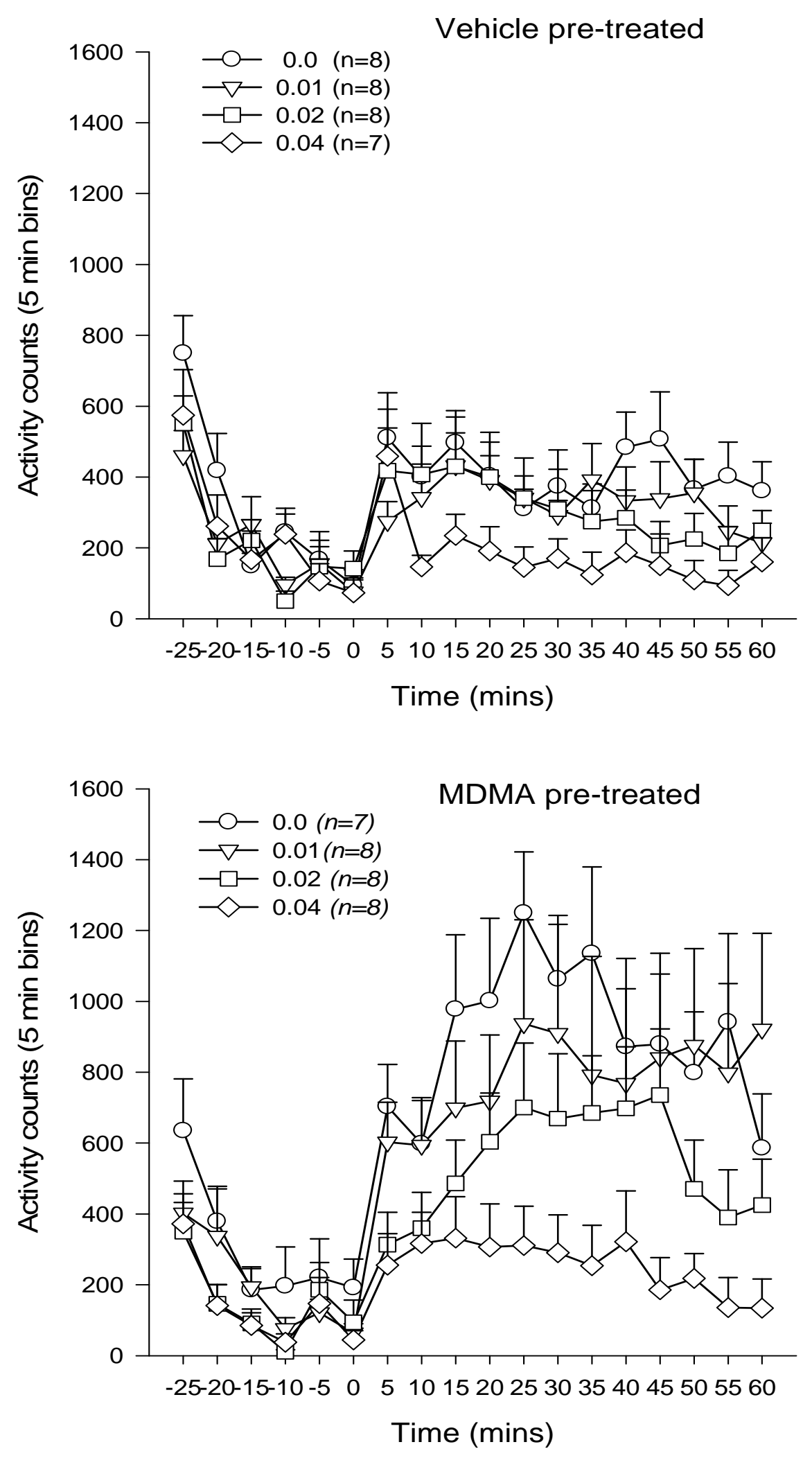

Figure 2.3. Locomotor activating effects of SCH23390 in MDMA and vehicle pre-treated rats. Symbols represent the mean (+SEM) number of activity counts. Locomotor counts are summed into bins of 5 minute intervals with time ' 0 ' being the time of drug injection. 
Figure 2.4 shows the above data presented as total locomotor counts following the injection of MDMA. A one-way ANOVA on data from vehicle pre-treated animals failed to reveal a main effect of Dose $(F(3,27)=1.79$, ns). There was however a main effect of dose in the MDMA pre-treated rats $(\mathrm{F}(3,27)=3.30, \mathrm{p}<0.05)$. In the MDMA pre-treated group, post hoc analysis showed the $0.04 \mathrm{SCH} 23390$ dose significantly decreased MDMA produced hyperactivity $(\mathrm{F}(1,13)=13.80, \mathrm{p}<0.05)$.

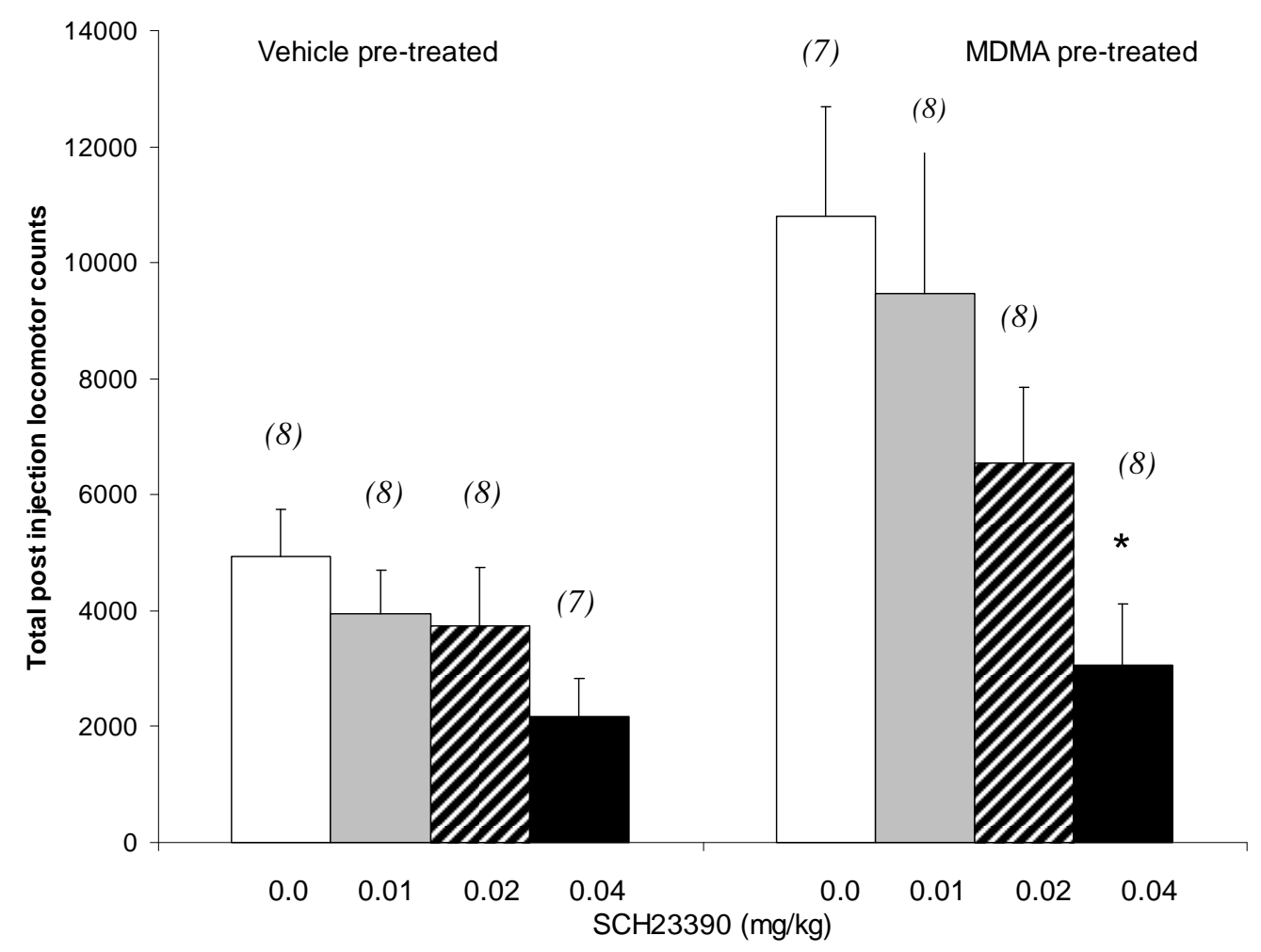

Figure 2.4. Effects of SCH 23390 on MDMA- $(5.0 \mathrm{mg} / \mathrm{kg})$ produced hyperactivity in vehicle and MDMA pre-treated rats. Symbols represent the mean number of activity counts (+SEM). Numbers in brackets above each column is the sample size. ${ }^{*}$ difference from vehicle pre-treated group

Because there was a sensitised response to MDMA, the data from vehicle and MDMA pre-treated rats were rescored as a percentage change from 'baseline' responding in Figure 2.5 below. A two-way ANOVA [Pre- 
treatment (10.0 MDMA or vehicle) X Dose $(0.0,0.01,0.02$, and 0.04)] failed to reveal a significant effect of Pre-treatment $(F(1,54)=0.24$, ns $)$ or a significant interaction between Pre-treatment and Dose $(\mathrm{F}(3,54)=0.22$, ns $)$ but a significant main effect of Dose was obtained $(F(3,54)=4.88, p<0.05)$. Subsequent post hoc analysis with a one-way ANOVA on vehicle pre-treated rats revealed that the 0.04 dose significantly reduced MDMA-produced hyperactivity $(\mathrm{F}(1,14) 6.50, \mathrm{p}<0.05)$. In the MDMA pre-treated group the 0.04 dose of SCH 23390 also significantly decreased MDMA-produced hyperactivity $(\mathrm{F}(1,14) 13.80, \mathrm{p}<0.05)$.

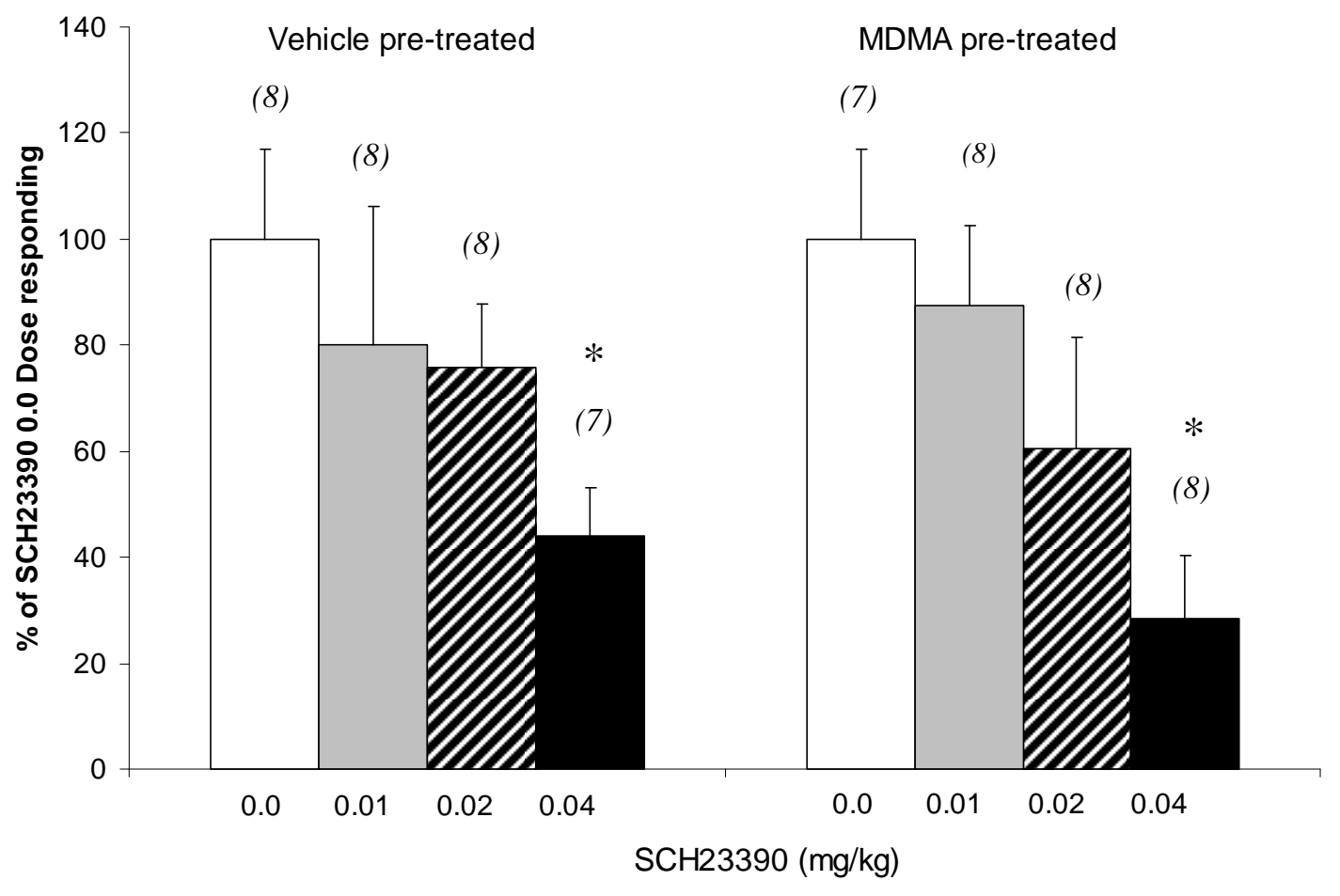

Figure 2.5. Effect of SCH 23390 on MDMA $(5.0 \mathrm{mg} / \mathrm{kg})$ produced hyperactivity in vehicle and MDMA-pre-treated rats. Data are expressed as mean percent change from vehicle $(+\mathrm{SEM}) . *$ difference from vehicle pre-treated group. 
$\underline{\text { Experiment }} \underline{2 b} \underline{\text { Results. }}$

Effects of Apomorphine in MDMA sensitised rats

Figure 2.6 shows the effect of apomorphine in vehicle and MDMA pretreated rats. A three-way ANOVA [Pre-treatment (10.0 MDMA or vehicle) X Dose (0.0, 0.5, 1.0, 2.0 and 4.0) X Time (12 five minute bins)] revealed a main effect of Pre-treatment $(F(1,72)=20.93, p<0.05)$, and of Dose $(F(4,72)$ $=11.97, \mathrm{p}<0.05)$. There was also a significant interaction between Pretreatment and Dose $(\mathrm{F}(4,72)=3.76, \mathrm{p}<0.05)$. 

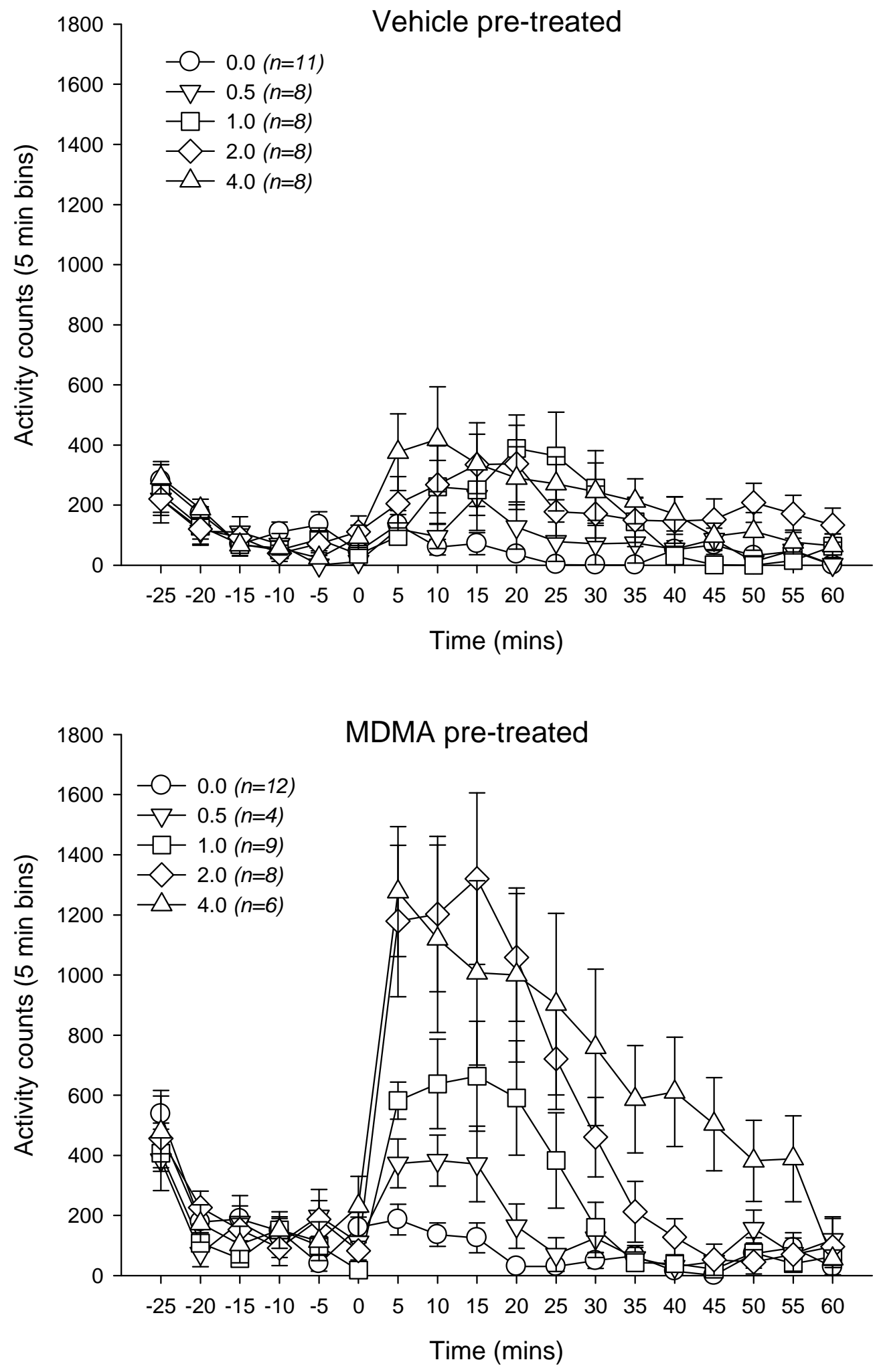

Figure 2.6. Locomotor activating effects of apomorphine in MDMA and vehicle pre-treated rats. Symbols represent the mean (+SEM) number of activity counts. Locomotor counts are summed into bins of 5 minute intervals with time ' 0 ' being the time of drug injection. 
Figure 2.7 below presents the above data expressed as total post injection locomotor counts. Analysis on total locomotor activity counts was conducted by using a 2-way ANOVA (Pre-treatment $x$ Dose) with post hoc contrasts. Post hoc results revealed that MDMA pre-treated rats were more responsive to the $2.0 \mathrm{mg} / \mathrm{kg}(\mathrm{F}(1,14)=6.76, \mathrm{p}<0.05)$, and the $4.0 \mathrm{mg} / \mathrm{kg}(\mathrm{F}(1,12)=6.97$, $\mathrm{p}<0.05)$ doses.

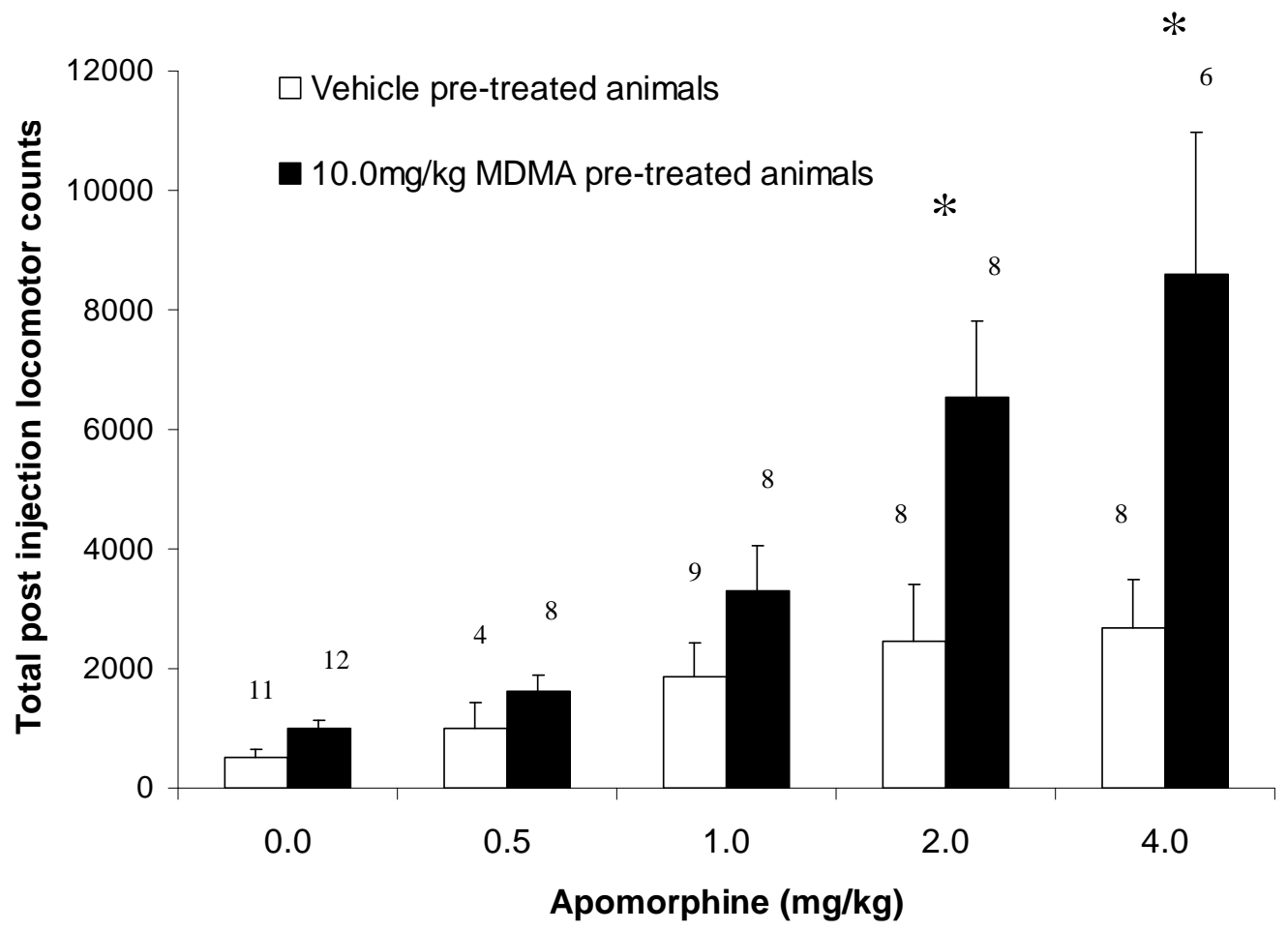

Figure 2.7. Mean total locomotor counts (+SEM) on challenge day during the 60 minute post injection period with for vehicle and MDMA $(10.0 \mathrm{mg} / \mathrm{kg}$ i.p. $)$ pre-treated rats. Numbers above each column represent the sample size used. $*$ difference from vehicle pre-treated group 
Effects of eticlopride in MDMA sensitised rats

Figure 2.8 shows the effect of eticlopride on MDMA-produced locomotor activity in the vehicle and MDMA pre-treated rats. A three-way ANOVA [Pre-treatment (10.0 MDMA or vehicle) X Dose (0.0, 0.05, 0.1, and 0.2) X Time (12 five minute bins)] was conducted. There was no main effect of Pretreatment $(\mathrm{F}(1,50)=2.29, \mathrm{~ns})$, or interaction between Pre-treatment and Dose $(\mathrm{F}(3,50)=1.21, \mathrm{~ns})$ but a main effect of Dose $(\mathrm{F}(3,50)=11.58, \mathrm{p}<0.05)$ was produced 

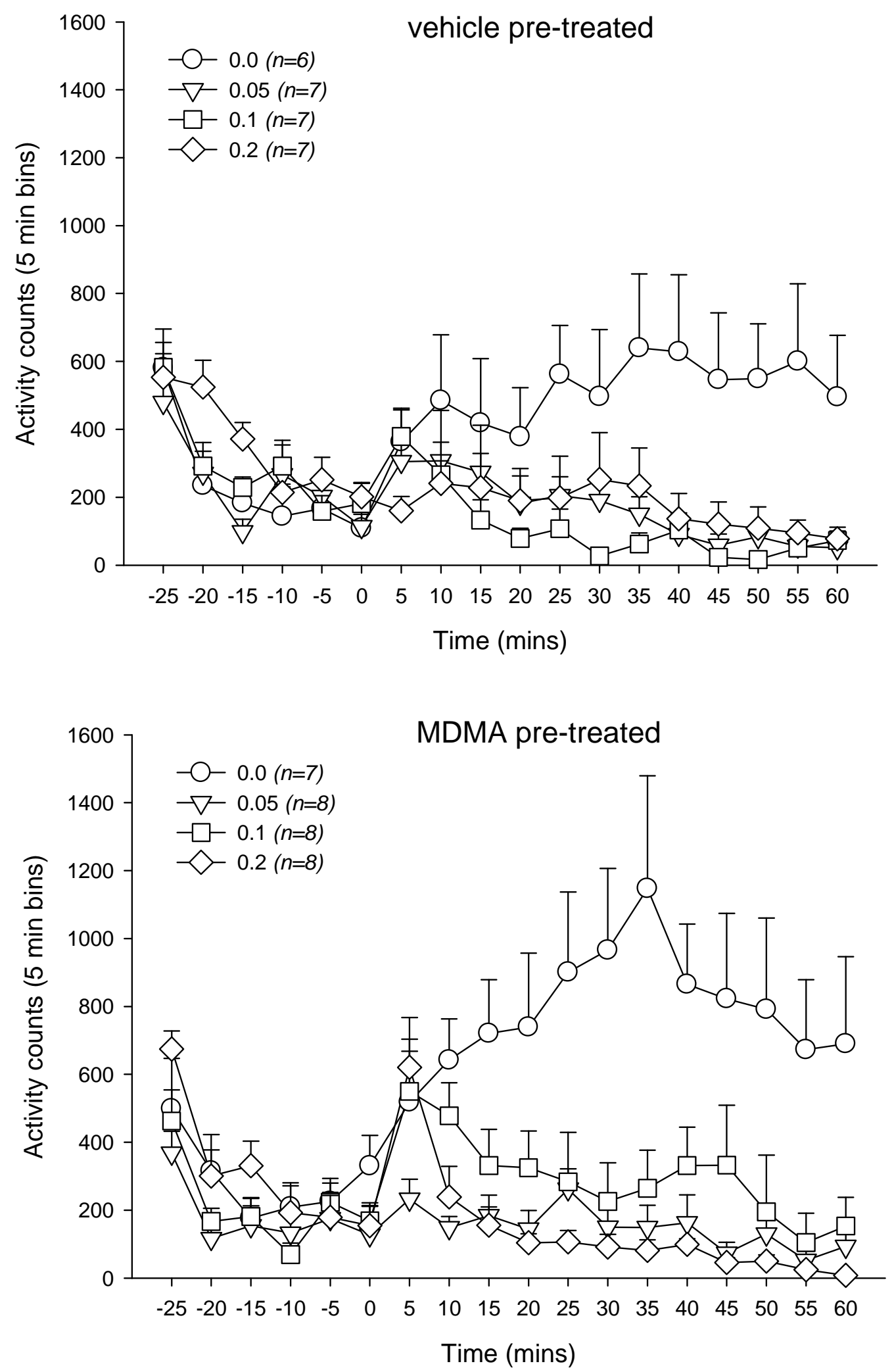

Figure 2.8. Effects of eticlopride on MDMA- $(5.0 \mathrm{mg} / \mathrm{kg})$ produced hyperactivity in vehicle and MDMA pre-treated rats. Symbols represent the mean number of activity counts (+SEM). Numbers in brackets above each column is the sample size. Locomotor counts are summed into bins of 5 minute intervals with time ' 0 ' being the time of drug injection. 
Figure 2.9 shows the data presented as total post injection locomotor counts.

There was a main effect of Dose for both the vehicle $(F(3,23)=4.35, P<0.05)$ and MDMA $(\mathrm{F}(3,27)=8.23, \mathrm{p}<0.05)$ pre-treated rats. A one-way ANOVA on the data from the vehicle and MDMA-pre-treated rats revealed that all doses of eticlopride reduced MDMA-produced hyperactivity ( $\mathrm{p}<0.05)$.

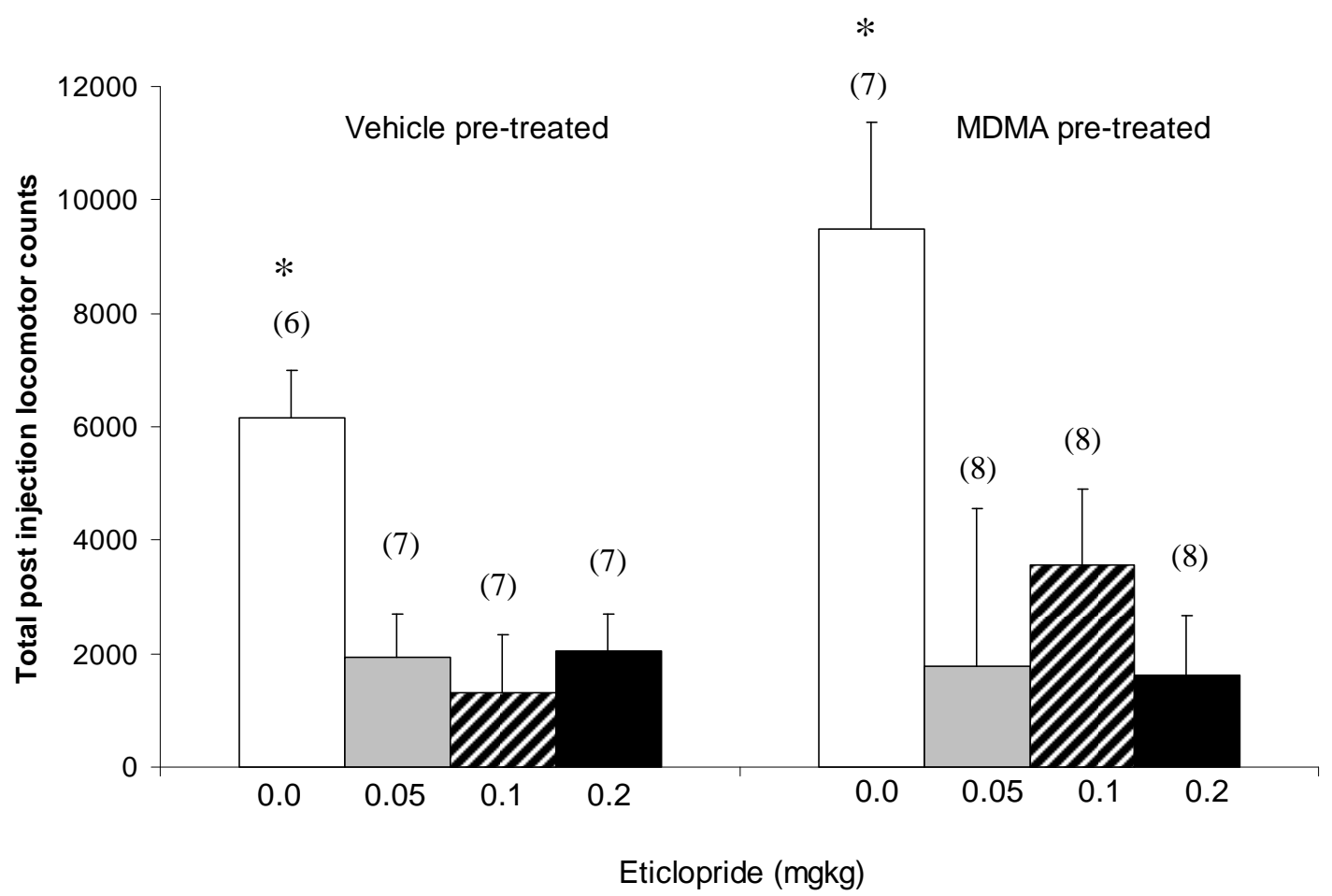

Figure 2.9. Effects of eticlopride on MDMA $(5.0 \mathrm{mg} / \mathrm{kg})$ produced hyperactivity in vehicle and MDMA pre-treated rats. Symbols represent the mean number of activity counts (+SEM). Numbers in brackets above each column is the sample size. $*$ difference from vehicle pre-treated group.

Figure 2.10 presents the above data as a percentage change from baseline. A two-way ANOVA [Pre-treatment (10.0 MDMA or vehicle) X Dose (0.0, $0.01,0.02$, and 0.04)] was conducted. There was a significant effect of Dose $(\mathrm{F}(3,50)=11.48, \mathrm{p}<0.05)$ but the effect of Pre-treatment $(\mathrm{F}(1,50)=0.09, \mathrm{~ns})$ or the interaction between Pre-treatment and Dose $(\mathrm{F}(3,50)=0.51$, ns $)$ were not significant. 
(7)

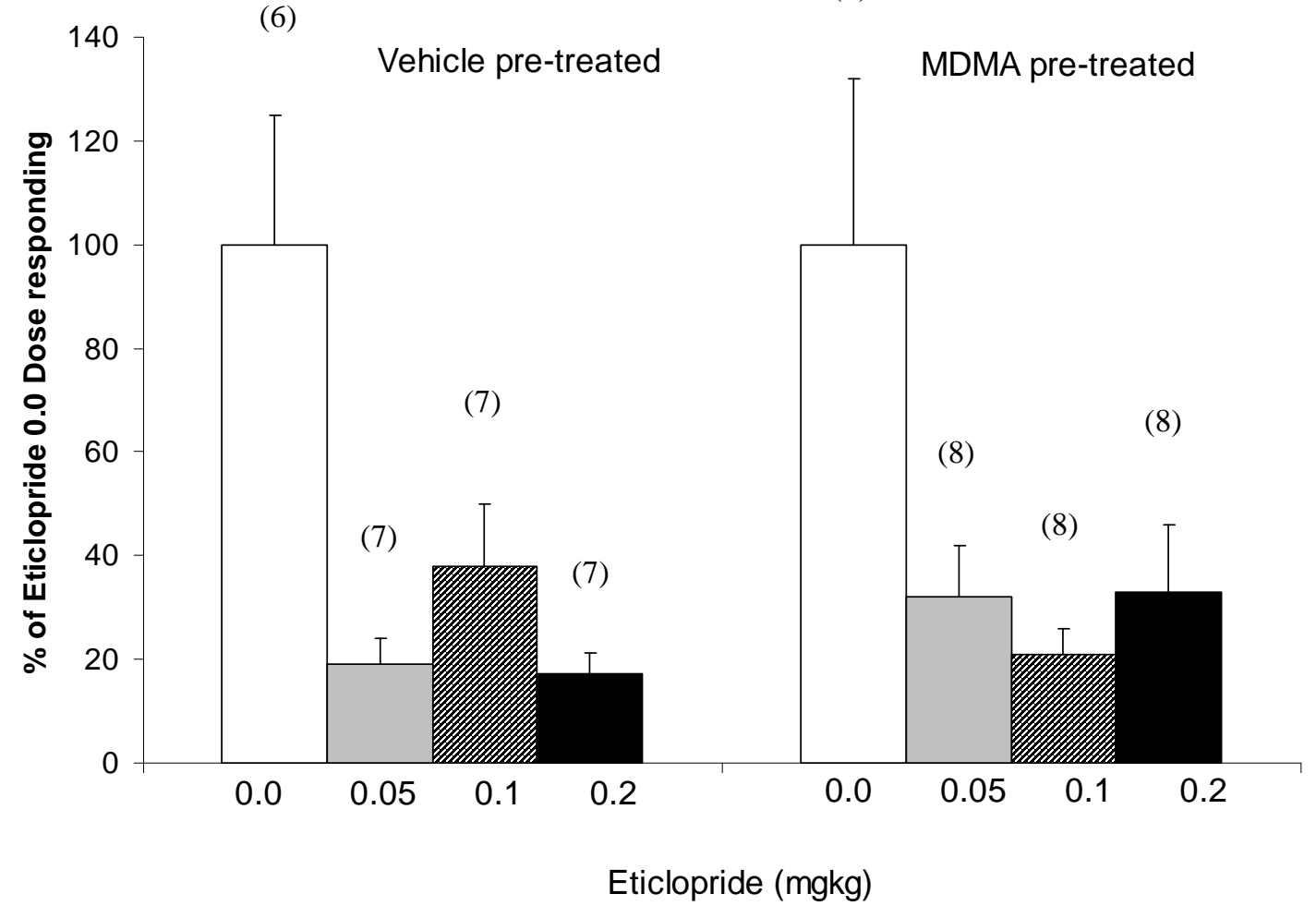

Figure 2.10. Effect of eticlopride on MDMA (5.0 mg/kg) produced hyperactivity in vehicle and MDMA-pre-treated rats. Data are expressed as mean percent change from vehicle (+SEM).

Effects of Lower Doses of Eticlopride in MDMA sensitised rats

In the previous groups, the lowest dose of eticlopride produced a large suppression of MDMA-produced activity in both groups. Therefore, several groups were subsequently tested with a lower dose range. Figure 2.11 shows the time course of MDMA (5.0 mg/kg) produced hyperactivity following this lower dose pre-treatment. A three-way ANOVA [Pre-treatment (10.0 MDMA or vehicle) X Dose (0.03, 0.01, 0.003 and 0.0) X Time (12 five minute bins)] was conducted. There was a significant main effect of Dose $(F(3,41)=3.15$, $\mathrm{p}<0.05)$ but no significant main effect of Pre-treatment $(\mathrm{F}(1,41)=1.49$, ns $)$ or a significant interaction between Pre-treatment and Dose $(F(3,41)=2.06$, ns $)$. 

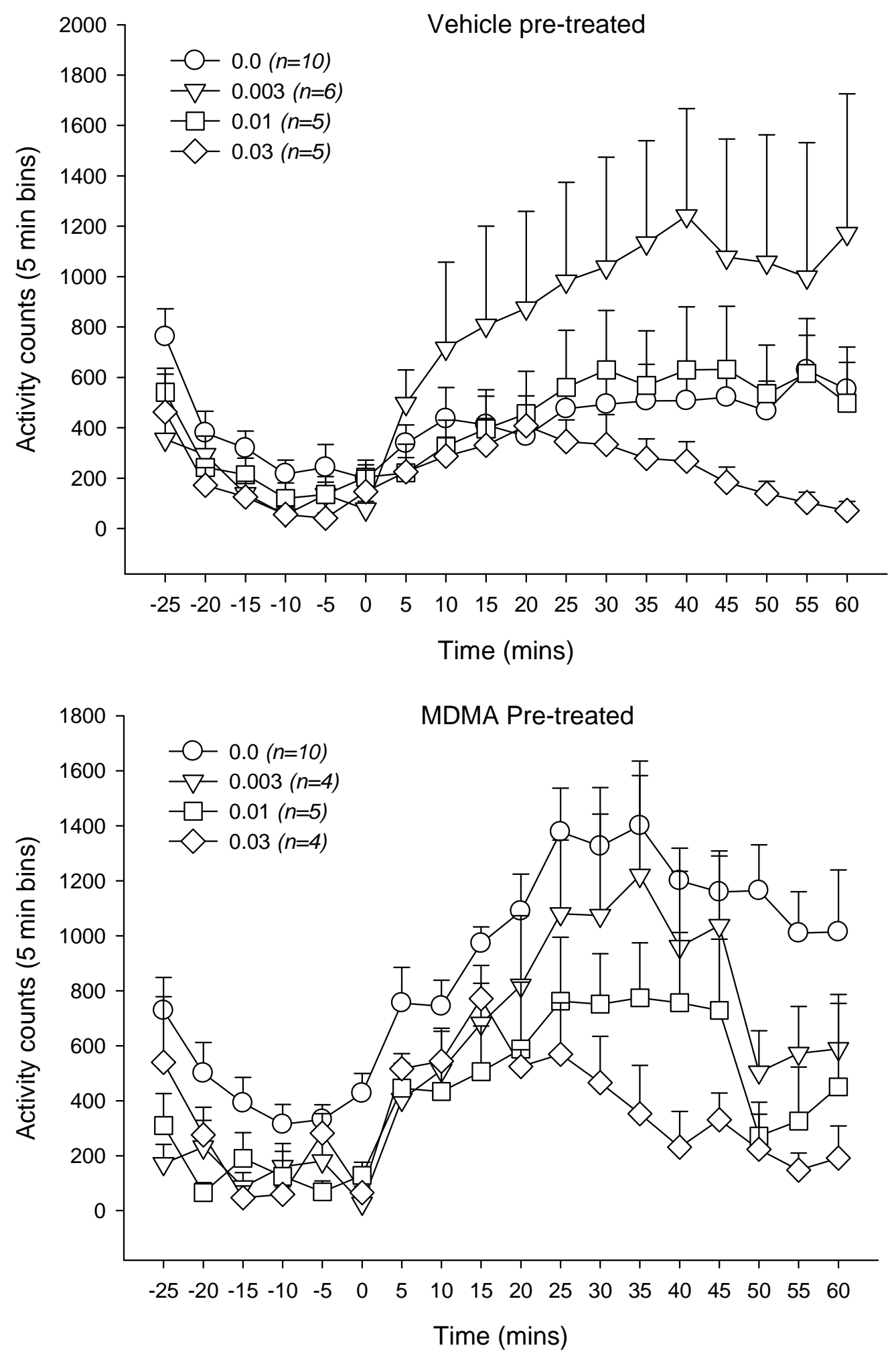

Figure 2.11. Effects of low doses of eticlopride on MDMA $(5.0 \mathrm{mg} / \mathrm{kg})$ produced hyperactivity in vehicle and MDMA pre-treated rats. Symbols represent the mean number of activity counts (+SEM).Numbers in brackets above each column is the sample size. Locomotor counts are summed into bins of 5 minute intervals with time ' 0 ' being the time of drug injection. 
Figure 2.12 shows the data above presented as total locomotor counts following the injection of MDMA. A two way ANOVA revealed a significant main effect of Dose $(F(3,41)=3.15, \mathrm{p}<0.05)$. A one-way ANOVA showed a significant main effect of Dose in the MDMA $(F(3,22)=$ 5.86, $\mathrm{p}<0.05)$ pre-treated groups but not in the vehicle pre-treated groups $(\mathrm{F}(3,22)=1.78, \mathrm{~ns})$. A one-way ANOVA on MDMA pre-treated rats showed all but the 0.003 dose to be significantly reduced compared to that of the 0.0 dose $(\mathrm{p}<0.05)$.

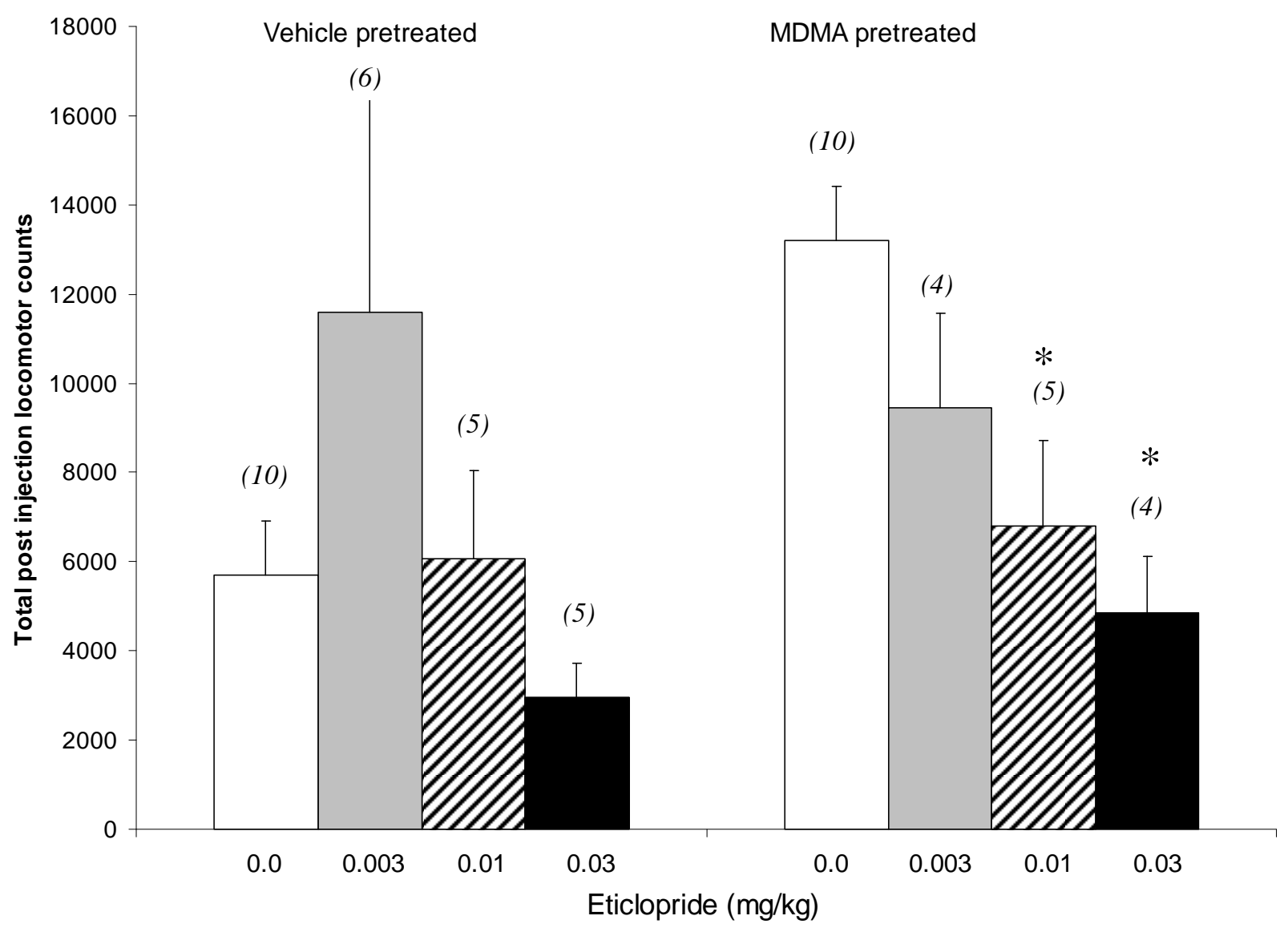

Figure 2.12. Effects of eticlopride on MDMA $(5.0 \mathrm{mg} / \mathrm{kg})$ produced hyperactivity in vehicle and MDMA pre-treated rats. Symbols represent the mean total number of activity counts (+SEM). Numbers in brackets above each column is the sample size. 
Experiment $\underline{2 c} \underline{\text { Results. }}$

Effects of RS102221 in MDMA sensitised rats

Figure 2.13 shows the effect of RS102221 in vehicle and MDMA pre-treated rats. A three-way ANOVA [Pre-treatment (10.0 MDMA or vehicle) X Dose (0.0, 0.25, 0.5, and 1.0) X Time (12 five minute bins)] revealed a significant main effect of Pre-treatment $(\mathrm{F}(1,50)=54.26, \mathrm{p}<0.05)$ and a significant interaction between Pre-treatment and Dose $(F(3,50)=3.99, \mathrm{p}<0.05)$, but the effect of Dose was not significant $(F(3,50)=1.06 \mathrm{~ns})$. 

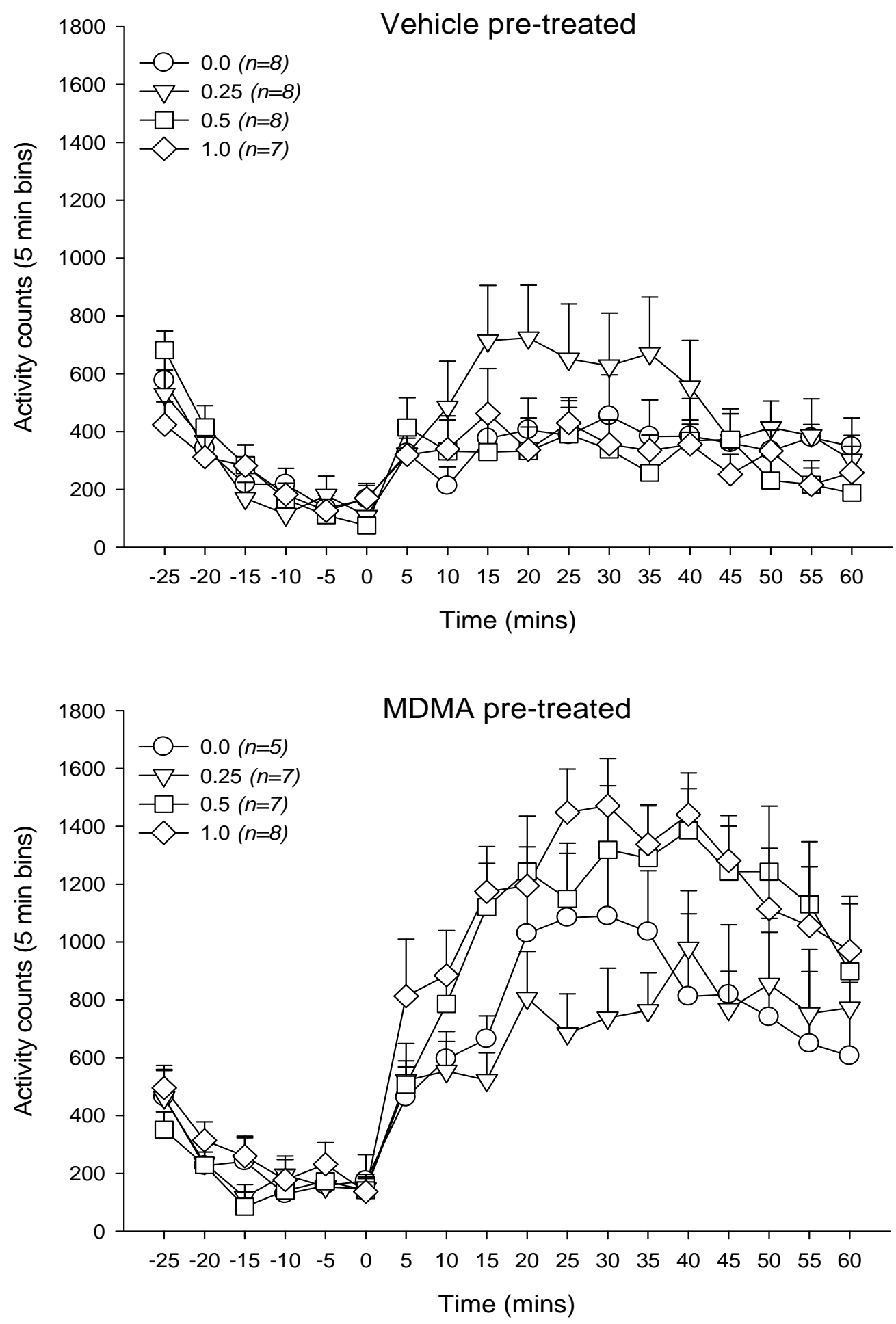

Figure 2.13. Effects of RS102221 on MDMA (5.0 mg/kg) produced hyperactivity in vehicle and MDMA pre-treated rats. Symbols represent the mean number of activity counts (+SEM). Numbers in brackets above each column is the sample size. Locomotor counts are summed into bins of 5 minute intervals with time ' 0 ' being the time of drug injection. 
Figure 2.14 shows the data above presented as total number of locomotor counts following the injection of 5.0mg/kg MDMA. A one-way ANOVA on vehicle data showed no effect of Dose $(F(3,27)=1.11$, ns $)$ but a one-way ANOVA on the data from the MDMA pre-treated groups revealed a main effect $(F(3,23)=3.10, p<0.05)$. Post hoc analysis revealed that the doses of 0.5 and $1.0 \mathrm{mg} / \mathrm{kg} \mathrm{RS} 102220$ increased activity relative to the $0.25 \mathrm{mg} / \mathrm{kg}$ dose $(\mathrm{p}<0.05)$.

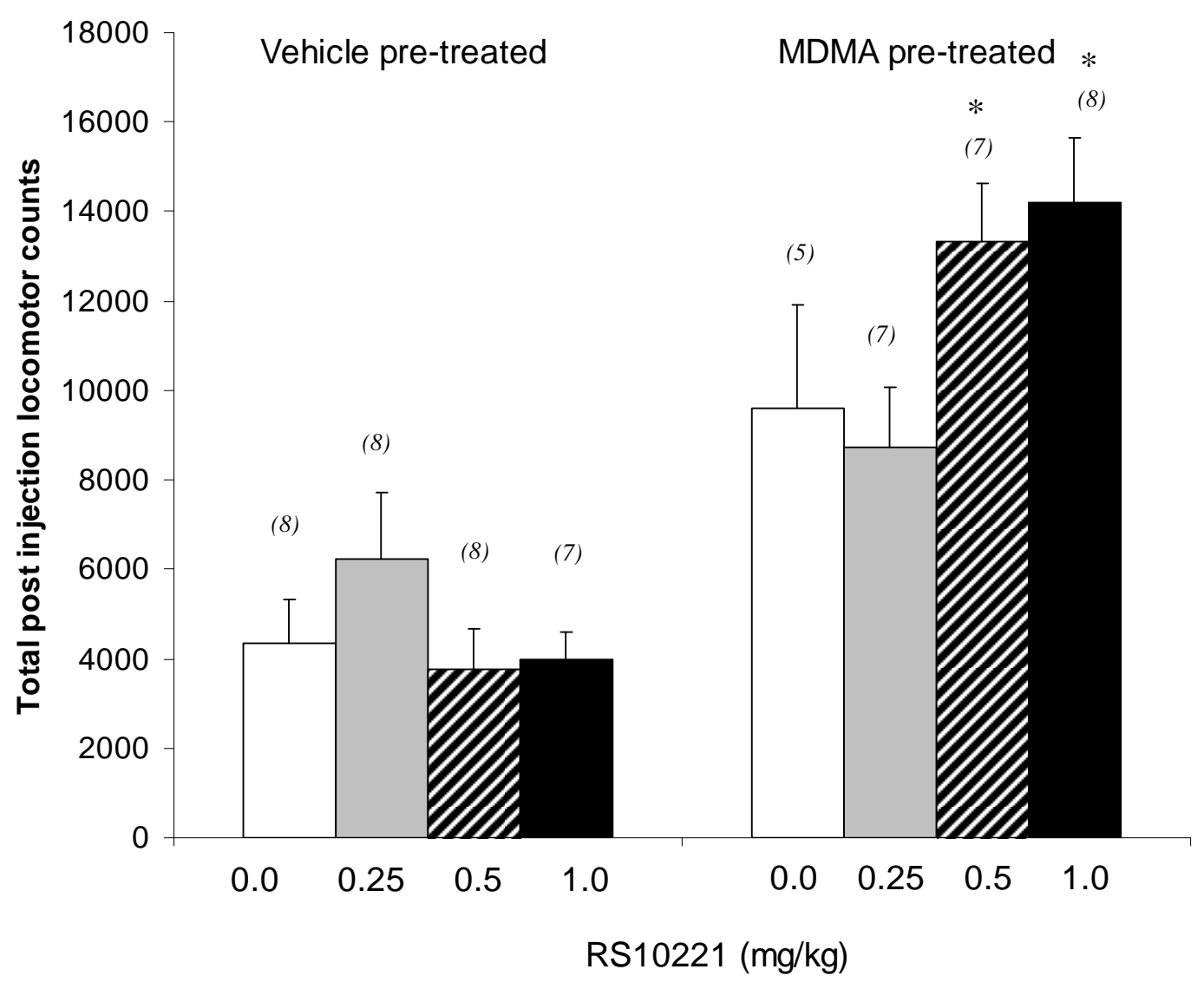

Figure 2.14. Effects of RS102221 on MDMA (5.0 mg/kg) produced hyperactivity in vehicle and MDMA pre-treated rats. Symbols represent the mean total number of activity counts $(+\mathrm{SEM})$. Numbers in brackets above each column is the sample size. $*$ difference from vehicle pretreated group 
Figure 2.15 presents the above data as a percentage change from 'baseline' (0.0 RS102221 dose) responding. A two-way ANOVA Pretreatment (10.0 MDMA or vehicle) X Dose (0.0,0.25, 0.5 and $1.0 \mathrm{mg} / \mathrm{kg})]$ showed no significant effect of Pre-treatment $(F(1,51)=0.87$, ns $)$, no main effect of Dose $(F(3,51)=0.31$, ns $)$ but an interaction between Pretreatment and Dose $(\mathrm{F}(3,51)=2.99, \mathrm{p}<0.05)$. A one-way ANOVA showed a difference in MDMA pre-treated data $(F(3,26)=3.10, p<0.05)$ with the difference between the 0.25 and 1.0 dose $F(1,14)=7.39$, $\mathrm{p}<0.05)$.

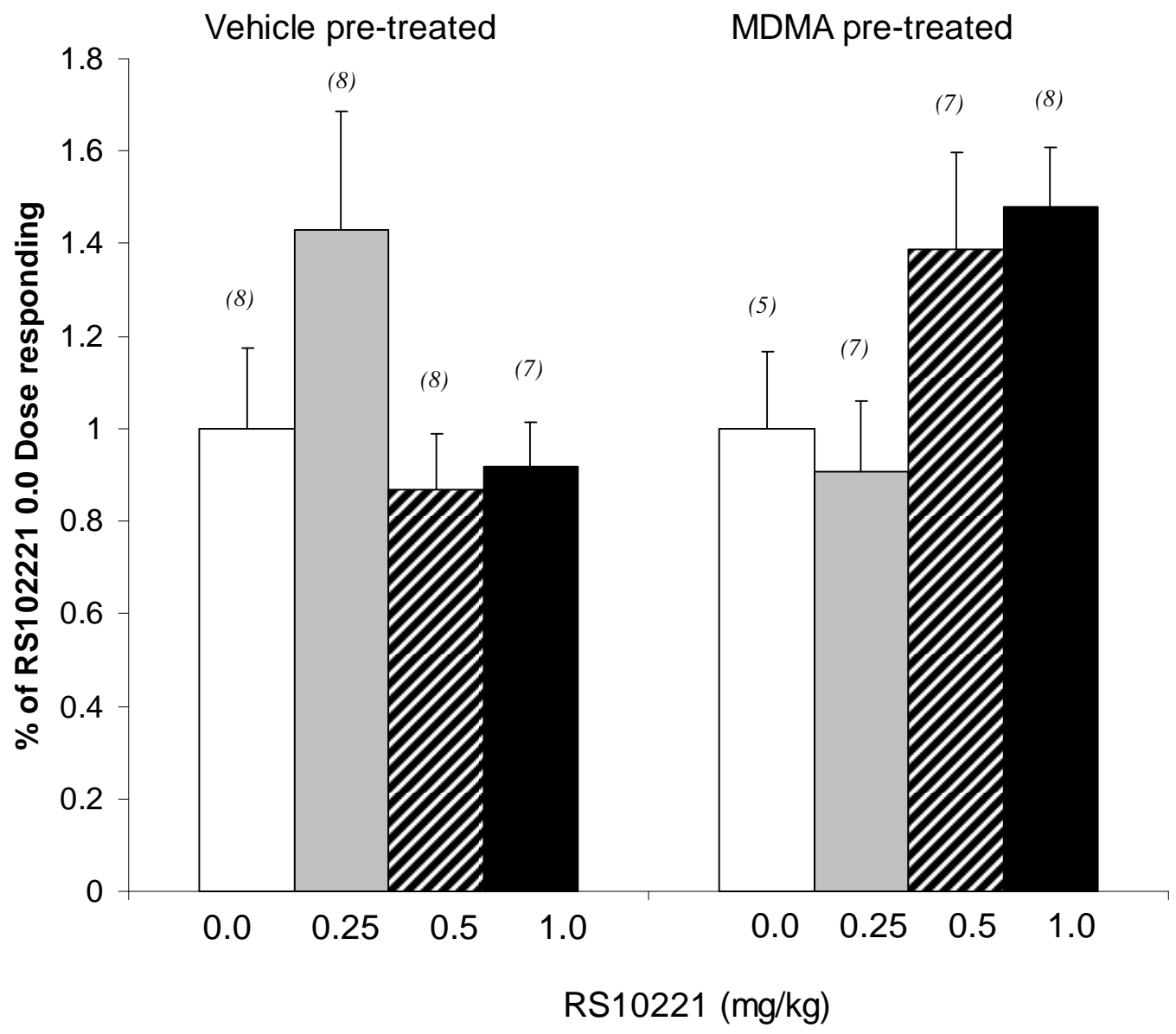

Figure 2.15. Effect of RS102221 on MDMA $(5.0 \mathrm{mg} / \mathrm{kg})$ produced hyperactivity in vehicle and MDMA pre-treated rats. Data are expressed as mean percent change from vehicle (+SEM). 


\section{Experiment $\underline{2} \underline{\text { Discussion }}$}

In accordance with experiment 1 , and previous literature, the present study demonstrated that pre-exposure to MDMA produces sensitisation to its locomotor producing effects. The locomotor activating effects of amphetamine are widely agreed to be mediated by DA (Kalivas \& Stewart, 1991; Nestler, 1992; Robinson \& Berridge, 1993: Segal, 1989) and the present investigation demonstrated hyperlocomotor producing effects of repeated MDMA might also reflect sensitisation in underlying dopaminergic substrates.

Following repeated exposure to MDMA the $\mathrm{D}_{1}$ agonist, SKF81297, produced a greater locomotor response when compared to vehicle pre-treated animals. The leftward shift in the dose response curve suggests a sensitisation of the $D_{1}$ receptor. Repeated exposure to amphetamine also produced $D_{1}$ receptor sensitivity in sub-cortical structures such as the NAc (Henry \& White, 1991) and VTA (Vezina, 1996). Further, pre-treatment with the $\mathrm{D}_{1}$-like receptor antagonist, SCH 23390, blocked both the development and expression of amphetamine produced behavioural sensitisation (Vezina, 1996; Vezina and Stewart 1989). In contrast, the development of MDMA-produced sensitisation was unaffected by pre-treatment with SCH23390 while but SCH23390 dose dependently blocked the expression of sensitisation (Ramos et al., 2004). 
In the current investigation, the administration of the $\mathrm{D}_{1}$-like receptor antagonist, SCH23390, decreased MDMA produced locomotor activity to a comparable degree in both MDMA and vehicle pre-treated animals. This reduction in the response to MDMA supports the idea that the $\mathrm{D}_{1}$ receptor plays a role in the expression of MDMA-produced hyperactivity, as has been previously suggested (Daniela et al., Ball et al., Ramos et al.,). The failure to observe an increased potency of SCH 23390 in the MDMA pre-treated rats is not consistent with the idea that the $\mathrm{D}_{1}$ receptor became supersensitive as a result of pre-exposure.

One possibility is that the effects of SCH 23390 are due to activity at alternate receptor sites. Thus, although SCH23390 has been extensively used as a dopamine $\mathrm{D}_{1}$ receptor antagonist (Bourne, 2001) it also binds with high affinity to $5-\mathrm{HT}_{2 \mathrm{C}}$ receptors functioning as an antagonist (Millan, NewmanTancredi, Quentric, \& Cussac, 2001). Administration of 5-HT $2 \mathrm{C}$ receptor antagonists increased DA firing rates and $5-\mathrm{HT}_{2 \mathrm{C}}$ receptor agonists decreased firing rates (Di Matteo et al. 2000; Gobert et al. 2000). Therefore, it is possible that these two effects of SCH 23390 counteracted each other. That is, the DA blocking effects would be expected to result in an antagonism of MDMA-produced hyperactivity whereas the effects on the 5HT2c receptor would be expected to enhance MDMA-produced hyperactivity. Indeed, the current results support this hypothesis as the selective $5-\mathrm{HT}_{2 \mathrm{C}}$ antagonist, RS102221, potentiated MDMA-produced hyperactivity in the MDMA pretreated rats. 
The locomotor activating effects of the mixed $D_{1} / D_{2}$ agonist, apomorphine, were increased across a range of doses in MDMA sensitised animals. Apomorphine is non-selective but it has greater affinity for the $\mathrm{D}_{2}$ receptor (Li, et al., 2006). The $\mathrm{K}_{i}$ for the $\mathrm{D}_{2}$ receptor was 5 nanomolars (nM) and for the $\mathrm{D}_{1}$ receptor it was $500 \mathrm{nM}$ (Missale, Nash, Robinson, Jaber, \& Caron, 1998). Apomorphine therefore is a preferential DA $D_{2}$ agonist.

Following amphetamine pre-treatment, there have been reports of either no change or down regulation of $\mathrm{D}_{2}$ receptors (Muller and Seeman, 1979; Robinson \& Becker, 1986) although DA $\mathrm{D}_{2}$ receptor agonists have been shown to induce augmented behavioural responses in sensitised rats (Levy et al., 1988; Ujike et al., 1990). It has been suggested, however, that sensitisation is accompanied by an increased sensitivity of the high-affinity $\mathrm{D}_{2}$ post synaptic receptors (Seeman, Tallerico, Ko, Tenn, \& Kapur, 2002; Seeman, McCormick \& Kapur, 2007). This might explain the increased apomorphine-produced hyperactivity observed in the present study.

A transient decrease in the sensitivity of $\mathrm{D}_{2}$ auto receptors has also been reported following repeated amphetamine administration (Wolf et al., 1993). To ascertain whether this could explain the supersensitive response to apomorphine, effects of a low dose of the $\mathrm{D}_{2}$ antagonist, eticlopride, which would have preferentially blocked $\mathrm{D}_{2}$ autoreceptors (Salmi, Malmgren, Svensson, Ahlenius, 1998), were determined. Under these circumstances, an increase in MDMA -produced hyperactivity might have been expected. This was not observed, however, even when extremely low doses of eticlopride 
were administered. These data are, therefore, not consistent with the idea that the autoreceptor became desensitised. Rather, the data suggest that MDMA pre-treatment resulted in an up-regulation of the postsynaptic $\mathrm{D}_{2}$ mechanisms.

Sustained receptor activation by DA agonists may alter the $\mathrm{D}_{2}$ coupling of the G-protein without alteration of receptor densities (Rudissaar, Harro, Pruus, Rinken, \& Allikmets, 2008). Extracellular signals produce increases or decreases of second messengers such as cyclic adenosine monophosphate (cAMP) resulting in a number of biological responses (Gelowitz \& Berger, 2001). For example, when cocaine is chronically administered there is increased adenylyl cyclase and cAMP dependent protein kinase in neurons in the NAc (Miserendino, \& Nestler, 1995). Further, administration of cholera toxin in the NAc, activating adenylyl cyclase, enhances the acute locomotor activating effects of amphetamine (Cunningham \& Kelley, 1993). The uncoupling of the G-protein had been reported following chronic administration of the $\mathrm{D}_{2}$ agonist, apomorphine, without altering locomotor activity (Rudissaar, et al., 2008). However, supersensitivity of the $\mathrm{D}_{2}$ receptors following unilateral lesions of the striatal system, enhanced $G_{i}$ coupling and subsequent locomotor responses (Cai, Wang, \& Friedman, 2002; Cai, Zhen, Uryu, \& Friedman, 2000). These data suggest that in neurons expressing $D_{2}$ receptors an enhanced $G_{i}$ coupling may be produced following amphetamine sensitisation however, the exact mechanisms of action are, as yet, still unclear (Rudissaar et al., 2008; Schwendt, \& McGinty, 2007; Traynor \& Neubig, 2005). It is seemingly likely however, 
that during the MDMA sensitising regimen changes in coupling to the adenylyl cyclase inhibiting $\mathrm{D}_{2} \mathrm{G}$-protein occurred. This may explain the differential locomotor producing effects of the $\mathrm{D}_{2}$ agonist and antagonist.

\section{Experiment $2 \underline{2} \underline{\text { summary }}$}

The current results are consistent with the hypothesis that locomotor sensitisation to MDMA is mediated by DA receptor mechanisms. There was cross-sensitisation between the effects of MDMA and both the $\mathrm{D}_{1}$-like agonist, SKF81297, and the preferential DA $\mathrm{D}_{2}$-like agonist, apomorphine. These effects were not, however, reflected in sensitised responses to the antagonists. Whereas the failure for the response to SCH 23390 to be increased in MDMA sensitised rats might be due to non selective effects, the failure to observe differential effects of the $\mathrm{D}_{2}$-like antagonist, eticlopride, suggests that there is an alteration in coupling of the $\mathrm{D}_{2}$ receptor mechanisms under conditions of $\mathrm{D}_{2}$ blockade. 


\title{
Experiment 3: Changes in potency of reinforcement of MDMA as measured in the self-administration paradigm following repeated intermittent exposure to MDMA
}

\author{
Background
}

There is now strong evidence supporting the relationship between drug induced changes in mesolimbic dopamine and the rewarding effects and abuse liability of drugs as modelled by self administration. For example, neurotoxic lesions (Roberts, Koob, Klonoff, \& Fibiger, 1980) or administration of $\mathrm{D}_{1}$-like and $\mathrm{D}_{2}$-like receptors antagonists (Caine \& Koob 1994; Pierre \& Vezina, 1998; Woolverton \& Virus, 1989) produced a rightward shift in the dose effect curve. Conversely, administration of direct or indirect (Schenk et al, 2003; Spealman, Barrett-Larimore, Rowlett, Platt, \& Khroyan, 1999) dopamine agonists produced a leftward shift (Caine \& Koob, 1994) supporting the idea that dopaminergic mechanisms underlie the reinforcing effects of drugs of abuse.

The magnitude of the initial reinforcing effects of drugs was inversely related to drug dose. Thus, self-administration was acquired more rapidly when higher doses were available (Schenk et al, 1993; Carroll \& Lac, 1997). Following systemic pre-treatment with amphetamine or cocaine, latency to acquisition of self-administration was reduced, suggesting an enhancement of the initial reinforcing effects (Horger et al., 1990; 1992; Schenk \& Partridge, 2000; Vezina et al., 1999). Pre-treatment with drugs other than the self- 
administered drug has also been shown to decrease the latency to acquisition of self-administration (Schenk et al, 1993; Schenk \& Izenwasser, 2002). These findings suggest that pre-exposure to psychostimulants may increase their reinforcing effects and may produce neuroadaptations that are common and might underlie the abuse liability of some drugs. Given the role of dopamine in self administration it further suggests that these neuroadaptations are within the dopamine system.

Latency to acquisition of self-administration of other drugs of abuse was inversely related to drug dose; higher doses led to more rapid acquisition (Schenk et al., 1991, 1993; Schenk \& Partridge, 2000). In the case of MDMA, only one report has provided data on the relationship between acquisition rate and available dose for self-administration. In that study (Schenk et al., 2007), two doses of MDMA (0.25 and $1.0 \mathrm{mg} / \mathrm{kg} /$ infusion) were available. Latency to acquisition did not differ as a function of dose and, in both cases, latency to acquire self-administration was more variable and longer than the latency to acquire cocaine $(0.5 \mathrm{mg} / \mathrm{kg} /$ infusion $)$ selfadministration.

Pre-exposure to MDMA facilitated cocaine self-administration (Fletcher, Robinson, \& Slippoy, 2001), suggesting a sensitised response but, to my knowledge, there have not been studies that have examined the effects of prior exposure to MDMA on latency to acquisition of MDMA selfadministration. 
Experiment two demonstrated an augmented locomotor response to both $\mathrm{D}_{1}$ and $\mathrm{D}_{2}$ agonists following repeated MDMA administration. It is therefore hypothesised that a sensitised dopamine response would facilitate the acquisition of self-administration. In the current experiment two doses of MDMA were chosen for this acquisition study (0.5 and $1.0 \mathrm{mg} / \mathrm{kg} / \mathrm{infusion})$. Both doses were based on previous research showing acquisition of MDMA within approximately 12 days (Schenk, et al., 2003; 2007).

\section{Materials and methods}

\section{${ }^{1}$ Subjects}

Subjects were male Sprague-Dawley rats bred in the vivarium at Victoria University of Wellington. They were initially housed in hanging polycarbonate cages in groups of four to six per cage, but once they reached weights of 250-275 g, they were individually housed. The humidity (74\%) and temperature (21C) controlled animal colony was maintained on a 12:12-h light/dark cycle with lights on at 0700 hours. Food and water were freely available except during the short duration (2 hour) self-administration tests described below.

\section{Surgery}

Rats were implanted with a silastic catheter in the right jugular vein. The rats were deeply anesthetized with ketamine $(60.0 \mathrm{mg} / \mathrm{kg}$, IP) and pentobarbital

\footnotetext{
${ }^{1}$ The Materials and methods sub-sections named 'subjects', 'surgery' and 'apparatus' have previously been described in Schenk S, Gittings D, Johnstone M, Daniela, E. (2003).
} 
$(20.0 \mathrm{mg} / \mathrm{kg}$, IP), the external jugular vein was isolated, a catheter inserted and the distal end (22 ga stainless steel tubing) was passed subcutaneously to an exposed portion of the skull, where it was fixed to embedded jeweller's screws with dental acrylic. Each day, the catheters were infused with $0.1 \mathrm{ml}$ of a sterile saline solution containing heparin $(30.0 \mathrm{IU} / \mathrm{ml})$ and ampicillin $(250,000 \mathrm{IU} / \mathrm{ml})$ to prevent infection and the formation of clots. The rats were allowed 5 days post-surgery for recovery prior to behavioural testing.

\section{Apparatus}

Self-administration training and testing were conducted in test chambers (Med Associates, ENV 001) enclosed in sound attenuating closets. The testing room containing the 31 test chambers was humidity (55\%) and temperature $\left(21^{\circ} \mathrm{C}\right)$ controlled. Each chamber was equipped with two levers and a stimulus light. Depression of one lever (the active lever) resulted in an infusion of drug. Depression of the other lever (the inactive lever) was without programmed consequence. Infusions were in a volume of $0.1 \mathrm{ml}$ delivered over $12.0 \mathrm{sec}$ via Razel pumps equipped with $1.0 \mathrm{rpm}$ motors and $20.0 \mathrm{ml}$ syringes.

\section{Procedure}

Rats received a pre-treatment consisting of MDMA $(0.0(n=17)$ or $10.0 \mathrm{mg} / \mathrm{kg}(n=18))$, i.p) as per the 5 day sensitising regimen described in the general procedure section of Experiment 1. This was followed by a two 
day withdrawal period. Catheters were implanted the following day and animals were allowed to recover for a further 5 days. Therefore, self administration testing began 9 days following the pre-treatment phase. This withdrawal period was chosen because a sensitised response to MDMA was produced 9 days following repeated MDMA administration in Experiment $1 b$.

Self-administration tests were conducted during daily 2 hour sessions. Every session began with an experimenter delivered infusion of MDMA. Thereafter, each depression of the active lever (FR1 reinforcement schedule) resulted in an automatic infusion of MDMA [0.5 or $1.0 \mathrm{mg} / \mathrm{kg} /$ infusion] paired with the illumination of a stimulus light located directly above the active lever.

Testing continued for 14 days or until the number of active lever responses was greater than 10 , and a preference for the active lever was demonstrated, as per Daniela et al., (2006) and Schenk et al., (2007). The number of days required to meet this criterion was determined for each rat.

\section{$\underline{\text { Results }}$}

Figure 3.1 shows the cumulative percentage of rats in each pre-treatment group that acquired MDMA self-administration as a function of days and MDMA dose. For all rats, regardless of pre-treatment and subsequent selfadministration dose, a total of $46 \%$ reached the self-administration criterion. 


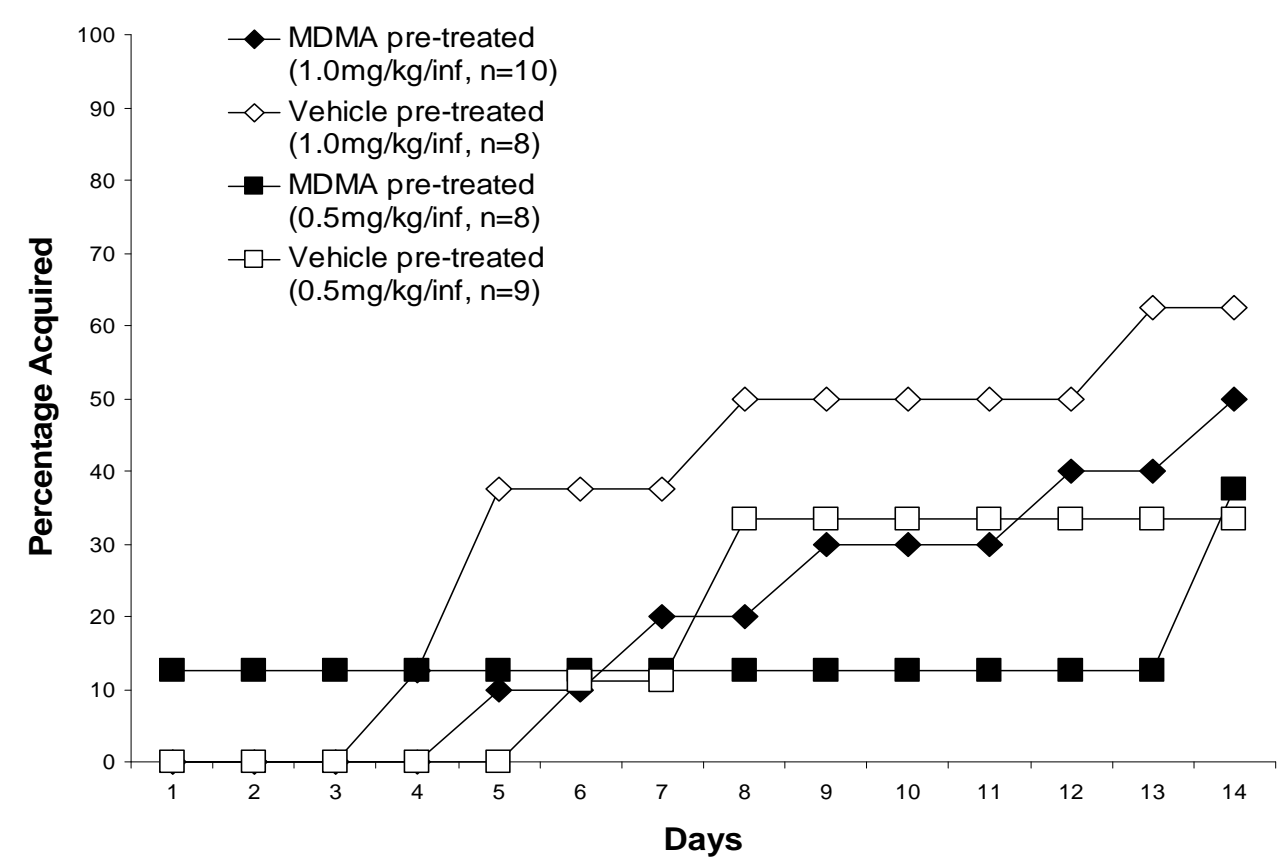

Figure 3.1. Cumulative percentage of rats that acquired MDMA selfadministration as a function of days of testing, pre-treatment condition and MDMA dose.

Of the vehicle pre-treated group that self-administered $1.0 \mathrm{mg} / \mathrm{kg} / \mathrm{infusion}$ nearly $40 \%$ met the criteria for acquisition by day 5 and in this group the highest percentage of rats that acquired self-administration during the 14 day test period. There was an increase in the latency to acquisition for the vehicle pre-treated group that self-administered the lower dose of $0.5 \mathrm{mg} / \mathrm{kg} / \mathrm{infusion}$ MDMA. The MDMA pre-treated rats were slower to acquire selfadministration and a lower percentage met the criteria within the test period when compared to their vehicle pre-treated counterparts.

Rats pre-exposed to $10.0 \mathrm{mg} / \mathrm{kg}$ MDMA for five days and tested with 1.0 $\mathrm{mg} / \mathrm{kg} /$ infusion MDMA had an average daily intake of $9.80 \mathrm{mg} / \mathrm{kg}$. Rats preexposed to vehicle for five days and tested $1.0 \mathrm{mg} / \mathrm{kg} /$ infusion MDMA had an average daily intake of $8.51 \mathrm{mg} / \mathrm{kg}$. There was no difference in average 
daily intake between MDMA and vehicle pre-exposed groups in the $1.0 \mathrm{mg} / \mathrm{kg} /$ inf condition $[\mathrm{t}(6)=1.45, \mathrm{p}=0.196]$.

Rats pre-exposed to 10.0 MDMA for five days and tested with 0.5 $\mathrm{mg} / \mathrm{kg} /$ infusion MDMA had an average daily intake of $3.59 \mathrm{mg} / \mathrm{kg}$. Rats preexposed to vehicle for five days and tested $0.5 \mathrm{mg} / \mathrm{kg} /$ infusion MDMA had an average daily intake of $6.90 \mathrm{mg} / \mathrm{kg}$. There was a significant difference in average daily intake between MDMA and vehicle pre-exposed groups in the $0.5 \mathrm{mg} / \mathrm{kg} /$ infusion condition $[\mathrm{t}(4)=-3.396, \mathrm{p}=0.027$ ] with vehicle animals having a higher daily average intake.

Figure two shows the range of responses on the active and inactive lever for all rats that failed to reach criterion. The failure for these rats to acquire was related to the criterion of 10 responses rather than lack of active lever preference.

Table 2.

Range of responses

\begin{tabular}{lccc}
\hline Pre-treatment & $\begin{array}{c}\text { MDMA } \\
(\mathrm{mg} / \mathrm{kg} / \text { infusion })\end{array}$ & Inactive lever & Active lever \\
\hline $\operatorname{Vehicle}_{(n=6)}$ & 0.5 & $0.3-3.1$ & $1.6-3.6$ \\
$\operatorname{Vehicle}_{(n=3)}$ & 1.0 & $0.0-5.0$ & $0.6-5.3$ \\
$\operatorname{MDMA}_{(n=5)}$ & 0.5 & $0.2-3.6$ & $1.4-4.6$ \\
$\operatorname{MDMA}_{(n=5)}$ & 1.0 & $0-3.2$ & $0.8-4.6$
\end{tabular}

Table 2. Range of responses on the active and inactive lever for rats that failed to reach criterion. 


\section{$\underline{\text { Discussion }}$}

The present study was designed to determine whether pre-exposure to MDMA, under conditions that produced sensitisation to the locomotor activating effects of MDMA, decreased the latency to acquisition of MDMA self-administration. Somewhat surprisingly, pre-treatment with MDMA did not decrease latency to acquisition. Indeed, in comparison to vehicle pretreated animals there was an increased latency to acquisition for the MDMA pre-treated rats.

An inverse relationship between drug dose and latency to acquisition of selfadministration of other drugs of abuse has been demonstrated (Schenk et al., 1991, 1993; Schenk \& Partridge, 2000). Consistent with these findings latency to acquisition of MDMA self-administration was shorter for the group that self-administered the higher dose and a higher percentage of these rats met the criterion for acquisition within the temporal parameters of this experiment.

In contrast to results of other studies, however, MDMA pre-treatment failed to decrease the latency to acquisition of self-administration. One possibility is that the doses of MDMA tested were too high to allow reliable decreases to be observed. Indeed, pre-exposure to amphetamine decreased the latency to acquisition of self-administration of low doses (Piazza, et al., 1989; Pierre \& Vezina, 1997) but failed to alter acquisition of self-administration when 
higher doses were available (Lorrain, Arnold, \& Vezina, 2000; Mendrek, Blaha, \& Phillips, 1998).

Another possibility is that pre-treatment with MDMA as in the present study sensitised the rats to the aversive effects of MDMA and hence delayed the acquisition of self administration. Indeed, there have been several reports of MDMA-produced aversion. A conditioned taste aversion was produced by MDMA (Lin, Atrens, Christie, Jackson, \& McGregor, 1993). MDMA also increased the latency to emerge from a darkened hide box (McGregor, et al., 2003) and reduced activity on the elevated plus maze (Bull, Hutson, \& Fone, 2004), suggesting an anxiogenic effect (Navarro \& Maldonado 2002). These initial aversive properties of MDMA might explain the gradual acquisition of self-administration in vehicle and also in MDMA-pre-treated rats.

A final possibility for the failure of MDMA pre-treatment to enhance the reinforcing effects of MDMA relates to pharmacological effects of repeated exposure. It has been suggested that reinforcing efficacy of drugs is related to the relative effects on DA and 5HT neurotransmission. More specifically, it has been suggested that increased serotonergic effects are associated with decreased potency as a reinforcer. This idea is based on a number of empirical findings. Firstly, administration of the 5-HT precursor tryptophan, which increases brain 5-HT synthesis, decreased self-administration of cocaine (McGregor, Lacosta, \& Roberts, 1993) and amphetamine (Smith, Yu, Smith, Leccese, \& Lyness, 1986). Secondly, pre-treatment with 5-HT reuptake inhibitors reduced cocaine self-administration (Carroll, Lac, 
Asencio, \& Kragh, 1990). Thirdly, the motivation to self-administer amphetamine analogues with greater 5-HT potency, but equipotent DA potency, was reduced as measured by progressive ratio responding (Wee, et al., 2005).

A number of studies have shown that MDMA increased 5-HT levels (Kalivas et al., 1998) and that chronic or long term exposure compromised 5HT neurotransmission (Battaglia, Yeh, \& De Souza, 1988). These pretreatment regimens, however, were more stringent than those used in this study. Therefore the effects of the current regimen of MDMA on tissue levels of DA, 5-HT and their major metabolites were measured in Experiment 4.

\section{Experiment 4: Alterations of brain amine levels following repeated intermittent administration of MDMA}

Background

Amphetamine administration increased DA levels and synaptic dopamine overflow throughout various neural substrates such as the striatum (Kolta, et al., 1985), prefrontal cortex (Ichikawa, Chung, Li, Dai, \& Meltzer, 2002),VTA (Wolf, et al., 1993), NAc (Kalivas \& Stewart, 1991; Robinson \& Berridge, 1993) and all DA terminal fields (Vezina, 2004). Because local application of amphetamine into the VTA, but not into the NAc, produced a sensitised locomotor response (Cador, et al., 1995; Kalivas \& Weber, 1988), 
it has been suggested that neuroadaptations initiated by the acute increase in synaptic DA in the VTA mediate sensitised hyperactivity (Vezina, 2004).

The relationship between augmented DA release and the observation of locomotor sensitisation has been equivocal. In some studies, concordance between sensitised behavioural and neurochemical responses has been reported. For example, 7 days after repeated amphetamine administration there were increases in amphetamine-produced DA in the NAc of rats which coincided with sensitised hyperlocomotion (Scholl, Feng, Watt, Renner, \& Forster, 2009). Other studies, however, have failed to replicate these effects. In one, sensitised hyperlocomotion was observed 7 days after withdrawal but there were no differences in amphetamine induced dopamine overflow in nucleus accumbens or striatal tissue (Weinstein, Narayanan, Byrnes, Uretsky, \& Wallace, 1997). In another, sensitised locomotor activity observed 2 days following withdrawal that was not associated with an augmented DA response; a sensitised DA response was not observed until 10 days later (Kuczenski, Segal, \& Todd, 1997; Wolf, et al., 1993). Finally, after repeated high doses of amphetamine, amphetamine-produced stereotypical behaviour was observed but there were no changes in amphetamine-produced increases in NAc DA levels (Segal, \& Kuczenski 1999). These data suggest that, under certain regimens of administration, the behavioural and neurochemical indices of sensitisation to amphetamine may be dissociated.

Following acute administration, MDMA increased extracellular synaptic 5HT and produced a moderate increase in dopamine levels (Schmidt, 1987). 
Following chronic or high dose administration, however, MDMA reduced brain levels of 5-HT, tryptophan hydroxylase and the 5-HT metabolite, 5HIAA, (see Capela et al., 2009 for a review). Under some conditions, repeated administration of MDMA also produced behavioural and neurochemical sensitisation (Bubar, et al. 2004; Kalivas, et al, 1998; Yamamoto \& Spanos, 1988). Behavioural sensitisation was accompanied by a moderate decrease in ventral striatal 5-HT (Ludwig, Mihov, \& Schwarting, 2007).

In order to determine whether sensitisation produced in the present investigations was accompanied by changes in overall levels of 5-HT or DA, rats were pre-treated with $10.0 \mathrm{mg} / \mathrm{kg}$ MDMA in a manner that induced sensitisation and sacrificed two days after their final drug administration. Using HPLC tissue levels of DA, its metabolite HVA, 5-HT and its metabolite 5-HIAA were measured. It is hypothesised that, in accordance with previous literature, there will be a reduction in 5-HT levels of brain neurotransmitter along with its metabolite 5-HIAA. It is not predicted that there will be any change in DA or HVA.

\section{General Procedure}

Rats were pre-treated once daily with $\operatorname{MDMA}(0.0,10.0 \mathrm{mg} / \mathrm{kg})$ or, as a comparison, amphetamine (2.0 mg/kg I.P) for five days in as described in the general sensitisation protocols, experiment 1 . Following two days withdrawal 
rats were rendered unconscious with $\mathrm{CO}_{2}$ in an air tight chamber, decapitated and the brains rapidly removed.

\section{Brain Dissection}

Whole brains were placed in a stainless steel block for dissection into $1.0 \mathrm{~mm}$ coronal slices ( Heffner, Hartman, \& Seiden, 1980). Slices were placed onto an inverted petri dish chilled by ice. The dorsal striatum, NAc, frontal cortex and amygdala and were dissected, placed in vials, weighed and stored at $-80^{\circ}$ C until analysed.

\section{HPLC analysis}

Tissue samples were homogenised in $0.1 \mathrm{~N}$ perchloric acid and centrifuged at $10000 \mathrm{~g}$ for $30 \mathrm{~min}$ at $4^{\circ} \mathrm{C}$. The supernatant was filtered and injected onto a high-performance liquid chromatography system (Agilent 1100 series) with electrochemical detection. The injection volume was $10 \mu \mathrm{L}$ for the striatum and $20 \mu \mathrm{l}$ for the other regions. 5-HT, 5-HIAA, DA and HVA were separated using a C18 reversed phase column $(150 \times 4.6 \mathrm{~mm}, 5 \mu \mathrm{m}$ particle size; Eclipse XDB-C18, Agilent, USA). The mobile phase consisted of NaH2PO4 (75 mM), octane-1-sulphonic acid (1.7 mM), EDTA (0.25 mM), triethylamine $(100 \mu \mathrm{L} / \mathrm{L})$ and methanol (10\%), and was adjusted to $\mathrm{pH} 3$ with phosphoric acid. The flow rate was $1 \mathrm{ml} / \mathrm{min}$. Detection was performed using a coulometric detector (Coulochem III, ESA, USA). The guard cell potential was set at $450 \mathrm{mV}$ and the analytical cell potential at $400 \mathrm{mV}$. 
Chromatograms were acquired with ChemStation software. Concentrations are expressed as ng per mg of tissue.

Peak areas corresponding to the DA, 5-HT, HVA and 5-HIAA were measured and concentrations were determined from the regression curve obtained with external standards. Working external standards (500 - 15.125 $\mathrm{ng} / \mathrm{ml}$ in $0.1 \mathrm{~N}$ perchloric acid) were prepared daily from $1 \mathrm{mg} / \mathrm{ml}$ stock solutions and kept at $-80^{\circ} \mathrm{C}$.

\section{$\underline{\text { Results }}$}

Figure 4.1 below shows a chromatogram of 5-HT, 5-HIAA, DA and HVA standards separated using a C18 reversed phase column. 


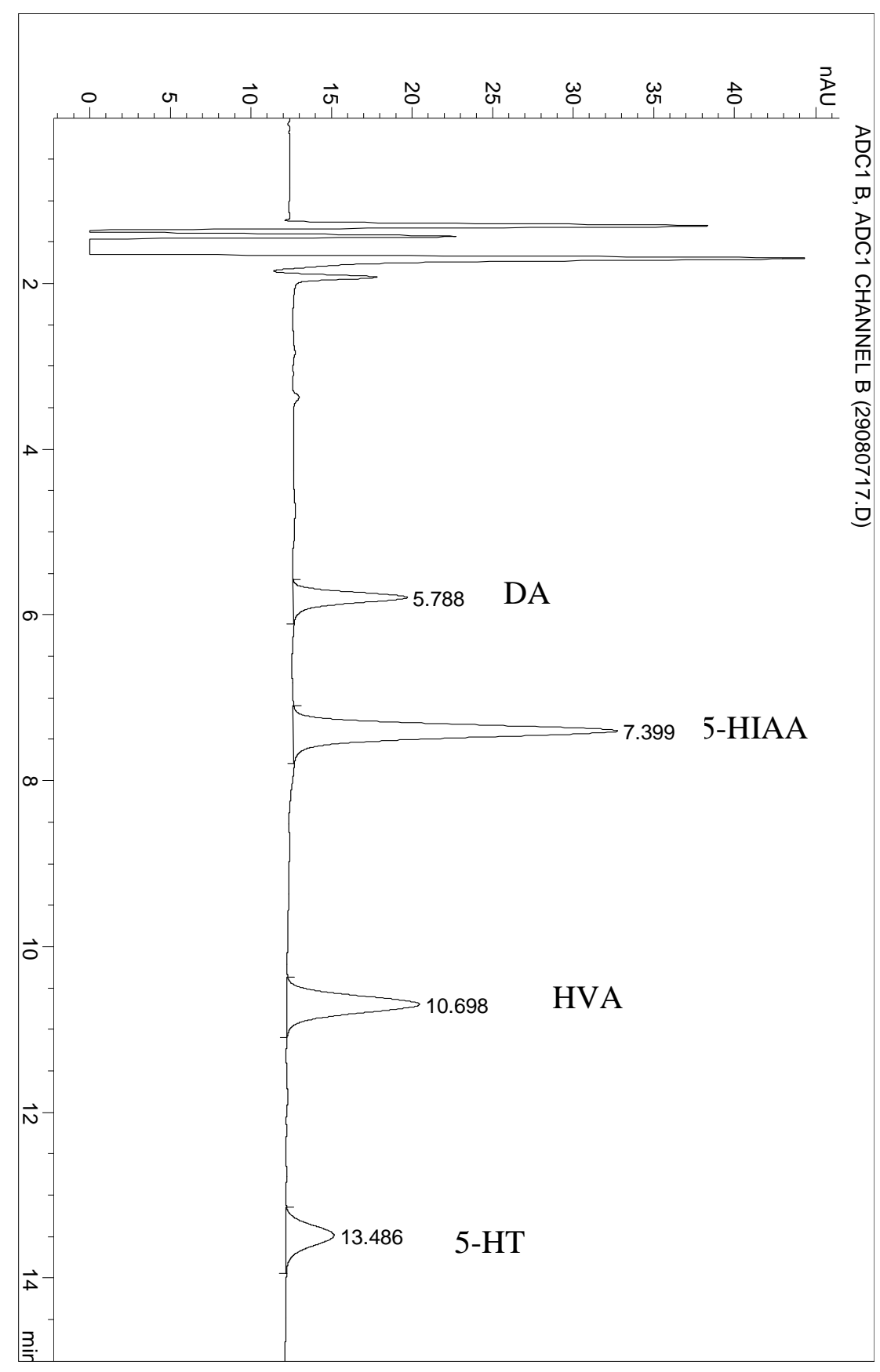

Figure 4.1. Chromatogram of amine standards injected onto a C18 reversed phase column

Table 4.1 presents results of the analyses of each of five brain regions from control rats and those that had undergone a sensitising regimen of MDMA (10.0 mg/kg I.P) or amphetamine (2.0mg/kg. I.P). Amphetamine and MDMA were compared to vehicle groups with a Bonferonni correction applied. 
Table 4.1. Neurochemical concentrations in tissue of rats that received either vehicle, MDMA (10.0 mg/kg I.P) or amphetamine $(2.0 \mathrm{mg} / \mathrm{kg}$. I.P) during a 5 -day pretreatment regimen. $* *=$ difference from vehicle pre-treated group $(p<0.01), n=6$ except for the 'Amygdala MDMA' group where $n=5$.

\section{DA $\quad$ 5-HIAA $\quad$ HVA 5 5-HT}

Striatum

$\begin{array}{ccccc}\text { Vehicle } & 31.14 \pm 3.69 & 0.55 \pm 0.03 & 1.65 \pm 0.14 & 0.79 \pm 0.11 \\ \text { Amph } & 30.26 \pm 2.93 & 0.52 \pm 0.04 & 1.44 \pm 0.08 & 0.79 \pm 0.11 \\ \text { MDMA } & 30.76 \pm 3.05 & 0.46 \pm 0.03 & 1.48 \pm 0.13 & 0.74 \pm 0.08\end{array}$

Nucleus Acc

$\begin{array}{ccccc}\text { Vehicle } & 12.08 \pm 2.68 & 0.79 \pm 0.04 & 1.37 \pm 0.11 & 0.87 \pm 0.13 \\ \text { Amph } & 13.07 \pm 2.53 & 0.68 \pm 0.06 & 1.10 \pm 0.10 & 0.83 \pm 0.06 \\ \text { MDMA } & 13.91 \pm 3.49 & 0.63 \pm 0.04 & 1.09 \pm 0.11 & 0.86 \pm 0.14\end{array}$

Frontal Cortex

$\begin{array}{ccccc}\text { Vehicle } & 0.20 \pm 0.04 & 0.54 \pm 0.03 & 0.08 \pm 0.01 & 0.98 \pm 0.14 \\ \text { Amph } & 0.20 \pm 0.01 & 0.43 \pm 0.03^{* *} & 0.08 \pm 0.01 & 0.94 \pm 0.08 \\ \text { MDMA } & 0.22 \pm 0.03 & 0.38 \pm 0.02^{* *} & 0.07 \pm 0.01 & 0.92 \pm 0.16\end{array}$

Amygdala

$\begin{array}{ccccc}\text { Vehicle } & 0.88 \pm 0.16 & 0.62 \pm 0.06 & 0.11 \pm 0.01 & 1.12 \pm 0.14 \\ \text { Amph } & 0.88 \pm 0.16 & 0.52 \pm 0.07 & 0.07 \pm 0.01 & 1.18 \pm 0.18 \\ \text { MDMA } & 0.86 \pm 0.09 & 0.42 \pm 0.05 & 0.07 \pm 0.01 & 0.94 \pm 0.17\end{array}$

Hippocampus

$\begin{array}{ccccc}\text { Vehicle } & 0.07 \pm 0.01 & 0.54 \pm 0.02 & 0.005 \pm 0.003 & 0.68 \pm 0.09 \\ \text { Amph } & 0.06 \pm 0.00 & 0.44 \pm 0.02^{* *} & 0.000 \pm 0.000 & 0.75 \pm 0.07 \\ \text { MDMA } & 0.07 \pm 0.01 & 0.35 \pm 0.02^{* *} & 0.003 \pm 0.002 & 0.75 \pm 0.07\end{array}$




\section{$\underline{\text { Discussion }}$}

A large number of studies have reported neurochemical effects of MDMA pre-treatment. In most studies, the MDMA pre-treatment regimen was substantive with animals exposed to doses of $20-40 \mathrm{mg} / \mathrm{kg} /$ day. These exposures typically resulted in behavioural tolerance rather than sensitisation to the behavioural effects of MDMA. Tolerance was accompanied by substantial decreases in both 5-HT and 5-HIAA (Marston et al., 1999; McNamara et al. 1995). The regimen in the current study was less extreme and produced a different profile of behaviour; i.e. sensitisation rather than tolerance. Differences in the neurochemical consequences were also observed in the present study.

There were no significant effects of the daily exposures on 5-HT although there was a significant decrease in the primary metabolite, 5-HIAA, in two of the 5 sites measured. This finding is consistent with the decrease in 5-HIAA in the frontal cortex previously reported (Ludwig, Mihov, \& Schwarting, 2008). Comparable effects were produced by repeated exposure to a sensitising regimen of amphetamine.

A number of studies have also failed to observe changes in basal DA and 5HT levels, synthesis or metabolism following repeated exposure to amphetamine that resulted in sensitisation (Bonhomme, Cador, Stinus, Le Moal, \& Spampinato, 1995; Paulson, et al., 1991). Other studies, however, have suggested that following more stringent exposure regimens alterations 
in tissue levels were produced. For example, a reduction in levels of 5-HT and 5-HIAA in the striatum was observed 24 hrs after the last dose of a daily administration regimen of $5.0 \mathrm{mg} / \mathrm{kg}$ amphetamine (McMillen, Scott, \& Williams, 1991). Additionally, chronic amphetamine administration in cats (twice daily increasing doses of $5-15 \mathrm{mg} / \mathrm{kg}$ amphetamine for ten days) reduced levels of 5-HT and 5-HIAA up to50\% in the cortex, hippocampus, striatum, brain stem and spinal chord when measured 9 days but not 14 days post withdrawal (Trulson \& Jacobs, 1979).

In the current results it is noticeable that the 5-HT metabolite 5-HIAA was reduced while levels of the parent molecule remained unchanged. Release and reuptake of 5-HT is the main source of extracellular 5-HIAA. Once released, the SERT moves the 5-HT molecules back into the presynaptic cell where it is bound into storage vesicles or deaminated to 5-HIAA. This metabolite is not stored but is passed back through to the extracellular area (Stenfors \& Ross, 2004). Without 5-HT release there is a reduction in 5HIAA levels. A reduction in release could explain why there is no difference in absolute tissue levels of 5-HT but, at the same time, there is a reduction in 5-HIAA levels. If there was a reduction in firing rates of serotonin neurons, differences in levels of 5-HIAA would be seen in all 5-HT terminal regions. Although only effects of MDMA or amphetamine were significant in two regions, for all regions there was a trend for reduced 5-HIAA.

5-HT release is regulated by the $5-\mathrm{HT}_{1 \mathrm{~A}}$ and $5-\mathrm{HT}_{1 \mathrm{~B}}$ receptors with selective antagonists blocking both the feedback mechanism and increasing 
extracellular 5-HT while reducing absolute 5-HIAA levels (Hjorth, et al., 2000). (Note that this is an absolute decrease in 5-HIAA and as there is 1000 times more extracellular 5-HIAA than 5-HT there remains a larger proportional amount of 5-HIAA). However, there is a differential role of the 5- $\mathrm{HT}_{1 \mathrm{~A}}$ and the 5- $\mathrm{HT}_{1 \mathrm{~B}}$ receptor in mediating changes in 5-HIAA levels as a function of 5-HT. Administration of the 5- $\mathrm{HT}_{1 \mathrm{~A}}$ receptor antagonist, robalzotan, directly into the frontal cortex, increased citalopram-produced extracellular 5-HT and decreased 5-HIAA levels (Hjorth, 1998). Administration of the 5- $\mathrm{HT}_{1 \mathrm{~B}}$ receptor antagonist, GR127935, also increased citalopram induced increases in extracellular 5-HT levels, but no change in 5HIAA levels was produced. Although antagonism of both the 5-HT $\mathrm{HA}_{1 \mathrm{~A}}$ and the 5-HT $\mathrm{H}_{1 \mathrm{~B}}$ autoreceptors increased 5-HT levels, only antagonism of the 5- $\mathrm{HT}_{1 \mathrm{~B}}$ disrupted the normal inverse relationship between 5-HT and5-HIAA. Stenfors and Ross (2004) interpreted this as due to stimulation of $5-\mathrm{HT}_{1 \mathrm{~B}}$ autoreceptors by the elevated synaptic 5-HT concentration resulting in decreased 5-HT release. Applied to the current results it may suggest that intermittent MDMA administration produces an altered 5- $\mathrm{HT}_{1 \mathrm{~B}}$ auto receptor state, reducing 5-HT release (but not overall storage levels) and subsequent decrease of 5-HIAA levels.

\section{Experiment $4 \underline{4} \underline{\text { Summary }}$}

In previous studies, pre-exposure to amphetamine or MDMA under conditions that produced sensitised behavioural responses did not alter tissue levels of either DA or 5-HT (Bonhomme, et al. 1995; Paulson, et al., 1991). 
The current results are consistent with this except that decreased levels of the serotonin metabolite 5-HIAA was produced in the frontal cortex and hippocampus. The reduction in 5-HIAA levels may be due to a disruption to the 5-HT $1 \mathrm{~B}$ autoreceptor. Further evidence for this could be obtained through a microdialysis assay of terminal regions of serotonin cells which would be hypothesised to show a reduction in extracellular levels of 5-HT.

Electrophysiology studies would be required to confirm a reduction in tonic firing of 5-HT cells.

\section{General Discussion}

The aim of the current thesis was to determine (1) some of the parameters for induction and expression of locomotor sensitisation following repeated MDMA exposure (2) Changes in sensitivity of the dopamine receptor mechanisms in sensitisation, and (3) if sensitisation was linked to reductions in the potency of the reinforcing effects of MDMA as measured by self administration and (4) what, if any, long term alterations in brain tissue levels of amines resulted from repeated exposure to MDMA. A group of four experiments were used to evaluate the above questions and results can be briefly summarised in the following manner.

1) A single dose of $10.0 \mathrm{mg} / \mathrm{kg}$ MDMA administered daily for five days produces reliable behavioural sensitisation.

2) Following the sensitisation regimen, there is cross sensitisation to $\mathrm{D}_{1}$ and $\mathrm{D}_{2}$ agonists. However, even though a dose dependent 
reduction in MDMA produced responding is attenuated by $\mathrm{D}_{1}$ and $\mathrm{D}_{2}$ antagonists, the potency of these antagonists is not altered by MDMA pre-treatment. This suggests that there are underlying mechanisms other than just receptor hypersensitivity responsible for the augmented locomotor activating effect of MDMA following a sensitisation dosing regimen.

3) The protocol that induces locomotor sensitisation does not decrease latency to acquisition of MDMA in the self- administration paradigm suggesting there are no changes in the potency of MDMA as a reinforcer after the current pre-treatment regimen

4) Following five single daily injections of $10.0 \mathrm{mg} / \mathrm{kg}$ MDMA there are only minor reductions in the 5-HT metabolite 5-HIAA and no change in other brain amines tested.

Experiment one demonstrated that of the two pre-exposure regimens, pretreatment with $10.0 \mathrm{mg} / \mathrm{kg} /$ day MDMA was the more effective and that behavioural sensitisation, unlike amphetamine sensitisation, was relatively short-lived. A sensitising regimen of amphetamine has shown increases in DA overflow up to three months following drug exposure (Hamamura, et al., 1991). Further, sensitised locomotor activity was apparent one year following amphetamine exposure (Paulson, et al., 1991). This may suggest that persistent sensitisation does not occur under the current pre-treatment regimen of MDMA however, a clear sensitised locomotor response was evident in all of the behavioural assays. These sensitised behavioural responses may nevertheless underlie motivational aspects of drug seeking and contribute to compulsive drug-taking that characterises abuse (Robinson \& Berridge, 1993, 2003). 
It has been suggested that escalating dose administrations produce a different behavioural profile to that of repeated intermittent administration (Segal \& Kuczenski, 1999). Animals treated previously with an intermittent or escalating dose of amphetamine have exhibited different patterns of FosB and c-Fos expression in mesolimbic dopaminergic cell bodies (Murphy, Pezze, Russig and Feldo, 2001). Furthermore, following different escalating dose administrations of amphetamine Russig, Murphy and Feldon (2005) found a reduction in amphetamine produced locomotor activity in day 1 of the withdrawal phase but an increase (behavioural sensitisation) after 5 or 38 days. Given different administration schedules of amphetamine lead to different behavioural consequences, future research could establish if the long term expression of MDMA is evident following an escalating pretreatment dosing regimen compared to that of the current intermittent exposure.

The current investigation demonstrated cross sensitisation to other dopamine agonists suggesting an underlying dopamine mechanism that is common in locomotor activating effects of psychostimulants. It has been suggested that the action of amphetamine in midbrain DA cell bodies is necessary for the induction of behavioural sensitisation. For example, repeated amphetamine injections into the ventral tegmental area, but not into the DA terminal field in the nucleus accumbens, produce an enhanced locomotor response to subsequent peripheral administration of amphetamine (Kalivas and Weber 1988; Vezina and Stewart 1990). Also, the local microinjection of a DA $D_{1}$ receptor antagonist into the ventral tegmental area is sufficient to prevent the 
development of behavioural sensitisation to systemic amphetamine treatment (Stewart and Vezina 1989). Ramos and colleagues $(2004,2005)$ investigated the action of $\mathrm{D}_{1}$ antagonist, $\mathrm{SCH} 23390$, in the prevention of development and expression of MDMA produced hyperlocomotion. It was argued that projections from the prefrontal cortex (PFC) might mediate behavioural sensitisation to MDMA and that dopaminergic mechanisms were implicated the expression of sensitisation. With the current investigation strongly implicating a sensitised $D_{1}$ receptor and an augmented $D_{2}$ mechanism in response to the current regimen of MDMA administration, it would be advantageous for future investigations to examine if these changes translate into increases in extracellular dopamine release using a more specific $\mathrm{D}_{1}$ antagonist as SCH23390 activates 5-HT modulating effects of DA.

Microdialysis analysis in the ventral tegmental area, nucleus accumbens and frontal cortex may aid in answering the questions as to what, if any, common underlying dopamine mechanisms exist with MDMA and amphetamine sensitisation. There have been consistent reports of amphetamine induced sensitisation related adaptations in DA neurotransmission in striatal (Kalivas and Stewart, 1991; Robinson, 1991; Robinson and Berridge, 1993; White and Wolf, 1991) caudate or nucleus accumbens (Kolta et al., 1985, Robinson and Becker, 1982; Robinson et al., 1982; Wilcox et al., 1986; Yamada et al., 1988) DA release. To date however, few studies have investigated neuroadaptations following repeated MDMA administrations that produce behavioural sensitisation. Fos expression, which measures protein changes in the expression of the immediate early gene c-fos, has been positively correlated 
with the behavioural consequences of repeated drug exposure in the NAc shell (Colussi-Mas \& Schenk, 2008) suggesting DA mediated changes from repeated intermittent exposure. As experiment two demonstrated alterations in receptor mechanism sensitivity and experiment four failed to show any changes in gross storage pools of brain amine levels, microdialysis techniques may help in the future. Recording relative extracellular levels of brain amines in specific areas of the mesolimbic DA pathway may indicate downstream alterations in DA overflow responsible for MDMA produced locomotor sensitisation.

Changes in dopamine sensitivity may have been expected to increase the reinforcing effects of MDMA. When this was tested by examining latency to acquisition of self-administration, acquisition was delayed in MDMA pretreated animals. Of interest, pre-treatment with MDMA in rats sensitises cocaine-induced behavioural responses and increases cocaine-stimulated place preference (Horan et al., 2000; Kalivas et al., 1998). As the current pretreatment regimen produced sensitised locomotor activation, and may have modulated a common dopaminergic mechanism. This raises a question as to what, if any, circumstances could decrease latency to acquisition following MDMA administration? As mentioned above, different administration schedules of amphetamine lead to different behavioural consequences. Previous investigations that have looked at changes in potency to amphetamine (Piazza et al, 1990) and cocaine (Schenk \& Partridge 1997) self administration did not use an escalating dosing regimen of stimulant. This may suggest that an escalating pre-treatment would not be hypothesised to 
change the potency of latency to MDMA self-administration acquisition. It may have been that the self administration doses selected in the current investigation were too high and future studies that commence acquisition on a lower dose may show a change in potency resulting in a decrease in latency to acquisition.

Throughout the current set of experiments neurochemical changes have been induced from exposure to MDMA. This was demonstrated by the reduction in 5-HIAA levels. The deficits observed in the current investigation are mirrored in a number of MDMA studies that identify neurochemical changes following MDMA administration (Battaglia, Yeh, et al., 1988; Commins, et al., 1987; Goñi-Allo, et al., 2007; Nair \& Gudelsky, 2006). It has become increasingly clear that long lasting and perhaps permanent changes in the brain underlie maladaptive alterations associated with compulsive drug craving (Nestler, 2001). The current testing was conducted under steady state conditions whereas most neurochemical adaptations are examined in response to a further drug administration (Kalivas, et al. 1998).

Neurochemical analysis under drug conditions may reveal differing neurochemical levels to those revealed in the current investigation. During amphetamine sensitisation there was a significantly elevated DA release in dorsal and ventral striatum (Paulson, Robinson, 1995; Robinson, Jurson, Bennett, \& Bentgen, 1988) however there was no reported change in DA levels in the caudate or accumbens (Segal \& Kuczenski, 1992). In future investigations, recording of DA release in dorsal and ventral striatum as well 
as caudate and accumbens brain regions, during the MDMA sensitisation regimen, may reveal if there is any overlap in alterations of brain amine levels.

Taken together, the current research shows that repeated administration of MDMA produces sensitisation to its locomotor activating effects that induced lasting dopaminergic and serotonergic neural adaptations. 


\section{References}

Ahmed, S. H., Stinus, L., Le Moal, M., \& Cador, M. (1993). Controlling interindividual differences in the unconditioned response to amphetamine in the study of environment-dependent sensitization. Behavioural Pharmacology, 4(4), 355-365.

Algeri, S., Brunello, N., \& Vantini, G. (1980). Different adaptive responses by rat striatal dopamine synthetic and receptor mechanisms after repeated treatment with d-amphetamine, methylphenidate and nomifensine. Pharmacological Research Communications, 12(7), 675-681.

Alloway, K. D., \& Rebec, G. V. (1983). Shift from inhibition to excitation in the neostriatum but not in the nucleus accumbens following long-term amphetamine. Brain Research, 273(1), 71-79.

Amato, J. L., Bankson, M. G., \& Yamamoto, B. K. (2007). Prior exposure to chronic stress and MDMA potentiates mesoaccumbens dopamine release mediated by the 5-HT(1B) receptor. Neuropsychopharmacology, 32(4), 946-954.

Anagnostaras, S. G., \& Robinson, T. E. (1996). Sensitization to the psychomotor stimulant effects of amphetamine: modulation by associative learning. Behav Neurosci, 110(6), 1397-1414.

Badiani, A., Anagnostaras, S. G., \& Robinson, T. E. (1995). The development of sensitization to the psychomotor stimulant effects of amphetamine is enhanced in a novel environment. Psychopharmacology (Berl). , 117(4), 443-452.

Badiani, A., Browman, K. E., \& Robinson, T. E. (1995). Influence of novel versus home environments on sensitization to the psychomotor stimulant effects of cocaine and amphetamine. Brain Research, 674(2), 291-298.

Badiani, A., Camp, D. M., \& Robinson, T. E. (1997). Enduring enhancement of amphetamine sensitization by drug-associated environmental stimuli. The Journal of Pharmacology and Experimental Theraputics, 282(2), 787794.

Ball, K. T., Budreau, D., \& Rebec, G. V. (2003). Acute effects of 3,4methylenedioxymethamphetamine on striatal single-unit activity and behavior in freely moving rats: differential involvement of dopamine D(1) and D(2) receptors. Brain Res, 994(2), 203-215.

Ball, K. T., Budreau, D., \& Rebec, G. V. (2006). Context-dependent behavioural and neuronal sensitization in striatum to MDMA (ecstasy) administration in rats. . The European Journal of Neuroscience, 24(1), 217-228.

Ball, K. T., \& Rebec, G. V. (2005). Role of 5-HT2A and 5-HT2C/B receptors in the acute effects of 3,4-methylenedioxymethamphetamine (MDMA) on striatal single-unit activity and locomotion in freely moving rats. Psychopharmacology (Berl). , 181(4), 676-687.

Banks, M. L., Czoty, P. W., Gage, H. D., Bounds, M. C., Garg, P. K., Garg, S., et al. (2007). Effects of cocaine and MDMA self-administration on serotonin transporter availability in monkeys. Neuropsychopharmacology 33(2), 219-225.

Bankson, M. G., \& Yamamoto, B. K. (2004). Serotonin-GABA interactions modulate MDMA-induced mesolimbic dopamine release. J Neurochem, 91(4), 852-859. 
Battaglia, G., Brooks, B. P., Kulsakdinun, C., \& De Souza, E. B. (1988). Pharmacologic profile of MDMA (3,4methylenedioxymethamphetamine) at various brain recognition sites. Eur J Pharmacol, 149(1-2), 159-163.

Battaglia, G., Yeh, S. Y., \& De Souza, E. B. (1988). MDMA-induced neurotoxicity: parameters of degeneration and recovery of brain serotonin neurons. Pharmacology, Biochemistry and Behavior, 29(2), 269-274.

Battaglia, G., Yeh, S. Y., O'Hearn, E., Molliver, M. E., Kuhar, M. J., \& De Souza, E. B. (1987). 3,4-Methylenedioxymethamphetamine and 3,4methylenedioxyamphetamine destroy serotonin terminals in rat brain: quantification of neurodegeneration by measurement of $[3 \mathrm{H}]$ paroxetinelabeled serotonin uptake sites. J Pharmacol Exp Ther, 242(3), 911-916.

Baumann, M. H., Clark, R. D., Budzynski, A. G., Partilla, J. S., Blough, B. E., \& Rothman, R. B. (2005). N-substituted piperazines abused by humans mimic the molecular mechanism of 3,4methylenedioxymethamphetamine (MDMA, or 'Ecstasy'). Neuropsychopharmacology, 30(3), 550-560.

Baumann, M. H., Wang, X., \& Rothman, R. B. (2006). 3,4methylenedioxymethamphetamine (MDMA) neurotoxicity in rats: a reappraisal of past and present findings. Psychopharmacology.

Berg, K. A., Navailles, S., Sanchez, T. A., Silva, Y. M., Wood, M. D., Spampinato, U., et al. (2006). Differential effects of 5-methyl-1-[[2-[(2methyl-3-pyridyl)oxyl]-5-pyridyl]carbamoyl]-6-trifluoromethylindone (SB 243213) on 5-hydroxytryptamine(2C) receptor-mediated responses. The journal of Pharmacology and Experimental Therapeutics, 319(1), 260-268.

Berger, U. V., Gu, X. F., \& Azmitia, E. C. (1992). The substituted amphetamines 3,4-methylenedioxymethamphetamine, methamphetamine, $\mathrm{p}$ chloroamphetamine and fenfluramine induce 5-hydroxytryptamine release via a common mechanism blocked by fluoxetine and cocaine. Eur J Pharmacol, 215(2-3), 153-160.

Bjijou, Y., Stinus, L., Le Moal, M., \& Cador, M. (1996). Evidence for selective involvement of dopamine D1 receptors of the ventral tegmental area in the behavioral sensitization induced by intra-ventral tegmental area injections of D-amphetamine. J Pharmacol Exp Ther., 277(2), 11771187.

Bonhomme, N., Cador, M., Stinus, L., Le Moal, M., \& Spampinato, U. (1995). Short and long-term changes in dopamine and serotonin receptor binding sites in amphetamine-sensitized rats: a quantitative autoradiographic study. Brain Research, 675(1-2), 215-223.

Bonhaus, D.W., Flippin, L.A., Greenhouse, R.J., Jaime, S., Rocha, C., Dawson, M., et al (1997). RS-102221: a novel high affinity and selective, 5-HT2C receptor antagonist. Neuropharmacology 36, 621-629.

Bourne, J.A. (2001). SCH 23390: the first selective dopamine D1-like receptor antagonist. CNS Drug Review, 7, 399-414.

Braida, D., \& Sala, M. (2002). Role of the endocannabinoid system in MDMA intracerebral self-administration in rats. British Journal of Pharmacology, 136, 1089-1092. 
Brennan, K. A., \& Schenk, S. (2006). Initial deficit and recovery of function after MDMA preexposure in rats. Psychopharmacology (Berl). 184(2), 239246.

Bronson, M. E., Jiang, W., Clark, C. R., \& DeRuiter, J. (1994). Effects of designer drugs on the chicken embryo and 1-day-old chicken. Brain Research Bulletin, 34(2), 143-150.

Browne, R. G., \& Segal, D. S. (1977 ). Metabolic and experimental factors in the behavioral response to repeated amphetamine. Pharmacology, Biochemistry and Behavior, 6(5), 545-552.

Bubar, M. J., Pack, K. M., Frankel, P. S., \& Cunningham, K. A. (2004). Effects of dopamine D1- or D2-like receptor antagonists on the hypermotive and discriminative stimulus effects of (+)-MDMA. Psychopharmacology (Berl), 173(3-4), 326-336.

Cadoni, C., Solinas, M., Pisanu, A., Zernig, G., Acquas, E., \& Di Chiara, G. (2005). Effect of 3,4-methylendioxymethamphetamine (MDMA, "ecstasy") on dopamine transmission in the nucleus accumbens shell and core. Brain Research, 1055(1-2), 143-148.

Cador, M., Bjijou, Y., \& Stinus, L. (1995). Evidence of a complete independence of the neurobiological substrates for the induction and expression of behavioral sensitization to amphetamine. Neuroscience, 65(2), 385-395.

Cai, G., Wang, H.Y., \& Friedman, E. (2002). Increased dopamine receptor signaling and dopamine receptor-G protein coupling in denervated striatum. J Pharmacol Exp Ther, 302(3), 1105-1112.

Cai, G., Zhen, X., Uryu, K., \& Friedman, E. (2000). Activation of extracellular signal-regulated protein kinases is associated with a sensitized locomotor response to $\mathrm{D}(2)$ dopamine receptor stimulation in unilateral 6hydroxydopamine-lesioned rats. The Journal of Neuroscience, 20(5), 1849-1857.

Caine, S.B. \& Koob, G.F. (1995). Effects of dopamine D1 and D2 antagonists on cocaine self-administration under different schedules of reinforcement in the rat. J Pharmacol Exp Ther, 270, 209-218.

Callaway, C. W., \& Geyer, M. A. (1992). Tolerance and cross-tolerance to the activating effects of 3,4-methylenedioxymethamphetamine and a 5hydroxytryptamine1B agonist. J Pharmacol Exp Ther, 263(1), 318-326.

Callaway, C. W., Wing, L. L., \& Geyer, M. A. (1990). Serotonin release contributes to the locomotor stimulant effects of 3,4methylenedioxymethamphetamine in rats. J Pharmacol Exp Ther, 254(2), 456-464.

Capela, J.P., Carmo, H., Remião, F., Bastos, M.L., Meisel, A., \& Carvalho, F. (2009). Molecular and cellular mechanisms of ecstasy-induced neurotoxicity: an overview. Molecular Neurobiology, 39(3), 210-271.

Carboni, E., Imperato, A., Perezzani, L., \& Di Chiara, G. (1989). Amphetamine, cocaine, phencyclidine and nomifensine increase extracellular dopamine concentrations preferentially in the nucleus accumbens of freely moving rats. Neuroscience, 28(3), 653-661.

Carelli, R. M. (2004). Nucleus accumbens cell firing and rapid dopamine signaling during goal-directed behaviors in rats Neuropharmacology, 47(1), 180-189 
Carroll, M.E., \& Lac, S.T. (1997). Acquisition of i.v. amphetamine and cocaine self-administration in rats as a function of dose. Psychopharmacology (Berl), 129, 206-14.

Carroll, M.E., Lac, S.T., Asencio, M., \& Kragh, R. (1990). Fluoxetine reduces intravenous cocaine self-administration in rats. Pharmacol Biochem Behav. 35(1), 237-244.

Castañeda, E., Becker, J. B., \& Robinson, T. E. (1988). The long-term effects of repeated amphetamine treatment in vivo on amphetamine, $\mathrm{KCl}$ and electrical stimulation evoked striatal dopamine release in vitro. Life sciences, 42(24), 2447-2456.

Chiang, Y.C., Chen, P.C., \& Chen, J.C. (2003). D(3) dopamine receptors are down-regulated in amphetamine sensitized rats and their putative antagonists modulate the locomotor sensitization to amphetamine. Brain Research, 972 (1-2), 159-67

Civelli, O., Bunzow, J. R., \& Grandy, D. K. (1993). Molecular diversity of the dopamine receptors. Annual Review of pharmacology and Toxicology, 33, 281-307.

Colado, M. I., Murray, T. K., \& Green, A. R. (1993). 5-HT loss in rat brain following 3,4-methylenedioxymethamphetamine (MDMA), pchloroamphetamine and fenfluramine administration and effects of chlormethiazole and dizocilpine. Br J Pharmacol, 108(3), 583-589.

Colado, M. I., O'Shea, E., \& Green, A. R. (2004). Acute and long-term effects of MDMA on cerebral dopamine biochemistry and function. Psychopharmacology (Berl), 173(3-4), 249-263.

Cole, J. C., \& Sumnall, H. R. (2003). The pre-clinical behavioural pharmacology of 3,4-methylenedioxymethamphetamine (MDMA) Neuroscience \& Biobehavioral Reviews 27(3), 199-217

Colussi-Mas, J., \& Schenk, S. (2008). Acute and sensitized response to 3,4methylenedioxymethamphetamine in rats: different behavioral profiles reflected in different patterns of Fos expression. European Journal of Neuroscience, 28(9), 1895 - 1910.

Commins, D. L., Vosmer, G., Virus, R. M., Woolverton, W. L., Schuster, C. R., \& Seiden, L. S. (1987). Biochemical and histological evidence that methylenedioxymethylamphetamine (MDMA) is toxic to neurons in the rat brain. J Pharmacol Exp Ther, 241(1), 338-345.

Cools, A. R., \& Van Rossum, J. M. (1976). Excitation-mediating and inhibitionmediating dopamine-receptors: a new concept towards a better understanding of electrophysiological, biochemical, pharmacological, functional and clinical data. Psychopharmacologia, 45(3), 243-254.

Cornish, J. L., Shahnawaz, Z., Thompson, M. R., Wong, S., Morley, K. C., Hunt, G. E., et al. (2003). Heat increases 3,4-methylenedioxymethamphetamine self-administration and social effects in rats. European Journal of Pharmacology, 482, 339-341.

Crespi, D., Mennini, T., \& Gobbi, M. (1997). Carrier-dependent and Ca(2+)dependent 5-HT and dopamine release induced by (+)-amphetamine, 3,4methylendioxymethamphetamine, p-chloroamphetamine and (+)fenfluramine. British Journal of Pharmacology, 121(8), 1735-1743.

Cunningham, S.T., \& Kelley, A.E. (1993). Hyperactivity and sensitization to psychostimulants following cholera toxin infusion into the nucleus accumbens. J Neurosci, 13(6), 2342-50. 
Dackis, C. A., \& O'Brien, C. P. (2001). Cocaine dependence: a disease of the brain's reward centers Journal of Substance Abuse Treatment, 21(3), 111117

Daniela, E., Brennan, K., Gittings, D., Hely, L., \& Schenk, S. (2004). Effect of SCH 23390 on (+/-)-3,4-methylenedioxymethamphetamine hyperactivity and self-administration in rats. Pharmacol Biochem Behav, 77(4), 745750.

Daniela, E., Gittings, D., \& Schenk, S. (2006). Conditioning following repeated exposure to MDMA in rats: role in the maintenance of MDMA selfadministration. Behavioral Neuroscience, 120(5), 1144-1150.

De Souza, E. B., Battaglia, G., \& Insel, T. R. (1990). Neurotoxic effect of MDMA on brain serotonin neurons: evidence from neurochemical and radioligand binding studies. Annals of the New York Academy of Sciences, 600, 682-697.

Demellweek, C., \& Goudie, A. J. (1983). Behavioural tolerance to amphetamine and other psychostimulants: the case for considering behavioural mechanisms. Psychopharmacology (Berl). , 80(4), 287-307.

Deminiere, J. M., Piazza, P. V., Le Moal, M., \& Simon, H. (1989). Experimental approach to individual vulnerability to psychostimulant addiction. Neuroscience and Biobehavioral Reviews, 13(2-3), 141-147.

Deroche-Gamonet, V., Belin, D., \& Piazza, P. V. (2004). Evidence for addictionlike behavior in the rat. Science, 305(5686), 1014-1017.

Di Chiara, G. (1993). Searching for the hidden order in chaos. Commentary on Kalivas et al. "The pharmacology and neural circuitry of sensitization to psychostimulants". Behavioural Pharmacology, 4(4), 335-337.

Di Chiara, G., Bassareo, V., Fenu, S., De Luca, M. A., Spina, L., Cadoni, C., et al. (2004). Dopamine and drug addiction: the nucleus accumbens shell connection Neuropharmacology, 47(1), 227-241

Di Matteo, V., Di Giovanni, G., Di Mascio, M., Esposito, E. (2000). Biochemical and electrophysiological evidence that RO 60-0175 inhibits mesolimbic dopaminergic function through serotonin2C receptors. Brain Res, 865(1), 85-90.

Dougherty, G. G., \& Ellinwood, E. H. (1981). Chronic D-amphetamine in nucleus accumbens: lack of tolerance or reverse tolerance of locomotor activity. Life sciences, 28(20), 2295-2298.

Downs, A. W., \& Eddy, N. B. (1932). The effect of repeated doses of cocaine on the rat. The Journal of Pharmacology and Experimental Therapeutics, 46, 199-202.

Drew, K. L., \& Glick, S. D. (1988). Environment-dependent sensitization to amphetamine-induced circling behavior. Pharmacology, Biochemistry and Behavior, 31(3), 705-708.

Ellison, G., \& Morris, W. (1981). Opposed stages of continuous amphetamine administration: parallel alterations in motor stereotypies and in vivo spiroperidol accumulation. European Journal of Pharmacology, 74(2-3), 207-214.

Fantegrossi, W. E., Ullrich, T., Rice, K.C., Woods, J.H., Winger, G. (2002). Methylenedioxymethamphetamine (MDMA, 'ecstasy') and its stereoisomers as reinforcers in rhesus monekys: serotonergic involvement. Psychopharmacology, 161(4), 356-364. 
Fantegrossi, W. E., Woolverton, W. L., Kilbourn, M., Sherman, P., Yuan, J., Hatzidimitriou, G., et al. (2004). Behavioral and neurochemical consequences of long-term intravenous self-administration of MDMA and its enantiomers by rhesus monkeys. Neuropsychopharmacology 29, 1270-1281.

Fischer, C., Hatzidimitriou, G., Wlos, J., Katz, J., \& Ricaurte, G. (1995).

Reorganization of ascending 5-HT axon projections in animals previously exposed to the recreational drug (+/-)3,4-

methylenedioxymethamphetamine (MDMA, "ecstasy"). J Neurosci, 15(8), 5476-5485.

Fischman, M. W., \& Schuster, C. R. (1978). Drug seeking: a behavioral analysis in animals and humans. NIDA Res Monogr, 20, 4-23.

Fitzgerald, J. L., \& Reid, J. J. (1990). Effects of

methylenedioxymethamphetamine on the release of monoamines from rat brain slices. Eur J Pharmacol, 191(2), 217-220.

Fletcher, P. J., Robinson, S. R., \& Slippoy, D. L. (2001). Pre-exposure to (+/)3,4-methylenedioxy-methamphetamine (MDMA) facilitates acquisition of intravenous cocaine self-administration in rats.

Neuropsychopharmacology 25(2), 195-203.

Frederick, D. L., Ali, S. F., Slikker, W. J., Gillam, M. P., Allen, R. R., \& Paule, M. G. (1995). Behavioral and neurochemical effects of chronic methylenedioxymethamphetamine (MDMA) treatment in rhesus monkeys. Neurotoxicology and Teratology, 17(5), 531-543.

Gardner, E. L. (2000). What we have learned about addiction from animal models of drug self-administration. The American Journal on Addictions, 9(4), 285-313.

Gelowitz, D.L., \& Berger, S.P. (2001). Signal transduction mechanisms and behavioral sensitization to stimulant drugs: an overview of cAMP and PLA2. Journal of Addictive Diseases, 20(93), 33-42.

Gold, L. H., Koob, G. F., \& Geyer, M. A. (1988). Stimulant and Hallucinogenic Behavioral Profiles of 3,4 Methylenedioxymethamphetamine and Nethyl-3,4-Methylenedioxyamphetamine in Rats. The journal of Pharmacology and Experimental Therapeutics, 247(2), 547-555.

Goñi-Allo, B., Puerta, E., Ramos, M., Lasheras, B., Jordán, J., \& Aguirre, N. (2007). Minoxidil prevents 3,4-methylenedioxymethamphetamineinduced serotonin depletions: role of mitochondrial ATP-sensitive potassium channels, Akt and ERK. Journal of Neurochemistry, 104(4), 914-925.

Gough, B., Ali, S. F., Slikker, W., Jr., \& Holson, R. R. (1991). Acute effects of 3,4-methylenedioxymethamphetamine (MDMA) on monoamines in rat caudate. Pharmacol Biochem Behav, 39(3), 619-623.

Gouzoulis-Mayfrank, E., \& Daumann, J. (2006 ). Neurotoxicity of methylenedioxyamphetamines (MDMA; ecstasy) in humans: how strong is the evidence for persistent brain damage? Addiction, 101(3), 348-361.

Green, A. R., Mechan, A. O., Elliott, J. M., O'Shea, E., \& Colado, M. I. (2003). The pharmacology and clinical pharmacology of 3,4methylenedioxymethamphetamine (MDMA, "ecstasy"). Pharmacol Rev, 55(3), 463-508. 
Green, A. R., O'Shea, E., \& Colado, M. I. (2004). A review of the mechanisms involved in the acute MDMA (ecstasy)-induced hyperthermic response. Eur J Pharmacol, 500(1-3), 3-13.

Gu, X. F., \& Azmitia, E. C. (1993). Integrative transporter-mediated release from cytoplasmic and vesicular 5-hydroxytryptamine stores in cultured neurons. Eur J Pharmacol, 235(1), 51-57.

Gudelsky, G. A., \& Yamamoto, B. K. (2008). Actions of 3,4methylenedioxymethamphetamine (MDMA) on cerebral dopaminergic, serotonergic and cholinergic neurons. Pharmacology, Biochemistry and Behavior, 90(2), 198-207.

Hamamura, T., Akiyama, K., Akimoto, K., Kashihara, K., Okumura, K., Ujike, H., et al. (1991). Co-administration of either a selective D1 or D2 dopamine antagonist with methamphetamine prevents methamphetamineinduced behavioral sensitization and neurochemical change, studied by in vivo intracerebral dialysis. Brain Research, 546(1), 40-46.

Haney, M., \& Spealman, R. (2008). Controversies in translational research: drug self-administration. Psychopharmacology (Berl). 199(3), 403-419.

Hatzidimitriou, G., McCann, U. D., \& Ricaurte, G. A. (1999). Altered serotonin innervation patterns in the forebrain of monkeys treated with $(+/-) 3,4-$ methylenedioxymethamphetamine seven years previously: factors influencing abnormal recovery. J Neurosci, 19(12), 5096-5107.

Heffner, T. G., Hartman, J. A., \& Seiden, L. S. (1980). A rapid method for the regional dissection of the rat brain. Pharmacol Biochem Behav, 13(3), 453-456.

Hekmatpanah, C. R., \& Peroutka, S. J. (1990). 5-hydroxytryptamine uptake blockers attenuate the 5-hydroxytryptamine-releasing effect of 3,4methylenedioxymethamphetamine and related agents. Eur J Pharmacol, 177(1-2), 95-98.

Henningfield, J. E., Cohen, C., \& Heishman, S. J. (1991). Drug selfadministration methods in abuse liability evaluation. British Journal of Addiction, 86(12), 1571-1577.

Hitzemann, R. J., Tseng, L. F., Hitzemann, B. A., Sampath-Khanna, S., \& Loh, H. H. (1977). Effects of withdrawal from chronic amphetamine intoxication on exploratory and stereotyped behaviors in the rat. Psychopharmacology (Berl). 54(3), 295-302.

Hitzemann, R. J., Wu, J., Hom, D., \& Loh, H. (1980). Brain locations controlling the behavioral effects of chronic amphetamine intoxication. Psychopharmacology (Berl). 72(1), 93-101.

Hjorth, S. (1998). In vivo rat brain microdialysis studies of the new 5-HT1A receptor antagonist robalzotan. European Neuropsychopharmacology, $8(\mathrm{~S}: 175)$.

Hjorth, S., Bengtsson, H. J., Kullberg, A., Carlzon, D., Peilot, H., \& Auerbach, S. B. (2000). Serotonin autoreceptor function and antidepressant drug action. Journal of Psychopharmacology, 14(2), 177-185.

Hooks, M. S., Jones, G. H., Liem, B. J., \& Justice Jr, J. B. (1992). Sensitization and individual differences to IP amphetamine, cocaine, or caffeine following repeated intra-cranial amphetamine infusions. Annals of the New York Academy of Sciences, 654, 444-447. 
Hooks, M. S., Jones, G. H., Smith, A. D., Neill, D. B., \& Justice Jr, J. B. (1991). Individual differences in locomotor activity and sensitization. Pharmacology, Biochemistry and Behavior, 38(2), 467-470.

Horger, B. A., Giles, M. K., \& Schenk, S. (1992). Pre-exposure to amphetamine and nicotine predisposes rats to self-administer a low dose of cocaine. Psychopharmacology 107, 271-276.

Hotsenpiller, G., \& Wolf, M. E. (2002). Conditioned locomotion is not correlated with behavioral sensitization to cocaine: An intra-laboratory multi-sample analysis. Neuropsychopharmacology, 27, 924-929.

Hoyer, D., Hannon, J. P., \& Martin, G. R. (2002). Molecular, pharmacological and functional diversity of 5-HT receptors. Pharmacol Biochem Behav, 71(4), 533-554.

Ichikawa, J., Chung, Y. C., Li, Z., Dai, J., \& Meltzer, H. Y. (2002). Cholinergic modulation of basal and amphetamine-induced dopamine release in rat medial prefrontal cortex and nucleus accumbens. Brain Research, 958(1), 176-184.

Insel, T. R., Battaglia, G., Johannessen, J. N., Marra, S., \& De Souza, E. B. (1989). 3,4-Methylenedioxymethamphetamine ("ecstasy") selectively destroys brain serotonin terminals in rhesus monkeys. J Pharmacol Exp Ther, 249(3), 713-720.

Iravani, M. M., Asari, D., Patel, J., Wieczorek, W. J., \& Kruk, Z. L. (2000). Direct effects of 3,4-methylenedioxymethamphetamine (MDMA) on serotonin or dopamine release and uptake in the caudate putamen, nucleus accumbens, substantia nigra pars reticulata, and the dorsal raphe nucleus slices. Synapse, 36(4), 275-285.

Jackson, D. M., Bailey, R. C., Christie, M. J., Crisp, C. A., \& Skerritt, J. H. (1981). Long-term d-amphetamine in rats: lack of change in post-synaptic dopamine receptor sensitivity. Psychopharmacology (Berl). 73(3), 276280.

Jacocks, H. M., 3rd, \& Cox, B. M. (1992). Serotonin-stimulated release of $[3 \mathrm{H}]$ dopamine via reversal of the dopamine transporter in rat striatum and nucleus accumbens: a comparison with release elicited by potassium, Nmethyl-D-aspartic acid, glutamic acid and D-amphetamine. J Pharmacol Exp Ther, 262(1), 356-364.

Johnson, M. P., Hoffman, A. J., \& Nichols, D. E. (1986). Effects of the enantiomers of MDA, MDMA and related analogues on $[3 \mathrm{H}]$ serotonin and $[3 \mathrm{H}]$ dopamine release from superfused rat brain slices. Eur $J$ Pharmacol, 132(2-3), 269-276.

Kalivas, \& Stewart, J. (1991). Dopamine transmission in the initiation and expression of drug and stress-induced sensitization of motor activity. Brain Research. Brain Research Reviews, 16(3), 223-244.

Kalivas, \& Weber, B. (1988). Amphetamine injection into the ventral mesencephalon sensitizes rats to peripheral amphetamine and cocaine. The journal of Pharmacology and Experimental Therapeutics, 245(3), 1095-1102.

Kalivas, P. W., \& Duffy, P. (1993). Time course of extracellular dopamine and behavioral sensitization to cocaine. I. Dopamine axon terminals. The Journal of Neuroscience, 13, 266-275. 
Kalivas, P. W., Duffy, P., \& White, S. R. (1998). MDMA elicits behavioral and neurochemical sensitization in rats. Neuropsychopharmacology, 18(6), 469-479.

Kato, T., Dong, B., Ishii, K., \& Kinemuchi, H. (1986). Brain dialysis: in vivo metabolism of dopamine and serotonin by monoamine oxidase A but not B in the striatum of unrestrained rats. Journal of Neurochemistry, 46(4), 1277-1282.

Kauer, J. A., \& Malenka, R. C. (2007). Synaptic plasticity and addiction. Nature reviews. Neuroscience, $8(11), 844-858$.

Kebabian, J. W., \& Calne, D. B. (1979). Multiple receptors for dopamine. Nature, 277(5692), 93-96.

Keen, M., (1995). The problems and pitfalls of radioligand binding. Methods in Molecular Biology, 41, 1-16.

Kehne, J. H., Ketteler, H. J., McCloskey, T. C., Sullivan, C. K., Dudley, M. W., \& Schmidt, C. J. (1996). Effects of the selective 5-HT2A receptor antagonist MDL 100,907 on MDMA-induced locomotor stimulation in rats. Neuropsychopharmacology, 15(2), 116-124.

Kelley, A. E., \& Berridge, K. C. (2002). The neuroscience of natural rewards: relevance to addictive drugs. $J$ Neurosci., 22(9), 3306-3311.

Koch, S., \& Galloway, M. P. (1997). MDMA induced dopamine release in vivo: role of endogenous serotonin. Journal of Neural Transmission, 104(2-3), 135-146.

Kolta, M. G., Shreve, P., De Souza, V., \& Uretsky, N. J. (1985). Time course of the development of the enhanced behavioral and biochemical responses to amphetamine after pretreatment with amphetamine. Neuropharmacology, 24(9), 823-829.

Koob, G. F. (2006). The neurobiology of addiction: a neuroadaptational view relevant for diagnosis. Addiction, 101(1), 23-30.

Kuczenski, R., \& Leith, N. J. (1981). Chronic amphetamine: is dopamine a link in or a mediator of the development of tolerance and reverse tolerance? Pharmacology, Biochemistry and Behavior, 15(3), 405-413.

Kuczenski, R., Segal, D. S., \& Todd, P. K. (1997). Behavioral sensitization and extracellular dopamine responses to amphetamine after various treatments. Psychopharmacology (Berl), 134(3), 221-229.

Laudrup, P., \& Wallace, L. J. (1999). Sensitization elicited by directly and indirectly acting dopaminergic agonists: comparison using neural network analysis. Psychopharmacology (Berl), 141(2), 169-174.

Leonardi, E. T., \& Azmitia, E. C. (1994). MDMA (ecstasy) inhibition of MAO type A and type B: comparisons with fenfluramine and fluoxetine (Prozac). Neuropsychopharmacology, 10(4), 231-238.

Lewander, T. (1971). A mechanism for the development of tolerance to amphetamine in rats Psychopharmacology, 21(1), 17-31.

Li, A., Guo, H., Luo, X., Sheng, J., Yang, S., Yin, Y., Zhou, J., Zhou, J. (2006). Apomorphine-induced activation of dopamine receptors modulates FGF2 expression in astrocytic cultures and promotes survival of dopaminergic neurons. FASEB J, 20(8), 1263-5.

Lin, H. Q., Atrens, D. M., Christie, M. J., Jackson, D. M., \& McGregor, I. S. (1993). Comparison of conditioned taste aversions produced by MDMA and d-amphetamine. Pharmacology, Biochemistry and Behavior, 46(1), 153-156. 
Logan, B.J., Laverty, R., Sanderson, W.D., \& Yee, Y.B. (1988). Differences in rats and Mice in MDMA (methylenedioxymethamphetamine) neurotoxicity. European journal of Pharmacology, 152, 227-234.

Lorrain, D. S., Arnold, G. M., \& Vezina, P. (2000). Previous exposure to amphetamine increases incentive to obtain the drug: long-lasting effects revealed by the progressive ratio schedule. Behav Brain Res, 107(1-2), 919.

Ludwig, V., Mihov, Y., \& Schwarting, R. K. (2007). Behavioral and neurochemical consequences of multiple MDMA administrations in the rat: role of individual differences in anxiety-related behavior. Behavioural Brain Research, 189(1), 52-64.

Ludwig, V., Mihov, Y., \& Schwarting, R. K. (2008). Behavioral and neurochemical consequences of multiple MDMA administrations in the rat: role of individual differences in anxiety-related behavior. Behavioural Brain Research, 189(1), 52-64.

Lyles, J., \& Cadet, J. L. (2003). Methylenedioxymethamphetamine (MDMA, Ecstasy) neurotoxicity: cellular and molecular mechanisms. Brain Res Brain Res Rev, 42(2), 155-168.

Malpass, A., White, J. M., Irvine, R. J., Somogyi, A. A., \& Bochner, F. (1999). Acute toxicity of 3,4-methylenedioxymethamphetamine (MDMA) in Sprague-Dawley and Dark Agouti rats. Pharmacol Biochem Behav, 64(1), 29-34.

Marston, H. M., Reid, M. E., Lawrence, J. A., Olverman, H. J., \& Butcher, S. P. (1999). Behavioural analysis of the acute and chronic effects of MDMA treatment in the rat. Psychopharmacology (Berl), 144(1), 67-76.

Mazurski, E. J., \& Beninger, R. J. (1987). Environment-specific conditioning and sensitization with (+)-amphetamine. Pharmacology, Biochemistry and Behavior, 27(1), 61-65.

Mazurski, E. J., \& Beninger, R. J. (1987). Environment-specific conditioning and sensitization with (+)-amphetamine. Pharmacology, Biochemistry and Behavior, 27(1), 61-65.

McCann, U. D., Mertl, M., Eligulashvili, V., \& Ricaurte, G. A. (1999). Cognitive performance in (+/-) 3,4-methylenedioxymethamphetamine (MDMA, "ecstasy") users: a controlled study. Psychopharmacology (Berl), 143(4), 417-425.

McCreary, A. C., Bankson, M. G., \& Cunningham, K. A. (1999). Pharmacological studies of the acute and chronic effects of (+)-3, 4methylenedioxymethamphetamine on locomotor activity: role of 5hydroxytryptamine(1A) and 5-hydroxytryptamine(1B/1D) receptors. $J$ Pharmacol Exp Ther, 290(3), 965-973.

McGregor, A., Lacosta, S., \& Roberts, D.C. (1993). L-tryptophan decreases the breaking point under a progressive ratio schedule of intravenous cocaine reinforcement in the rat. Pharmacol Biochem Behav. 44(3), 651-655.

McMillen, B. A., Scott, S. M., \& Williams, H. L. (1991). Effects of subchronic amphetamine or amfonelic acid on rat brain dopaminergic and serotonergic function. Journal of Neural Transmission. General Section, 83(1-2), 55-66.

McNamara, C. G., Davidson, E. S., \& Schenk, S. (1993). A comparison of the motor-activating effects of acute and chronic exposure to amphetamine 
and methylphenidate. Pharmacology, Biochemistry and Behavior, 45(3), 729-732.

Millan, M.J., Newman-Tancredi, A., Quentric, Y., Cussac, D. (2001). The 'selective' dopamine D1 receptor antagonist, $\mathrm{SCH} 23390$, is a potent and high efficacy agonist at cloned human serotonin2C receptors. Psychopharmacology 15, 658-62.

Missale, C., Nash, S.R., Robinson, S.W., Jaber, M., \& Caron, M.G. (1998). Dopamine receptors: from structure to function. Physiological reviews, 78(1), 189-225.

Mendrek, A., Blaha, C. D., \& Phillips, A. G. (1998). Pre-exposure of rats to amphetamine sensitizes self-administration of this drug under a progressive ratio schedule. Psychopharmacology (Berl), 135(4), 416-422.

Miserendino, M.J., \& Nestler, E.J. (1995). Behavioral sensitization to cocaine: modulation by the cyclic AMP system in the nucleus accumbens. Brain research, 674(2), 299-306.

Modi, G. M., Yang, P. B., Swann, A. C., \& Dafny, N. (2006). Chronic exposure to MDMA (ecstasy) elicits behavioral sensitization in rats but fails to induce cross-sensitization to other psychostimulants. Behavioral and Brain Functions, 2(1), 1-29.

Muller, P., \& Seeman, P. (1979). Presynaptic subsensitivity as a possible basis for sensitization by long-term dopamine mimetics. European journal of pharmacology,l 55, 149-157.

Nair, S. G., \& Gudelsky, G. A. (2004). Protein kinase C inhibition differentially affects 3,4-methylenedioxymethamphetamine-induced dopamine release in the striatum and prefrontal cortex of the rat. Brain Res, 1013(2), 168173.

Nair, S. G., \& Gudelsky, G. A. (2006). Effect of a serotonin depleting regimen of 3,4-methylenedioxymethamphetamine (MDMA) on the subsequent stimulation of acetylcholine release in the rat prefrontal cortex. Brain Research Bulletin, 69(4), 382-387.

Nash, J. F. (1990). Ketanserin pretreatment attenuates MDMA-induced dopamine release in the striatum as measured by in vivo microdialysis. Life Sci, 47(26), 2401-2408.

Nash, J. F., \& Brodkin, J. (1991). Microdialysis studies on 3,4methylenedioxymethamphetamine-induced dopamine release: effect of dopamine uptake inhibitors. J Pharmacol Exp Ther, 259(2), 820-825.

Navarro, J.F., \& Maldonado, E. (2002). Acute and subchronic effects of MDMA ("ecstasy") on anxiety in male mice tested in the elevated plus-maze. Prog Neuropsychopharmacol Biol Psychiatry. 26,(6) 1151-1154.

Nelson, C. L., Wetter, J. B., Milovanovic, M., \& Wolf, M. E. (2007). The laterodorsal tegmentum contributes to behavioral sensitization to amphetamine Neuroscience, 146(1), 41-49

Nestler, E. J. (2004). Molecular mechanisms of drug addiction. Neuropharmacology, 47, 24-32.

Nestler, E. J. (2005). Is there a common molecular pathway for addiction? Nature Neuroscience, 8(11), 1445-1449.

Nishisawa, S., Mzengeza, S., \& Diksic, M. (1999). Acute effects of 3,4methylenedioxymethamphetamine on brain serotonin synthesis in the dog studied by positron emission tomography. Neurochem Int, 34(1), 33-40. 
Nisoli, E., Tonello, C., Imhof, R., Scherschlicht, R., da Prada, M., \& Carruba, M. O. (2009). Neurochemical and behavioral evidence that Ro 41-9067 is a selective presynaptic dopamine receptor agonist. The Journal of Pharmacology and Experimental Theraputics, 266(1), 97-105.

Nordquist, R. E., Vanderschuren, L. J., Jonker, A. J., Bergsma, M., de Vries, T. J., Pennartz, C. M., et al. (2008). Expression of amphetamine sensitization is associated with recruitment of a reactive neuronal population in the nucleus accumbens core. . Psychopharmacology (Berl), 198(1), 113-126.

O'Hearn, E., Battaglia, G., De Souza, E.B., Kuhar, M.J., Molliver, M.E. (1988). Methylenedioxyamphetamine (MDA) and methylenedioxymethamphetamine (MDMA) cause selective ablation of serotonergic axon terminals in forebrain: immunocytochemical evidence for neurotoxicity. J Neurosci, 8(8), 2788-2803.

O'Shea, E., Granados, R., Esteban, B., Colado, M. I., \& Green, A. R. (1998). The relationship between the degree of neurodegeneration of rat brain 5-HT nerve terminals and the dose and frequency of administration of MDMA ('ecstasy'). Neuropharmacology, 37(7), 919-926.

Olds, J., \& Milner, P. (1954). Positive reinforcement produced by electrical stimulation of septal area and other regions of rat brain. Journal of Comparative and Physiological Psychology, 47(6), 419-427.

Paulson, P. E., Camp, D. M., \& Robinson, T. E. (1991). Time course of transient behavioral depression and persistent behavioral sensitization in relation to regional brain monoamine concentrations during amphetamine withdrawal in rats. Psychopharmacology (Berl), 103(4), 480-492.

Paulson, P. E., \& Robinson, T. E. (1995). Amphetamine-induced time-dependent sensitization of dopamine neurotransmission in the dorsal and ventral striatum: a microdialysis study in behaving rats. Synapse, 19(1), 56-65.

Pert, A., Post, R., \& Weiss, S. R. (1990). Conditioning as a critical determinant of sensitization induced by psychomotor stimulants. NIDA Research Monograph, 97, 208-241.

Perugini, M., \& Vezina, P. (1994). Amphetamine administered to the ventral tegmental area sensitizes rats to the locomotor effects of nucleus accumbens amphetamine. The Journal of Pharmacology and Experimental Therapeutics, 270(2), 690-696.

Pettit, H. O., Pan, H. T., Parsons, L. H., \& Justice, J. B., Jr. (1990). Extracellular concentrations of cocaine and dopamine are enhanced during chronic cocaine administration. $J$ Neurochem, 55(3), 798-804.

Pfaus, J. G., Damsma, G., Nomikos, G. G., Wenkstern, D. G., Blaha, C. D., Phillips, A. G., et al. (1990). Sexual behavior enhances central dopamine transmission in the male rat. Brain Research, 530(2), 345-348.

Piazza, D., Le Moal \& Simon (1989). Factors that predict individual vulnerability to amphetamine self administration. Science, 245(4925), 1511-1513.

Piazza, P. V., Deminiere, J. M., Le Moal, M., \& Simon, H. (1989). Factors that predict individual vulnerability to amphetamine self-administration. Science, 245.(4925), 1511-1513.

Pickens, R., \& Thompson, T. (1968). Cocaine-reinforced behavior in rats: effects of reinforcement magnitude and fixed-ratio size. The journal of Pharmacology and Experimental Therapeutics, 161(1), 122-129. 
Pierce, R. C., \& Kalivas, P. W. (1995). Amphetamine produces sensitized increases in locomotion and extracellular dopamine preferentially in the nucleus accumbens shell of rats administered repeated cocaine. $J$ Pharmacol Exp Ther, 275(2), 1019-1029.

Pierce, R. C., \& Kalivas, P. W. (1997). A circuitry model of the expression of behavioral sensitization to amphetamine-like psychostimulants. Brain Res Brain Res Rev, 25(2), 192-216.

Pierre, P. J., \& Vezina, P. (1997). Predisposition to self-administer amphetamine: the contribution of response to novelty and prior exposure to the drug. Psychopharmacology (Berl), 129(3), 277-284.

Pizarro, N., Farre, M., Pujadas, M., Peiro, A. M., Roset, P. N., Joglar, J., et al. (2004). Stereochemical analysis of 3,4-methylenedioxymethamphetamine and its main metabolites in human samples including the catechol-type metabolite (3,4-dihydroxymethamphetamine). Drug Metab Dispos, 32(9), 1001-1007.

Post, R. M., \& Rose, H. (1976). Increasing effects of repetitive cocaine administration in the rat. Nature, 260(5553), 731-732.

Ramos, M., Goni-Allo, B., \& Aguirre, N. (2004). Studies on the role of dopamine D1 receptors in the development and expression of MDMAinduced behavioral sensitization in rats. Psychopharmacology (Berl), 177(1-2), 100-110.

Ramos, M., Goni-Allo, B., \& Aguirre, N. (2005a). Administration of SCH 23390 into the Medial Prefrontal Cortex Blocks the Expression of MDMAInduced Behavioral Sensitization in Rats: An Effect Mediated by 5HT(2C) Receptor Stimulation and not by D(1) Receptor Blockade. Neuropsychopharmacology.

Ramos, M., Goni-Allo, B., \& Aguirre, N. (2005b). Ibotenic acid lesions of the medial prefrontal cortex block the development and expression of 3,4methylenedioxymethamphetamine-induced behavioral sensitization in rats. Behav Brain Res., 160(2), 304-311.

Ranaldi, R., Pocock, D., Zereik, R., \& Wise, R. A. (1999). Dopamine fluctuations in the nucleus accumbens during maintenance, extinction, and reinstatement of intravenous D-amphetamine self-administration. The Journal of Neuroscience, 19(10), 4102-4109.

Ratzenboeck, E., Saria, A., Kriechbaum, N., \& Zernig, G. (2001). Reinforcing effects of MDMA ("ecstasy") in drug-naive and cocaine-trained rats. Pharmacology, 62, 138 - 144.

Ricaurte, G. A. (1989). Studies of MDMA-induced neurotoxicity in nonhuman primates: a basis for evaluating long-term effects in humans. NIDA Res Monogr, 94, 306-322.

Ricaurte, G. A., DeLanney, L. E., Irwin, I., \& Langston, J. W. (1988). Toxic effects of MDMA on central serotonergic neurons in the primate: importance of route and frequency of drug administration. Brain Res, 446(1), 165-168.

Ricaurte, G. A., DeLanney, L. E., Wiener, S. G., Irwin, I., \& Langston, J. W. (1988). 5-Hydroxyindoleacetic acid in cerebrospinal fluid reflects serotonergic damage induced by 3,4-methylenedioxymethamphetamine in CNS of non-human primates. Brain Res, 474(2), 359-363.

Ricaurte, G. A., Martello, A. L., Katz, J. L., \& Martello, M. B. (1992). Lasting effects of (+-)-3,4-methylenedioxymethamphetamine (MDMA) on central 
serotonergic neurons in nonhuman primates: neurochemical observations. J Pharmacol Exp Ther, 261(2), 616-622.

Ricaurte, G. A., McCann, U. D., Szabo, Z., \& Scheffel, U. (2000).

Toxicodynamics and long-term toxicity of the recreational drug, 3, 4methylenedioxymethamphetamine (MDMA, 'Ecstasy'). Toxicology Letters, 112-113, 143-146.

Risner, M., \& Jones, B. E. (1976). Role of noradrenergic and dopaminergic processes in amphetamine self-administration. Pharmacology, Biochemistry and Behavior, 5(4), 477-482.

Roberts, D.C., Koob, G.F., Klonoff, P., \& Fibiger, H.C. (1980) Extinction and recovery of cocaine self-administration following 6-hydroxydopamine lesions of the nucleus accumbens. Pharmacology, Biochemistry and Behaviour, 12(5), 781-787.

Robinson, T. E. (1984). Behavioral sensitization: characterization of enduring changes in rotational behavior produced by intermittent injections of amphetamine in male and female rats. Psychopharmacology (Berl), 84(4), 466-475.

Robinson, T. E., \& Becker, J. B. (1982). Behavioral sensitization is accompanied by an enhancement in amphetamine-stimulated dopamine release from striatal tissue in vitro. European Journal of Pharmacology, 85(2), 253254.

Robinson, T. E., \& Becker, J. B. (1986). Enduring changes in brain and behavior produced by chronic amphetamine administration: a review and evaluation of animal models of amphetamine psychosis. Brain Res., 396(2), 157-198.

Robinson, T. E., Becker, J. B., \& Presty, S. K. (1982). Long-term facilitation of amphetamine-induced rotational behavior and striatal dopamine release produced by a single exposure to amphetamine: Sex differences Brain Research 253(1-2), 231-241.

Robinson, T. E., \& Berridge, K. C. (1993). The neural basis of drug craving: an incentive-sensitization theory of addiction. Brain Research. Brain Research Reviews, 18(3), 247-291.

Robinson, T. E., \& Berridge, K. C. (2003). Addiction. Annual Review of Psychology 54, 25-53.

Robinson, T. E., Browman, K. E., Crombag, H. S., \& Badiani, A. (1998). Modulation of the induction or expression of psychostimulant sensitization by the circumstances surrounding drug administration. Neurosci Biobehav Rev, 22(2), 347-354.

Robinson, T.E., \& Camp, D.M. (1987). Long-lasting effects of escalating doses of d-amphetamine on brain monoamines, amphetamine-induced stereotyped behavior and spontaneous nocturnal locomotion. Pharmacol Biochem Behav, 26(4), 821-827.

Robinson, T. E., \& Kolb, B. (1999). Alterations in the morphology of dendrites and dendritic spines in the nucleus accumbens and prefrontal cortex following repeated treatment with amphetamine or cocaine. The European Journal of Neuroscience, 11(5), 1598-1604.

Robinson, T.E., Jurson, P.A., Bennett, J.A., \& Bentgen, K.M. (1988). Persistent sensitization of dopamine neurotransmission in ventral striatum (nucleus accumbens) produced by prior experience with (+)-amphetamine: a 
microdialysis study in freely moving rats. Brain Research, 462(2), 21122.

Ross, J. D., Herin, D. V., Frankel, P. S., Thomas, M. L., \& Cunningham, K. A. (2006). Chronic treatment with a serotonin(2) receptor (5-HT(2)R) agonist modulates the behavioral and cellular response to (+)-3,4methylenedioxymethamphetamine [(+)-MDMA]. Drug Alcohol Depend, 81(2), 117-127.

Rudissaar, R., Harro, J., Pruus, K., Rinken, A., \& Allikmets, L. (2008). Repeated administration of the dopaminergic agonist apomorphine: development of apomorphine aggressiveness and changes in the interaction between dopamine $\mathrm{D}(2)$ receptors and G-proteins. Pharmacological Reports, 60(6), 827-833.

Rudnick, G., \& Wall, S. C. (1992). The molecular mechanism of "ecstasy" [3,4methylenedioxy-methamphetamine (MDMA)]: serotonin transporters are targets for MDMA-induced serotonin release. Proc Natl Acad Sci U S A, 89(5), 1817-1821.

Rudnick, G., \& Wall, S. C. (1993). Non-neurotoxic amphetamine derivatives release serotonin through serotonin transporters. Mol Pharmacol, 43(2), 271-276.

Russig, H., Murphy, C.A. \& Feldon, J. (2005). Behavioural consequences of withdrawal from three different administration schedules of amphetamine. Behavioural Brain Research, 165(1), 26-35.

Sabol, K. E., Richards, J. B., Layton, K., \& Seiden, L. S. (1995). Amphetamine analogs have differential effects on DRL 36-s schedule performance. Psychopharmacology (Berl), 121(1), 57-65.

Salamone, J. D., \& Correa, M. (2002). Motivational views of reinforcement: implications for understanding the behavioral functions of nucleus accumbens dopamine. Behavioural Brain Research, 137(1-2), 3-25

Salm,i P., Malmgren, K., Svensson, T.H., \& Ahlenius. S. (1998). Stimulation of forward locomotion by SCH-23390 and raclopride in d-amphetaminetreated rats. Naunyn-Schmiedebergs Archives of Pharmacology, 357(6), 593-599.

Scanzello, C. R., Hatzidimitriou, G., Martello, A. L., Katz, J. L., \& Ricaurte, G. A. (1993). Serotonergic recovery after (+/-)3,4-(methylenedioxy) methamphetamine injury: observations in rats. J Pharmacol Exp Ther, 264(3), 1484-1491.

Scheffel, U., Lever, J. R., Stathis, M., \& Ricaurte, G. A. (1992). Repeated administration of MDMA causes transient down-regulation of serotonin 5-HT2 receptors. Neuropharmacology, 31(9), 881-893.

Schenk, S., Gittings, D., Johnstone, M., \& Daniela, E. (2003). Development, maintenance and temporal pattern of self-administration maintained by ecstasy (MDMA) in rats. Psychopharmacology (Berl), 169(1), 21-27.

Schenk, S., Hely, L., Gittings, D., Lake, B., \& Daniela, E. (2008). Effects of priming injections of MDMA and cocaine on reinstatement of MDMAand cocaine-seeking in rats. Drug and Alcohol Dependence, 96, 249-255.

Schenk, S., Hely, L., Lake, B., Daniela, E., Gittings, D., \& Mash, D. C. (2007). MDMA self-administration in rats: acquisition, progressive ratio responding and serotonin transporter binding. The European Journal of Neuroscience, 26(11), 3229-3236. 
Schenk, S. \& Izenwasser, S. (2002). Pre-treatment with methylphenidate sensitizes rats to the reinforcing effects of cocaine. Pharmacology Biochemistry and Behavior, 72(3), 651-657.

Schenk, S., \& Partridge, B. (2000). Sensitization to cocaine's reinforcing effects produced by various cocaine pretreatment regimens in rats. Pharmacol Biochem Behav 66, 765-770.

Schenk, S., Valadez, A., McNamara, C., House, D.T., Higley, D., Bankson, M.G., Gibbs, S., \& Horger, B.A. (1993). Development and expression of sensitization to cocaine's reinforcing properties: role of NMDA receptors. Psychopharmacology (Berl). 111(3), 332-338.

Schifano F (2004) A bitter pill. Overview of ecstasy (MDMA, MDA) related fatalities. Psychopharmacology (Berl) 173, 242-248.

Schifano, F., Corkery, J., Deluca, P., Oyefeso, A., \& Ghodse, A. H. (2006). Ecstasy (MDMA, MDA, MDEA, MBDB) consumption, seizures, related offences, prices, dosage levels and deaths in the UK (1994-2003). Journal of Psychopharmacology, 20(3), 456-463.

Schmidt, C. J. (1987). Neurotoxicity of the psychedelic amphetamine, methylenedioxymethamphetamine. J Pharmacol Exp Ther, 240(1), 1-7.

Schmidt, C. J., Abbate, G. M., Black, C. K., \& Taylor, V. L. (1990). Selective 5hydroxytryptamine 2 receptor antagonists protect against the neurotoxicity of methylenedioxymethamphetamine in rats. The Journal of Pharmacology and Experimental Therapeutics, 255(2), 478-483.

Schmidt, C. J., Levin, J. A., \& Lovenberg, W. (1987). In vitro and in vivo neurochemical effects of methylenedioxymethamphetamine on striatal monoaminergic systems in the rat brain. Biochem Pharmacol, 36(5), 747755.

Scholl, J.L., Feng, N., Watt, M.J., Renner, K.J., \& Forster, G.L. (2009). Individual differences in amphetamine sensitization, behavior and central monoamines. Physiology and Behavior, 96(3), 493-504.

Schott, B. H., Minuzzi, L., Krebs, R. M., Elmenhorst, D., Lang, M., Winz, O. H., et al. (2008). Mesolimbic functional magnetic resonance imaging activations during reward anticipation correlate with reward-related ventral striatal dopamine release. The Journal of Neuroscience, 28(52), 14311-14319.

Schultz, W., Apicella, P., \& Ljungberg, T. (1993). Responses of monkey dopamine neurons to reward and conditioned stimuli during successive steps of learning a delayed response task. The Journal of Neuroscience, 13(3), 900-913.

Schuster, C. R., \& Thompson, T. (1969). Self administration of and behavioral dependence on drugs. Annual Review of Pharmacology, 9, 483-502.

Schwendt, M., \& McGinty, J.F. (2007). Regulator of G-protein signaling 4 interacts with metabotropic glutamate receptor subtype 5 in rat striatum: relevance to amphetamine behavioral sensitization. J Pharmacol Exp Ther, 323(2), 650-657.

Seeman, P., Tallerico, T., Ko, F., Tenn, C., \& Kapur, S. (2002). AmphetamineSensitized Animals Show a marked Increase in Dopamine D2 High Receptors Occupied by Endogenous Dopamine, Even in the Absence of Acute Challenges. Synapse, 46, 235-239. 
Seeman, P., McCormick,P.N., \& Kapur, S. (2007). Increased dopamine D2 high receptors in amphetamine-sensitized rats, measured by the agonist [3h]PHNO. Synapse, 61, 263-267.

Segal, D.S., \& Kuczenski, R. (1992). In vivo microdialysis reveals a diminished amphetamine-induced DA response corresponding to behavioral sensitization produced by repeated amphetamine pretreatment. Brain Research, 571(2), 330-7.

Segal, D.S., \& Kuczenski, R. (1999). Escalating dose-binge stimulant exposure: relationship between emergent behavioral profile and differential caudate-putamen and nucleus accumbens dopamine responses. Psychopharmacology (Berl). 142(2),182-192.

Seymour, C. M., \& Wagner, J. J. (2008). Simultaneous expression of cocaineinduced behavioral sensitization and conditioned place preference in individual rats. Brain Research, 1213, 57-68.

Shankaran, M., \& Gudelsky, G. A. (1998). Effect of 3,4methylenedioxymethamphetamine (MDMA) on hippocampal dopamine and serotonin. Pharmacology, Biochemistry and Behavior, 61(4), 361366.

Shankaran, M., \& Gudelsky, G. A. (1999). A neurotoxic regimen of MDMA suppresses behavioral, thermal and neurochemical responses to subsequent MDMA administration. Psychopharmacology (Berl), 147(1), 66-72.

Shankaran, M., Yamamoto, B. K., \& Gudelsky, G. A. (1999). Mazindol attenuates the 3,4-methylenedioxymethamphetamine-induced formation of hydroxyl radicals and long-term depletion of serotonin in the striatum. J Neurochem, 72(6), 2516-2522.

Sharp, T., Zetterstrom, T., Ljungberg, T., \& Ungerstedt, U. (1987). A direct comparison of amphetamine-induced behaviours and regional brain dopamine release in the rat using intracerebral dialysis. Brain Res, 401(2), 322-330.

Sibley, D. R., \& Monsma, F. J. J. (1992). Molecular biology of dopamine receptors. Trends in Pharmacological Science., 13(2), 61-69.

Smith, F.L., Yu, D.S., Smith, D.G., Leccese, A.P., \& Lyness, W.H. (1986). Dietary tryptophan supplements attenuate amphetamine selfadministration in the rat. Pharmacol Biochem Behav. 25(4), 849-855.

Spanos, L. J., \& Yamamoto, B. K. (1989). Acute and subchronic effects of methylenedioxymethamphetamine [(+/-)MDMA] on locomotion and serotonin syndrome behavior in the rat. Pharmacology, Biochemistry and Behavior, 32(4), 835-840.

Spealman, R. D., \& Goldberg, S. R. (1978). Drug self-administration by laboratory animals: control by schedules of reinforcement. Annual Review of pharmacology and Toxicology, 18, 313-339.

Spealman, R.D., Barrett-Larimore, R.L., Rowlett, J.K., Platt, D.M., \& Khroyan, T.V. (1999). Pharmacological and environmental determinants of relapse to cocaine-seeking behavior. Pharmacol Biochem Behav. 64, 327-336.

Steele, T. D., Nichols, D. E., \& Yim, G. K. (1987). Stereochemical effects of 3,4methylenedioxymethamphetamine (MDMA) and related amphetamine derivatives on inhibition of uptake of $[3 \mathrm{H}]$ monoamines into synaptosomes from different regions of rat brain. Biochem Pharmacol, 36(14), 2297-2303. 
Stenfors, C., \& Ross, S. B. (2004). Changes in extracellular 5-HIAA concentrations as measured by in vivo microdialysis technique in relation to changes in 5-HT release. Psychopharmacology (Berl). , 172, 119-128.

Stewart, J., \& Badiani, A. (1993). Tolerance and sensitization to the behavioral effects of drugs. Behav Pharmacol, 4(4), 289-312.

Stewart, J., \& Druhan, J. P. (1993). Development of both conditioning and sensitization of the behavioral activating effects of amphetamine is blocked by the non-competitive NMDA receptor antagonist, MK-801. Psychopharmacology (Berl). , 110(1-2), 125-132.

Stewart, J., \& Vezina, P. (1989). Microinjections of Sch-23390 into the ventral tegmental area and substantia nigra pars reticulata attenuate the development of sensitization to the locomotor activating effects of systemic amphetamine. Brain Research, 495(2), 401-406.

Stewart, J., \& Vezina, P. (1991). Extinction procedures abolish conditioned stimulus control but spare sensitized responding to amphetamine. Behavioural Pharmacology, 2(1), 65-71.

Stone, D. M., Stahl, D. C., Hanson, G. R., \& Gibb, J. W. (1986). The effects of 3,4-methylenedioxymethamphetamine (MDMA) and 3,4methylenedioxyamphetamine (MDA) on monoaminergic systems in the rat brain. European Journal of Pharmacology, 128, 41-48.

Strote, J., Lee, J. E., \& Wechsler, H. (2002). Increasing MDMA Use Among College Students:Results of a National Survey. Journal of Adolescent Health, 30, 64-72.

Sumnall, H. R., O'Shea, E., Marsden, C. A., \& Cole, J. C. (2004). The effects of MDMA pretreatment on the behavioural effects of other drugs of abuse in the rat elevated plus-maze test. Pharmacol Biochem Behav, 77(4), 805814.

Tatum, A. L., \& Seevers, M. H. (1931). Theories of Drug Addicition. Physiological Reviews, 11(2), 107-120.

Tenn, C. C., Fletcher, P. J., \& Kapur, S. (2003). Amphetamine-sensitized animals show a sensorimotor gating and neurochemical abnormality similar to that of schizophrenia. Schizophrenia Research, 64(2-3), 103-114.

The Expert Advisory Committee on Drugs [EACD] (2004). (MDMA)(3, 4 Methylenedioxymethamphetamine): EACD Advice to the Minister from http://www.ndp.govt.nz/moh.nsf/indexcm/ndp-publicationseacdmdma? Open.

Traynor, J.R., \& Neubig, R.R. (2005). Regulators of G protein signalling \& drugs of abuse. Molecular Interventions, 5(1), 30-41.

Trulson, M. E., \& Jacobs, B. L. (1979). Chronic amphetamine administration to cats: behavioral and neurochemical evidence for decreased central serotonergic function. The Journal of Pharmacology and Experimental Theraputics, 211(2), 375-384.

Vanderschuren, L.J., Beemster, P., \& Schoffelmeer, A.N. (2003). On the role of noradrenaline in psychostimulant-induced psychomotor activity and sensitization. Psychopharmacology (Berl), 169(2), 176-185,

Vanderschuren, L. J., \& Kalivas, P. W. (2000). Alterations in dopaminergic and glutamatergic transmission in the induction and expression of behavioral sensitization: a critical review of preclinical studies. Psychopharmacology (Berl), 151(2-3), 99-120. 
Vanderschuren, L. J., Schmidt, E. D., De Vries, T. J., Van Moorsel, C. A., Tilders, F. J., \& Schoffelmeer, A. N. (1999). A single exposure to amphetamine is sufficient to induce long-term behavioral, neuroendocrine, and neurochemical sensitization in rats. J Neurosci., 19(21), 9579-9586.

Vanderschuren, L. J., Schoffelmeer, A. N., Mulder, A. H., \& De Vries, T. J. (1999). Dopaminergic mechanisms mediating the long-term expression of locomotor sensitization following pre-exposure to morphine or amphetamine. Psychopharmacology (Berl), 143(3), 244-253.

Vezina, P. (1993). Amphetamine injected into the ventral tegmental area sensitizes the nucleus accumbens dopaminergic response to systemic amphetamine: an in vivo microdialysis study in the rat. Brain research, 605(2), 332-337.

Vezina, P. (1996). D1 dopamine receptor activation is necessary for the induction of sensitization by amphetamine in the ventral tegmental area. The Journal of Neuroscience, 16(7), 2411-2420.

Vezina, P. (2004). Sensitization of midbrain dopamine neuron reactivity and the self-administration of psychomotor stimulant drugs. Neuroscience and Biobehavioral Reviews, 27(8), 827-839.

Vezina, P., Giovino, A. A., Wise, R. A., \& Stewart, J. (1989). Environmentspecific cross-sensitization between the locomotor activating effects of morphine and amphetamine. Pharmacology, Biochemistry and Behavior, 32(2581-4.).

Vezina, P., \& Stewart, J. (1989). The effect of dopamine receptor blockade on the development of sensitization to the locomotor activating effects of amphetamine and morphine. Brain Res., 499(1), 108-120.

Võikar, V., Soosaar, A., Volke, V., Kõks, S., Bourin, M., Männistö, P.T., \& Vasar, E.(1999). Apomorphine-induced behavioural sensitization in rats: individual differences, role of dopamine and NMDA receptors. Eur Neuropsychopharmaco, 9(6), 507-514.

Wang, X., Baumann, M. H., Xu, H., \& Rothman, R. B. (2004). 3,4methylenedioxymethamphetamine (MDMA) administration to rats decreases brain tissue serotonin but not serotonin transporter protein and glial fibrillary acidic protein. Synapse, 53(4), 240-248.

Watson, L., \& Beck, J. (1991). New age seekers : MDMA use as an adjunct to spiritual pursuit. Journal of psychoactive drugs 23(3), 261-270

Webb, E., Ashton, C. H., Kelly, P., \& Kamali, F. (1998). An update on British medical students' lifestyles. Medical Education, 32(3), 325-331.

Wee, S., Anderson, K. G., Baumann, M. H., Rothman, R. B., Blough, B. E., \& Woolverton, W. L. (2005). Relationship between the serotonergic activity and reinforcing effects of a series of amphetamine analogs. The journal of Pharmacology and Experimental Therapeutics, 313(2), 848-854.

Weinstein, D.M., Narayanan, S., Byrnes, J.J., Uretsky, N.J., \& Wallace, L.J. (1997). Comparison of sensitization elicited by amphetamine and pertussis toxin: characterization of locomotor behavior and limbic dopamine release. Prog Neuropsychopharmacol Biol Psychiatry. 21(5), 885-897.

Westlund, K. N., Denney, R. M., Kochersperger, L. M., Rose, R. M., \& Abell, C. W. (1985). Distinct Monoamine Oxidase A and B Populations in Primate Brain. Science, 230(4722), 181-183 
White, F. J., \& Wang, R. Y. (1984). Electrophysiological evidence for A10 dopamine autoreceptor subsensitivity following chronic D-amphetamine treatment. Brain Research, 309(2), 283-292.

White, S. R., Duffy, P., \& Kalivas, P. W. (1994).

Methylenedioxymethamphetamine depresses glutamate-evoked neuronal firing and increases extracellular levels of dopamine and serotonin in the nucleus accumbens in vivo. Neuroscience, 62(1), 41-50.

White, S. R., Obradovic, T., Imel, K. M., \& Wheaton, M. J. (1996). The effects of methylenedioxymethamphetamine (MDMA, "Ecstasy") on monoaminergic neurotransmission in the central nervous system. Progress in Neurobiology, 49(5), 455-479.

Williamson, S., Gossop, M., Powis, B., Griffiths, P., Fountain, J., \& Strang, J. (1997). Adverse effects of stimulant drugs in a community sample of drug users. Drug and Alcohol Dependence 44(2-3), 87-94.

Wise, R. A. (1998). Drug-activation of brain reward pathways. Drug and Alcohol Dependence, 51, 13-22.

Wise, R. A., \& Bozarth, M. A. (1987). A psychomotor stimulant theory of addiction. Psychological Review, 94(4), 469-492.

Wolf, M. E. (1998). The role of excitatory amino acids in behavioral sensitization to psychomotor stimulants. Prog Neurobiol., 54(6), 679-720.

Wolf, M. E. (2002). Addiction: Making the Connection Between Behavioral Changes and Neuronal Plasticity in Specific Pathways. Molecular Interventions 2, 146-157

Wolf, M. E., White, F. J., \& Hu, X.T. (1994). MK-801 prevents alterations in the mesoaccumbens dopamine system associated with behavioral sensitization to amphetamine. The Journal of Neuroscience, 14(3 Pt 2), 1735-1745.

Wolf, M. E., White, F. J., Nassar, R., Brooderson, R. J., \& Khansa, M. R. (1993). Differential development of autoreceptor subsensitivity and enhanced dopamine release during amphetamine sensitization. The journal of Pharmacology and Experimental Therapeutics, 264(1), 249-255.

Wolf, M. E., \& Xue, C. J. (1998). Amphetamine and D1 dopamine receptor agonists produce biphasic effects on glutamate efflux in rat ventral tegmental area: modification by repeated amphetamine administration. $J$ Neurochem., 70(1), 198-209.

Woolverton, W.L., \& Virus, R.M. (1989). The effects of D1 and D2 dopamine antagonists on behavior maintained by cocaine or food. Pharmacol Biochem Behav, 32, 691-697.

Yamamoto, B. K., Nash, J. F., \& Gudelsky, G. A. (1995). Modulation of methylenedioxymethamphetamine-induced striatal dopamine release by the interaction between serotonin and gamma-aminobutyric acid in the substantia nigra. J Pharmacol Exp Ther, 273(3), 1063-1070.

Yamamoto, B. K., \& Spanos, L. J. (1988). The acute effects of methylenedioxymethamphetamine on dopamine release in the awakebehaving rat. Eur J Pharmacol, 148(2), 195-203.

Yokel, R. A., \& Wise, R. A. (1976). Attenuation of intravenous amphetamine reinforcement by central dopamine blockade in rats. Psychopharmacology (Berl), 48(3), 311-318. 
Young, A. M., Joseph, M. H., \& Gray, J. A. (1992). Increased dopamine release in vivo in nucleus accumbens and caudate nucleus of the rat during drinking: a microdialysis study. Neuroscience, 48(4), 871-876. 